Portland State University

PDXScholar

\title{
Modeling and Analyzing the Impact of Advanced Technologies on Transit Performance Measures in Arterial Corridors
}

Miguel A. Figliozzi

Portland State University, figliozzi@pdx.edu

Wei Feng

Portland State University, weifengpdx@gmail.com

Follow this and additional works at: https://pdxscholar.library.pdx.edu/cengin_fac

Part of the Civil Engineering Commons, Environmental Engineering Commons, Transportation Commons, and the Urban Studies Commons

Let us know how access to this document benefits you.

\section{Citation Details}

Figliozzi, Miguel and Wei Feng. Modeling and Analyzing the Impact of Advanced Technologies on Transit Performance Measures in Arterial Corridors. NITC-RR-579. Portland, OR: Transportation Research and Education Center (TREC), 2014. http://dx.doi.org/10.15760/trec.117

This Report is brought to you for free and open access. It has been accepted for inclusion in Civil and Environmental Engineering Faculty Publications and Presentations by an authorized administrator of PDXScholar. Please contact us if we can make this document more accessible: pdxscholar@pdx.edu. 


\section{MODELING AND ANALYZING THE IMPACT OF ADVANCED TECHNOLOGIES ON TRANSIT PERFORMANCE MEASURES IN ARTERIAL CORRIDORS}

\section{Draft Report}

NITC-RR-579

by

Miguel Figliozzi, Ph.D.

Wei Feng, Ph.D

Portland State University

for

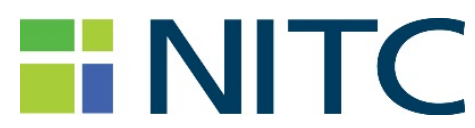

National Institute for

Transportation and Communities

P.O. Box 751

Portland, OR 97207

August 2014 



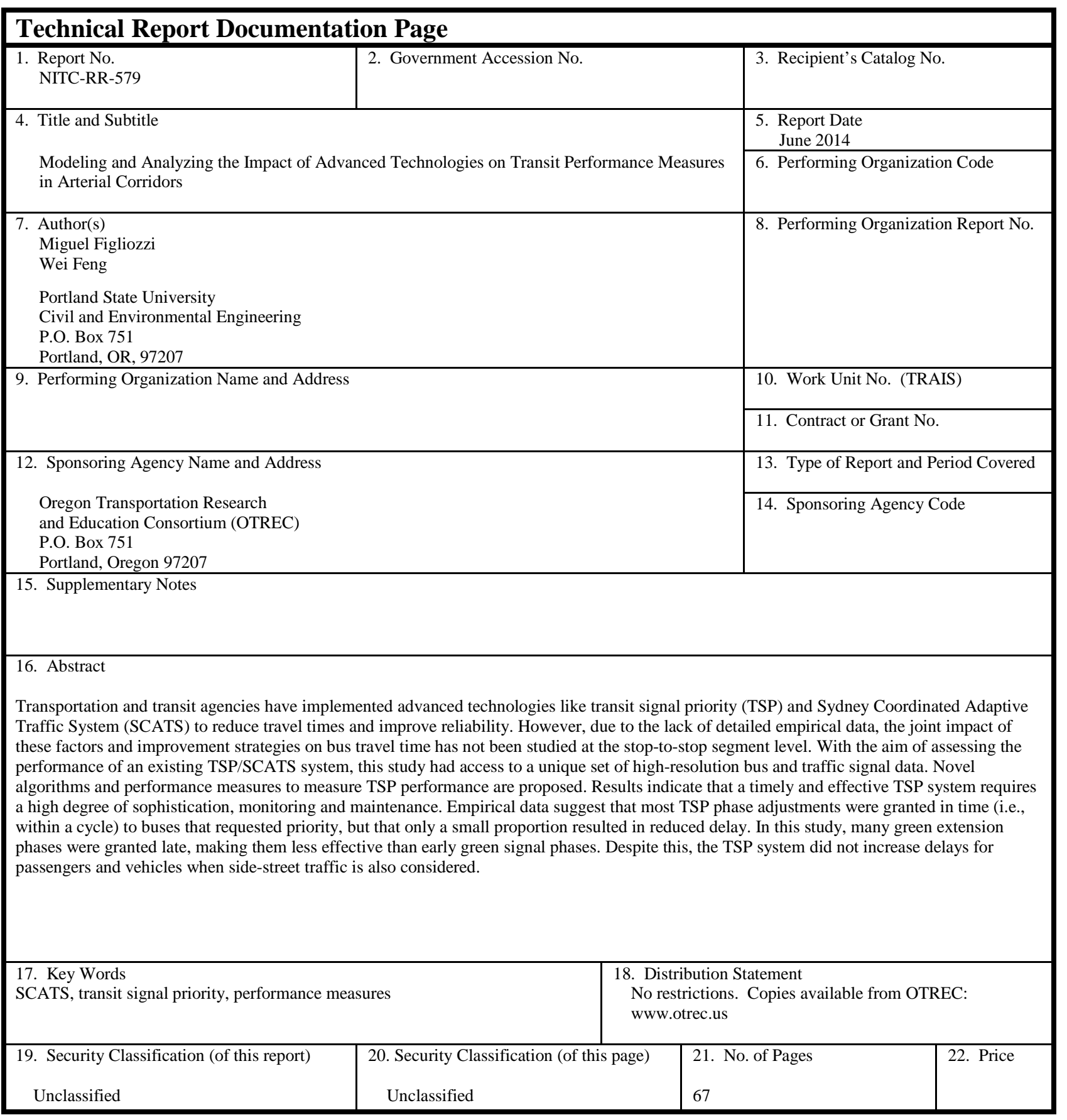




\section{ACKNOWLEDGEMENTS}

The authors gratefully acknowledge NITC and the Tri-County Metropolitan Transportation District of Oregon (TriMet) for sponsoring this project. The authors are also thankful to Steve Callas and David Crout from TriMet, as well as Willie Rotich from the Portland Bureau of Transportation for providing us with data and helpful comments. Any errors or omissions are the sole responsibility of the authors.

\section{DISCLAIMER}

The contents of this report reflect the views of the authors, who are solely responsible for the facts and the accuracy of the material and information presented herein. This document is disseminated under the sponsorship of the U.S. Department of Transportation University Transportation Centers Program in the interest of information exchange. The U.S. Government assumes no liability for the contents or use thereof. The contents do not necessarily reflect the official views of the U.S. Government. This report does not constitute a standard, specification, or regulation. 



\section{TABLE OF CONTENTS}

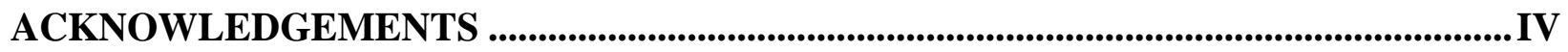

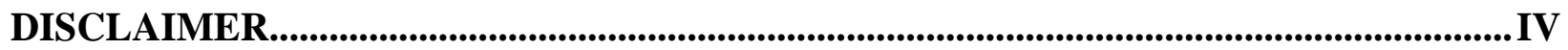

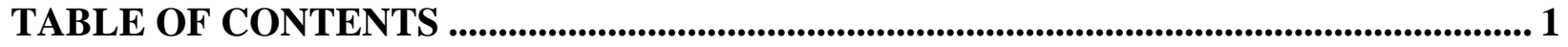

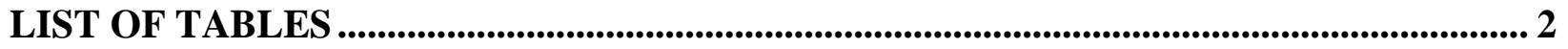

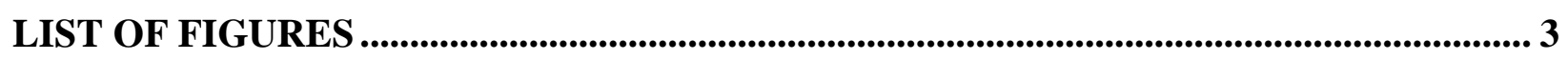

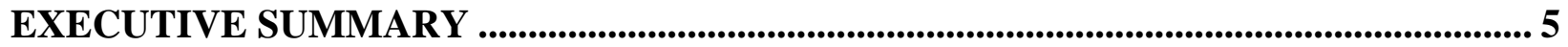

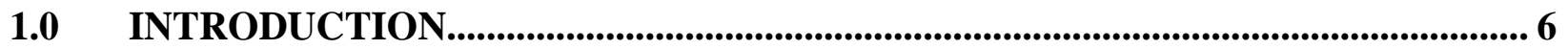

2.0 LITERATURE REVIEW ....................................................................................... 7

2.1 TRANSIT SERVICE RELIABILITY …............................................................. 7

2.2 TRANSIT SIGNAL PRIORITY PERFORMANCE EVALUATION ............................... 8

3.0 DATA AND METHODOLOGIES ............................................................................... 11

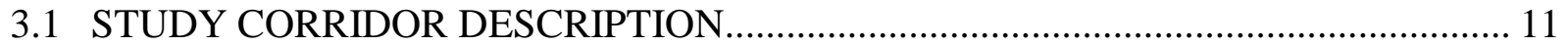

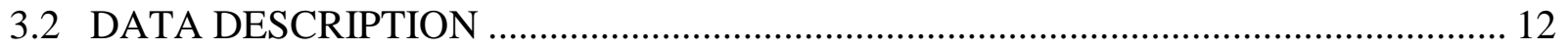

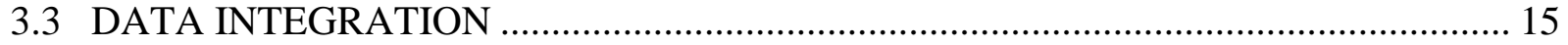

3.3.1 Bus-stop Activity Attributes and Stop-to-stop Segment Attributes......................... 15

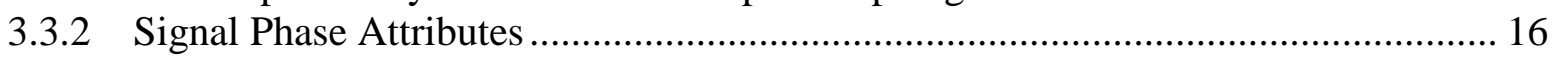

4.0 TRANSIT SIGNAL PRIORITY PERFORMANCE EVALUATION....................... 26

4.1 TRANSIT SIGNAL PRIORITY IN PORTLAND ................................................. 26

4.2 RELATIONSHIPS BETWEEN TSP PHASES AND TSP REQUESTS ........................ 29

4.2.1 Assumptions and Definitions ................................................................... 29

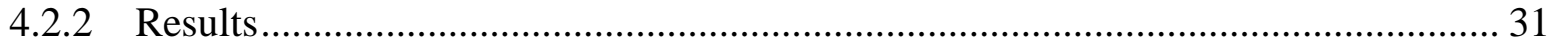

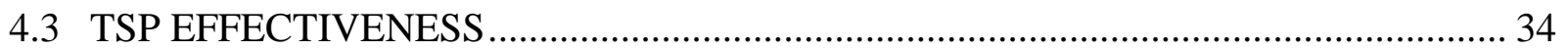

4.3.1 TSP Request Effectiveness ..................................................................... 36

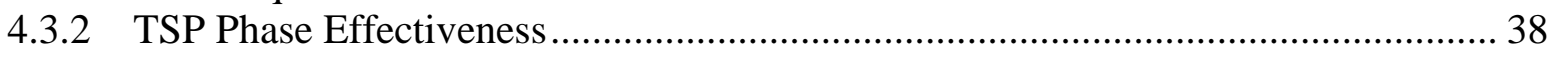

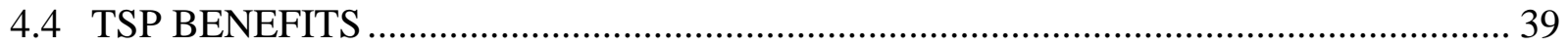

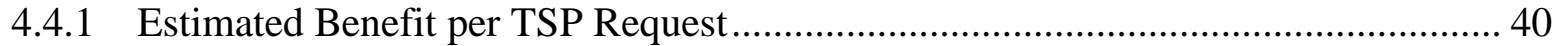

4.4.2 Estimated Benefit per TSP Phase ................................................................... 41

4.4.3 Time Savings and Delay between Buses and Other Vehicles ............................... 43

5.0 CONCLUSIONS AND DISCUSSIONS.................................................................. 48

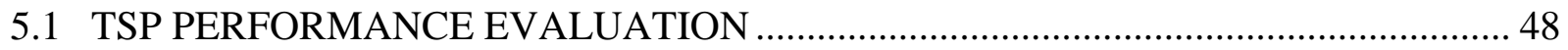

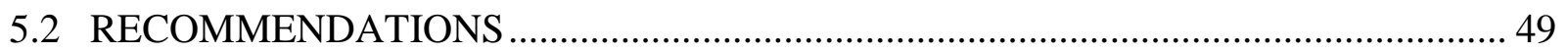

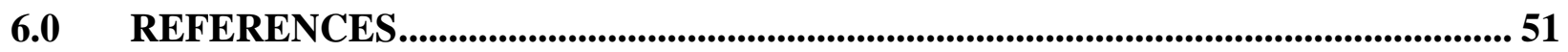

7.0 APPENDIX A: BUS TRAVEL SPEED EMPIRICAL DISTRIBUTIONS ................ 56 


\section{LIST OF TABLES}

Table 3-1 Bus stop-to-stop trip attributes ........................................................................... 15 


\section{LIST OF FIGURES}

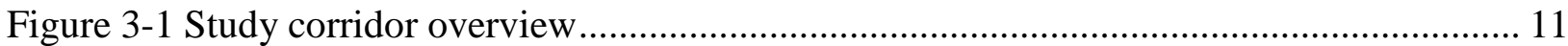

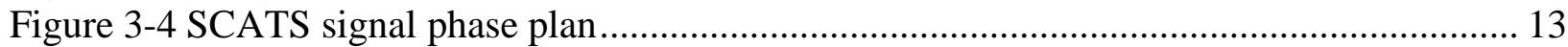

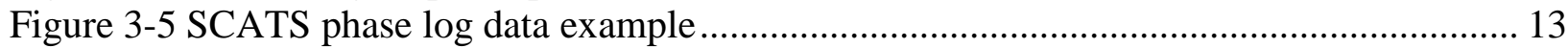

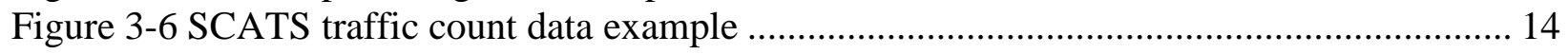

Figure 3-8 Time-space diagram of a bus that encounters a red signal delay ............................. 18

Figure 3-9 Feasible bus stop-to-stop trip trajectories ......................................................... 21

Figure 3-10 Feasible bus stop-to-stop trip trajectories with an early green phase....................... 23

Figure 3-11 Feasible bus stop-to-stop trip trajectories with a green extension phase ................. 25

Figure 4-1 TSP system decision framework (Byrne et al., 2005).......................................... 27

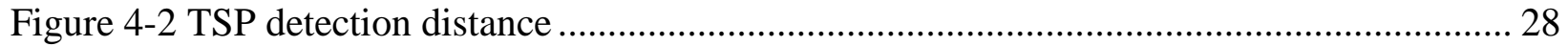

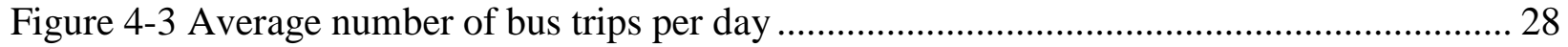

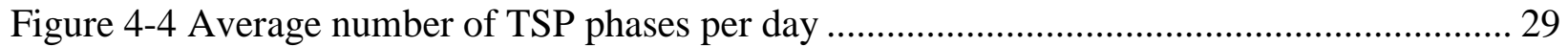

Figure 4-5 Relationships between TSP requests and TSP phases ........................................... 29

Figure 4-6 Relationships between TSP requests and green extension phases ........................... 30

Figure 4-7 Relationships between TSP requests and early green phases ................................. 31

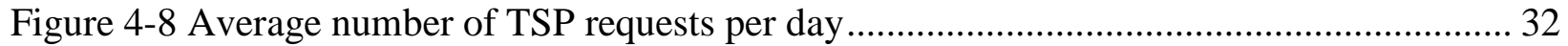

Figure 4-9 Average number of GE and EG phases per day ................................................ 34

Figure 4-10 Detailed relationships between TSP requests and TSP phases ............................... 35

Figure 4-11 Detailed relationships between TSP requests and green extension phases............... 35

Figure 4-12 Detailed relationships between TSP requests and early green phases ..................... 36

Figure 4-13 Probability that a bus TSP request can benefit from a TSP phase ......................... 37

Figure 4-14 Probabilities of TSP request outcomes for GE ............................................... 37

Figure 4-15 Probabilities of TSP request outcomes for EG ............................................... 38

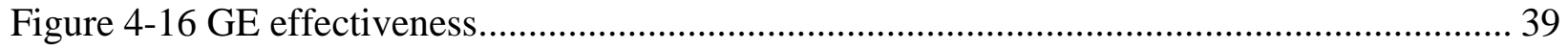

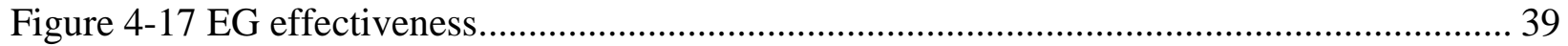

Figure 4-18 Estimated bus time savings per TSP request....................................................... 40

Figure 4-19 Estimated total passenger time savings per TSP request ..................................... 41

Figure 4-20 Estimated bus time savings per TSP phase ....................................................... 42

Figure 4-21 Estimated total passenger time savings per TSP phase....................................... 43

Figure 4-22 Illustration of major street time savings and side-street delay ................................ 44

Figure 4-23 Total passenger time savings and delay per TSP phase ......................................... 45

Figure 4-24 Total passenger time savings and vehicle delays per second TSP phase................. 47 


\section{EXECUTIVE SUMMARY}

Transit signal priority (TSP) is usually considered to be a relatively inexpensive and easy-toimplement tool to make transit service more reliable and faster. This research shows that TSP systems can be challenging to implement so that they are both timely and effective. TSP systems require not only maintenance but also monitoring to promptly detect problems and intersections with low TSP performance.

This study has two novel contributions: (a) an algorithm that integrates archived bus automatic vehicle location (AVL) and automatic passenger count (APC) data, Sydney Coordinated Adaptive Traffic System (SCATS) phase log data and vehicle count data at the intersection level and (b) novel performance measures to evaluate the TSP system effectiveness at the stop-to-stop segment level. Although this study is based on a specific urban arterial corridor where signals are operated under the SCATS system, the performance measures and algorithms can be applied to other transit routes and corridors.

Relationships between TSP requests (when buses are late) and TSP phases were studied by comparing TSP phase start and end times with bus arrival times. Results show that green extension phases were rarely used by buses that requested TSP and that most green extension phases were granted too late. Early green phases' effectiveness (percent of effective early green phases) is much higher than green extension phases' effectiveness. The estimated early green phase bus and passenger time savings are greater than the green extension phase time savings. On average, the estimated delay for vehicles on the side street due to a TSP phase is less than the time saved for buses and automobiles on the major street.

Although TSP system design and pre-implementation evaluation is important, results from this study indicate that post TSP implementation performance evaluation is also essential. The TSP performance evaluation results also provide valuable information to identify problems and improvement opportunities. For example, the low numbers of granted TSP phases at 26th, 33rd and 50th avenues suggest that TSP settings at these intersections were not working properly. 


\subsection{INTRODUCTION}

Transit service reliability is important to both passengers and transit agencies. Slow and unreliable transit service may increase transit user costs in the short term and reduce transit mode share and ridership in the long term, which in turn may lead to higher levels of congestion, emissions, energy consumption, and car dependency in urban areas. In addition, bus travel time is important to schedulers because excessive variability forces schedulers to add excess slack or layover time to transit schedules. Therefore, transit agencies want to reduce bus travel time and its variability. In practice, there are many factors that affect bus travel time and its variability, such as uncertain passenger demand, traffic conditions, driver behavior, signal delay at traffic lights and bus-stop locations, road geometry, vehicle incidents/accidents, weather, etc. (Turnquist, 1981; Levinson, 1991; Ceder, 2007).

Transit agencies generally try to reduce bus travel time and improve service reliability. Transit signal priority (TSP) is one of the strategies that can help buses reduce travel time delay across an intersection. Although some studies evaluated TSP system performance using simulation techniques (Balke et al., 2000; Dion et al., 2004; Shalaby et al., 2003), practical assessment of the TSP system showed that TSP benefits are not consistent across intersections (Albright and Figliozzi, 2012a) or across routes and time periods (Kimpel et al., 2005). Previous studies did not have access to detailed TSP phase data.

The novelty of this research arises from the fine granularity of the analyses (intersection level) as well as the integration of new data sources including bus AVL/APC data; SCATS signal phase log data (including TSP phases); and SCATS intersection traffic count data. The integration of these three data sources makes it possible to evaluate TSP system performance at a high level of detail that is novel.

The objectives of this study are to (1) develop an algorithm to integrate bus AVL/APC data, SCATS signal phase log data and intersection traffic count data; and (2) evaluate TSP system performance by evaluating TSP phase effectiveness, as well as bus and passenger time savings and delay. 


\subsection{LITERATURE REVIEW}

\subsection{TRANSIT SERVICE RELIABILITY}

Transit service reliability has been defined in a variety of ways (Turnquist and Blume, 1980; Abkowitz, 1978) and there is no single measure that can adequately address service quality. The most common measures of transit service reliability typically relate to schedule and headway adherence and travel time variation (Levinson, 1991; Turnquist, 1981; Strathman et al., 1999; Kimpel, 2001). On-time performance is commonly used by transit agencies to measure schedule adherence. It is defined as the percentage of buses that depart from a given location within a predetermined time window (Kittelson \& Associates, Inc., 2013). At the Tri-County Metropolitan Transportation District of Oregon (TriMet), the local transit provider for the Portland metropolitan area, a bus is defined as on time if the bus departs from a "time point" bus stop no more than one minute early and five minutes late. Time point bus stops are specific point locations on bus routes from which vehicles are scheduled to depart at specified times (Kimpel, 2001). On-time performance is a valuable measure for low-frequency bus service (scheduled headways longer than 10 minutes) and timed transfers. Headway coefficient of variation (standard deviation divided by mean) is used to measure headway adherence in high-frequency service (headways less than 10 minutes) (Kittelson \& Associates, Inc., 2013). Poor schedule/headway adherence indicates deterioration of service reliability. Schedule/headway delay at the beginning of a route tends to propagate along the route and result in bus bunching (two buses running too close to each other) and large headway gaps, which increase total passenger delay and decrease passenger satisfaction. Bus travel time is defined as the time needed by a bus to travel between two points along a route. These points can be the beginning and ending terminal stations of the route (route-level travel time), two consecutive time point bus stops (segment-level travel time), or any two consecutive bus stops (bus stop-to-stop travel time).

AVL and APC systems have been implemented by many transit agencies (Crout, 2007; Schweiger, 2003). With the availability of archived bus AVL and APC data, a substantial amount of statistical analyses were conducted to study how bus travel time and service reliability are affected by various impact factors and improvement strategies. Some studies analyzed bus travel time (Abkowitz and Engelstein, 1984; Bertini and El-Geneidy, 2004; El-Geneidy et al., 2011; Figliozzi and Feng, 2012; Slavin et al., 2013; Strathman et al., 2000). Others analyzed travel time delay (Diab and El-Geneidy, 2012; El-Geneidy et al., 2009, 2011; Strathman et al., 1999). And others analyzed travel time coefficient of variation (El-Geneidy et al., 2010; Diab and El-Geneidy, 2013) at the route level and time point segment level. Albright and Figliozzi (2012a) is the first study that analyzed bus travel time at the stop-to-stop segment level. Other studies analyzed bus schedule delay (Kimpel, 2001; Strathman et al., 1999); on-time performance (Strathman and Hopper, 1993; El-Geneidy and Surprenant-Legault, 2010; Rutherford and Watkins, 2011); and headway delay (Strathman et al., 1999; Kimpel, 2001; ElGeneidy et al., 2010; Strathman et al., 2003; Kimpel et al., 2008; Figliozzi and Feng, 2012; Albright and Figliozzi, 2012c) at time point bus stops. Dueker et al. (2004) and Milkovits (2008) also studied bus dwell time for all bus stops. Most of the studies agree on some basic factors that affect bus travel time and schedule/headway reliability. These factors include distance, number of bus stops, number of signalized intersections, passenger boarding/alighting activities, lift use, 
bus load, time of day, driver experience, departure delay, travel direction, bus vehicle type, route type and weather. Some of these factors affect bus travel time between stops, such as distance, number of signalized intersections, departure delay, traffic conditions and route type. Some factors affect bus travel time at stops (dwell time), such as passenger boarding/alighting activities, lift use and number of bus stops. Other factors affect bus travel time both between stops and at stops, including time of day, driver experience, travel direction, bus vehicle type and weather.

\subsection{TRANSIT SIGNAL PRIORITY PERFORMANCE EVALUATION}

A considerable number of researchers have proposed strategies to improve transit service reliability and have evaluated their impacts on bus travel time and service reliability. These strategies include bus-stop consolidation and relocation (El-Geneidy et al., 2006; Furth and Rahbee, 2000; Li and Bertini, 2009; Saka, 2001); bus rapid transit (BRT) implementation (Levinson et al., 2003); smart-card payment system (Diab and El-Geneidy, 2012; Tirachini, 2013); bus holding (Abkowitz and Lepofsky, 1990; Abkowitz et al., 1986; Eberlein et al., 2001; Sun and Hickman, 2008); expressing strategies (Eberlein et al., 1998; Fu et al., 2003; Sun and Hickman, 2005); and TSP implementation (Dion and Hellinga, 2002; Kimpel et al., 2005; Skabardonis, 2000). However, bus-stop consolidation and relocation, BRT implementation and smart-card payment system strategies are usually not easy to be implemented without a careful cost-benefit analysis process. Bus holding strategies reduce some passengers' out-of-vehicle waiting time but increase on-board passengers' in-vehicle waiting time, and vice versa for bus expressing strategies. Compared to these strategies, TSP is a relatively inexpensive and easily implemented tool that can make transit service more reliable, faster and more cost effective (Smith et al., 2005).

TSP is the process of detecting transit vehicles approaching signalized intersections and adjusting the phasing of the signal in real time to reduce the delay experienced by the transit vehicle (Furth and Muller, 2000). The two most common TSP phases are green extension and early green (or red truncation). Both are expected to reduce bus travel time delay at intersections. Green extension extends a regular green phase for a certain amount of time to help transit vehicles pass through the intersection before the green signal turns to red. Early green truncates a regular red phase for a few seconds and begins the green phase early to help transit vehicles start moving early. According to Smith et al. (2005), a TSP system typically consists of three components: (1) a priority request generator on a bus that alerts the traffic control system that the bus would like to receive priority; (2) a detection system that receives the priority request and lets the traffic controller know where the bus is located; and (3) priority control strategies that help the signal controller make decisions regarding whether to grant a TSP phase, which TSP phase should be granted, and when the TSP phase should start and end. There are a variety of priority control strategies that can be classified into three categories: unconditional (or passive) priority, conditional (or active) priority and real-time optimal priority. Passive priority grants a priority phase regardless of the state of the intersection or the bus. Active priority grants a priority phase only when the states of the bus and the intersection meet certain requirements. The duration of the green extension and early green phases are usually constant. Real-time optimal priority strategies make TSP decisions in real time based on the states of the bus and the intersection, as well as the objectives of the decision-makers. The objective may be to minimize the total passenger delay of an intersection (Christofa and Skabardonis, 2011; Mirchandani and 
Lucas, 2004), to minimize bus schedule deviations (Ma et al., 2013, 2010), or to minimize other composed performance measures (Conrad et al., 1998; Dion and Hellinga, 2002; He et al., 2011; Yagar and Han, 1994). Therefore, TSP phase start time and duration may vary from cycle to cycle.

A good number of researchers focus on evaluating the effects of proposed TSP strategies on transit vehicles and other traffic utilizing analytic or simulation models. However, results vary significantly in the literature. Balke et al. (2000) simulated an active priority strategy at an isolated intersection with both green extension and early green phases. They found significant reductions in bus travel time at different traffic levels with minor increases in total intersection delay under moderate traffic levels. Furth and Muller (2000) evaluated the performance of passive and active TSP systems in a corridor using simulation. Results showed that both passive and active priority significantly improved bus schedule adherence. However, active priority has almost no impact on traffic delay and passive priority significantly increased traffic delay. Skabardonis (2000) proposed both passive and active priority strategies and evaluated them on a corridor with 21 coordinated intersections through simulation. This study showed that TSP strategies provide modest improvement for the buses without adverse effects on automobile traffic. Dion et al. (2004) evaluated the performance of several active priority strategies using simulation models on an arterial corridor. They found that buses would typically benefit from TSP but at the expense of the overall traffic. However, when traffic flow on the side street is low, the overall negative impacts can be negligible. Byrne et al. (2005) evaluated the effectiveness of a conditional TSP system at a single intersection using a simulation model. Results showed that the TSP implementation yields an $11 \%$ reduction in bus travel time for the far-side stop configuration and a 6\% increase in bus travel time for the near-side stop consolidation. Some studies claimed that TSP is more efficient at far-side bus stops because there is less uncertainty in predicting the arrival time of a bus at an intersection (Chada and Newland, 2002). Therefore, bus arrival time prediction, especially upstream of intersections, is important to the effectiveness of TSP.

Unlike most of the previous studies that use simulation models to study the effects of the TSP system on buses and other traffic, Lin (2002) used analytical models to quantify the transit vehicle delay reduction due to signal priority. He found that delay reduction is especially small for buses traveling on the major street of an arterial, and buses from minor streets are expected to receive higher delay reduction. In summary, most of the proposed TSP control strategies were evaluated under idealistic assumptions and were based on either analytic or simulation models without ground tests on real-world data. Also, mixed results were found in the literature regarding the impact of the TSP system on buses and other vehicles. This may be because TSP performance is a function of many factors including intersection geometry, signal timing, traffic demand, TSP control strategies and parameters, transit vehicle headways, reliability of the detection system, and the TSP request generating system (Abdy and Hellinga, 2011).

There are also a few studies that evaluated the effects of TSP on buses and other vehicles by using real-world collected data. However, results are not consistent in the literature. For example, Hunter-Zaworski et al. (1995) collected travel time data for buses and other vehicles at four intersections on Powell Boulevard in Portland, OR, before and after the implementation of an active TSP system. They found that after TSP implementation, bus travel time decreased 
during peak hours but increased during off-peak hours, and intersection total person delay had mixed changes at different times of day. Subsequently, Koonce et al. (2002) evaluated the impact of a TSP system on bus travel time on another corridor (Barbur Boulevard) in Portland. Results showed that bus travel time decreased 0.4-3.2 minutes and travel time variability decreased 2.2$19.2 \%$ during different times of day and travel directions. However, no difference was found in bus travel time savings between buses that were late and those that were not late. Kimpel et al. (2005) evaluated changes in bus running times, on-time performance, and excess passenger waiting times following TSP implementation on several corridors in Portland. Results showed that the benefits of TSP are not consistent across routes and time periods, nor are they consistent across various performance measures. Slavin et al. (2013) evaluated the effect of TSP on bus travel time using regression models. Results showed that the TSP system significantly reduced bus travel time over the study corridor for buses that requested TSP after controlling for other factors. Albright and Figliozzi (2012b) also utilized regression models to study the effect of TSP on bus headways on the same corridor. Results showed that a bus that requested signal priority significantly shortened the headway to its preceding bus and increased the headway to its following bus. Another study by Albright and Figliozzi (2012c) was conducted on the same corridor. This study evaluated the effect of TSP on bus schedule recovery (bus schedule delay before and after an intersection) at several intersections along this corridor. Results showed that the effect of TSP on bus schedule delay varies across intersections. This study found that late bus schedule recovery is greater at intersections with less demand on the minor crossing streets. Diab and El-Geneidy (2012), Diab and El-Geneidy (2013) utilized regression models to study the impact of a TSP system on bus travel time and its variability on two bus routes in Montreal, Canada. Active TSP systems were implemented in these two corridors. Results indicated that bus travel times for the two bus routes significantly decreased after the implementation of a TSP system, and that TSP-equipped buses have shorter travel times than those buses that were not equipped with TSP. However, the bus travel time coefficient of variation increased after the implementation of the TSP system and for TSP-equipped buses.

In summary, previous studies only analyzed the impacts of TSP systems on bus travel time savings, on-time performance, headways, and the delay and time savings for other vehicles; no one has evaluated the effectiveness of TSP phases or the relationships between TSP requests and TSP phases. For example, it is possible that 10 buses requested signal priority at an intersection, 20 TSP phases were granted in the same time period, but only five buses benefited from these TSP phases due to uncertainty of the traffic conditions or TSP system reliability issues. There is no study that has accessed TSP phase log data, or integrated TSP phase log data with bus AVL/APC data to evaluate the TSP system performance. Therefore, this study will fill in this gap and evaluate TSP system performance by integrating unique data sources and proposing novel performance measures. 


\subsection{DATA AND METHODOLOGIES}

\subsection{STUDY CORRIDOR DESCRIPTION}

Powell Boulevard is a major commuter arterial located in Portland, Route 9 is the primary bus route operated along this corridor. Route 9 runs east-west with an average headway of 15 minutes during midday and an average headway of six to seven minutes during the morning and evening peak periods.

The study corridor, signalized intersections and bus stops are shown in Figure 3-1. The study corridor is a four-mile long urban arterial corridor with two lanes in each direction; downtown Portland is located to the west of the figure. Westbound (WB) peak traffic volume takes place in the morning rush hour (towards downtown Portland); eastbound (EB) peak traffic volume takes place in the evening rush hour (away from downtown Portland). The Sydney Coordinated Adaptive Traffic System (SCATS) is implemented in 12 signalized intersections between Milwaukie and $72^{\text {nd }}$ avenues. Most of the intersections have similar cycle lengths of 120 seconds on average. Red phase duration varies significantly across intersections; buses may experience longer delays at some major intersections such as Milwaukie, $39^{\text {th }}, 50^{\text {th }}$ and $52^{\text {nd }}$ avenues. Transit signal priority (TSP) is programmed to respond to bus priority requests from both the EB and WB directions at each of the 12 intersections.

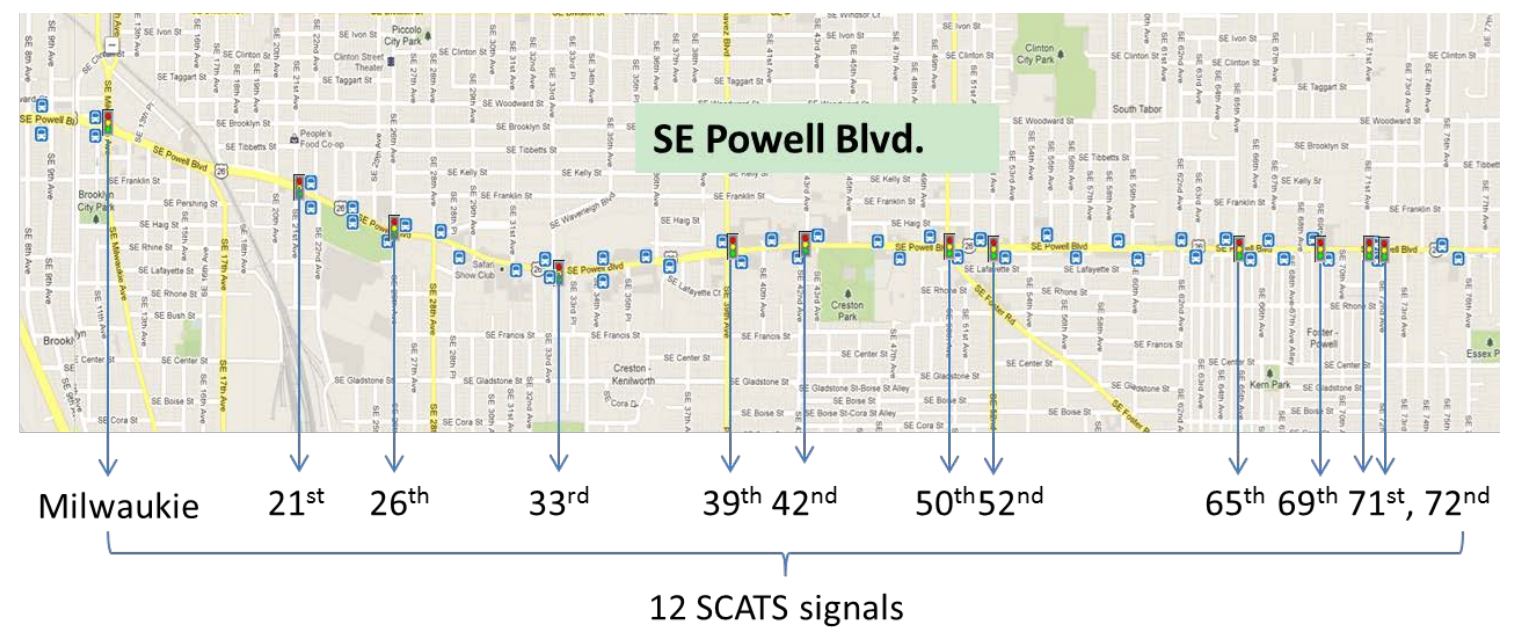

Figure 3-1 Study corridor overview

There are 22 bus stops and 21 bus stop-to-stop segments in ear Near-side segments lwaukie and $72^{\text {nd }}$ avenues. These bus stop-to-stop segments are classifiea into tour categories: near-side segment, far-side segment, segment with two signals and segment without a signal. Near-side segment means the departure stop of the stop-to-stop segment is a near-side stop; far-side segment means the arrival stop of the stop-to-stop segment is a far-side stop. In the intersections between Milwaukie and $72^{\text {nd }}$ avenues, there are six near-side segments, 12 far-side segments and three segments with two signals. Most of these segments are less than 0.2 miles long. Near-side 
bus stops are much closer to intersections than far-side stops. In this study, only 12 far-side segments and six near-side segments are chosen for bus travel time modeling analysis and TSP performance evaluation because it is difficult to integrate the signal phase data with bus AVL/APC data when there are two signals in one stop-to-stop segment.

\subsection{DATA DESCRIPTION}

Three archived databases were used for this corridor to conduct the analyses: bus AVL/APC data, SCATS signal phase log data and traffic count data. In the bus AVL/APC data, every time a bus makes a stop the arrival time, departure time and schedule time are recorded; other information such as stop location, vehicle information, passenger activities, onboard passengers and dwell time are also recorded. According to the TriMet Bus Dispatching System (BDS) AVL/APC data dictionary, each bus stop in the TriMet system is referenced by a 50 -foot stop circle in the agency's geographic information system (GIS). Arrival time refers to the time that a bus first enters the 50-foot stop circle except when a door opening occurs. If a door opening occurs within the stop circle, then arrival time is overwritten with the time of the door opening. Departure time refers to the time when a bus leaves the 50-foot stop circle. However, some nearside bus stops are close enough to the intersection stop bar (less than 50 feet) that signal delay for buses at near-side stops is not included in the time interval between the departure time from this near-side stop and the arrival time in the next bus stop. This issue leads to different modeling strategies between near-side and far-side bus stops to study the impact of signal delay on bus travel time reliability. Schedule time refers to the scheduled departure time for a bus stop (TriMet, 2013).

The SCATS phase log data provides the start time and end time of each phase (including TSP phase) in a cycle. For example, Figure 3-4 and Figure 3-5 show the SCATS signal phase plan and the disaggregated (original) SCATS phase log data for the intersection of $39^{\text {th }}$ Avenue and Powell Boulevard, respectively. Phases are granted in the order of “A," "B," "C," "D," "E” and "F." Phases "C1" and "C2" are extension phases of phase "C"; phases "E1" and "E2" are extension phases of phase " $E$ "; both of them are mutually exclusive. Phase "A" is the regular green phase for the EB and WB through movement. Phase " $B$ " and phase " $F$ " are the green extension (GE) phase and early green (EG) phase. In this study, we are only interested in the regular green phase, red phase, green extension phase and early green phase for the EB and WB through movement. Therefore, phases "C," “C1," “C2," “D," "E” and "E1” are aggregated into one red phase for the EB through movement. Phases "C1," "C2," "D," "E” and "E2" are aggregated into one red phase for the WB through movement. Similar phase aggregation is applied to other intersections along this corridor, although the phase order varies significantly across intersections. 


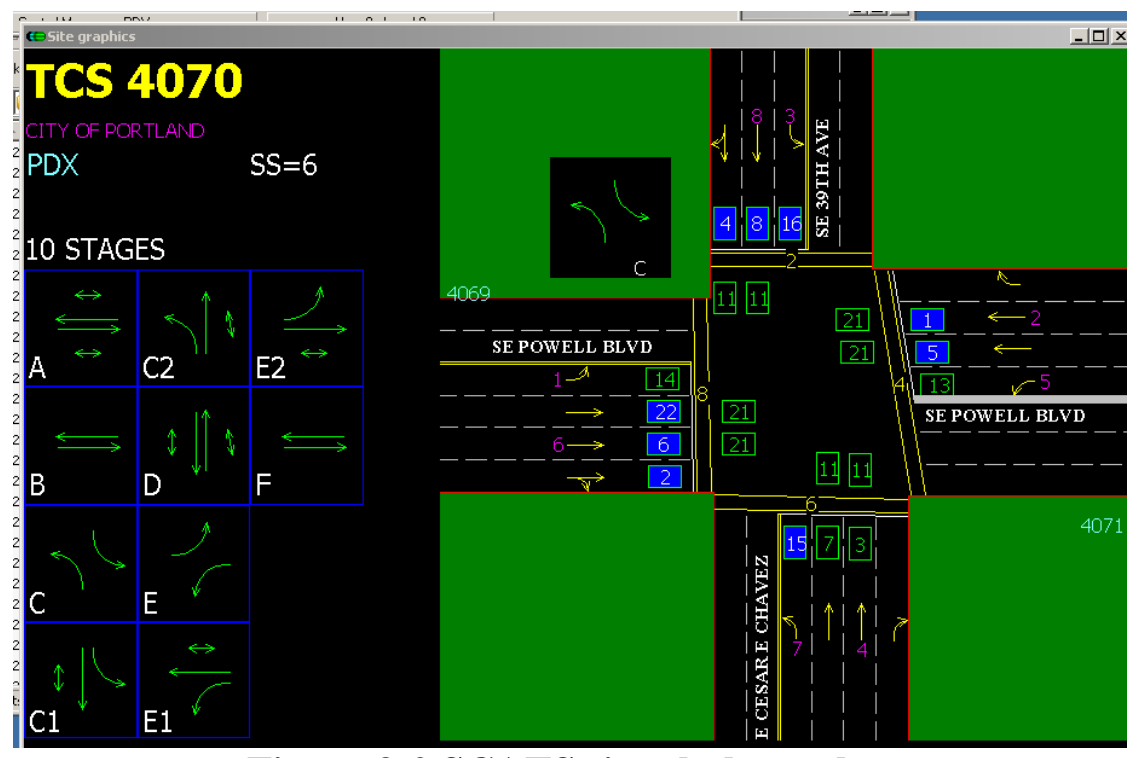

Figure 3-2 SCATS signal phase plan

(Source: Portland Bureau of Transportation SCATS system, City of Portland)

\begin{tabular}{|c|c|c|c|c|c|c|c|c|}
\hline 20 & 013-03-04_39th_ & Powell_SCATSphas & xt - Notepad & & & 므 & 回 & 3 \\
\hline File & Edit Format & View Help & & & & & & \\
\hline Date & & start Time & End Time & Duration & Phase & Gap & Error & $\Delta$ \\
\hline Mon & 4-Mar-2013 & $07: 23: 29$ & $07: 24: 33$ & & & & & \\
\hline Mon & $4-\operatorname{Mar}-2013$ & $07: 24: 33$ & $07: 24: 53$ & 20 & c & & & L \\
\hline Mon & 4-Mar-2013 & $07: 24: 53$ & $07: 25: 40$ & 47 & $\mathrm{D}$ & Yes & & \\
\hline Mon & $4-\mathrm{Mar}-2013$ & $07: 25: 40$ & $07: 26: 43$ & 63 & A & & & \\
\hline Mon & 4-Mar-2013 & $07: 26: 43$ & $07: 26: 50$ & 7 & B & & & \\
\hline Mon & $4-\mathrm{Mar}-2013$ & $07: 26: 50$ & $07: 27: 07$ & 17 & $c$ & & & \\
\hline Mon & 4-Mar-2013 & $07: 27: 07$ & $07: 27: 42$ & 35 & D & & & \\
\hline Mon & 4-Mar-2013 & $07: 27: 42$ & $07: 27: 52$ & 10 & $\mathrm{E}$ & & & \\
\hline Mon & 4-Mar-2013 & $07: 27: 52$ & $07: 28: 02$ & 10 & $\bar{F}$ & & & \\
\hline Mon & 4-Mar-2013 & $07: 28: 02$ & $07: 28: 53$ & 51 & A & & & \\
\hline Mon & 4-Mar-2013 & $07: 28: 53$ & $07: 29: 17$ & 24 & C & & & \\
\hline Mon & 4-Mar-2013 & $07: 29: 17$ & $07: 29: 52$ & 35 & D & & & \\
\hline Mon & 4-Mar-2013 & $07: 29: 52$ & $07: 30: 07$ & 15 & $\mathrm{E}$ & & & \\
\hline Mon & 4-Mar-2013 & $07: 30: 07$ & $07: 31: 04$ & 57 & $\bar{A}$ & & & \\
\hline Mon & $4-\mathrm{Mar}-2013$ & $07: 31: 04$ & $07: 31: 24$ & 20 & C & & & \\
\hline Mon & 4-Mar-2013 & $07: 31: 24$ & $07: 31: 48$ & 24 & D & Yes & & \\
\hline Mon & $4-M a r-2013$ & $07: 31: 48$ & $07: 32: 14$ & 26 & $\mathrm{E}$ & Yes & & \\
\hline Mon & 4-Mar-2013 & $07: 32: 14$ & $07: 33: 13$ & 59 & A & & & \\
\hline Mon & $4-\mathrm{Mar}-2013$ & $07: 33: 13$ & $07: 33: 20$ & 7 & B & & & \\
\hline Mon & 4-Mar-2013 & $07: 33: 20$ & $07: 33: 33$ & 13 & C & & & \\
\hline Mon & 4-Mar-2013 & $07: 33: 33$ & $07: 34: 08$ & 35 & $\mathrm{D}$ & & & \\
\hline Mon & 4-Mar-2013 & $07: 34: 08$ & $07: 34: 18$ & 10 & $\mathrm{E}$ & & & \\
\hline Mon & 4-Mar-2013 & $07: 34: 18$ & $07: 34: 28$ & 10 & $\mathrm{~F}$ & & & \\
\hline Mon & 4-Mar-2013 & $07: 34: 28$ & $07: 35: 23$ & 55 & A & & & \\
\hline Mon & 4-Mar-2013 & $07: 35: 23$ & $07: 35: 30$ & 7 & B & & & \\
\hline Mon & 4-Mar-2013 & $07: 35: 30$ & $07: 35: 39$ & 9 & C & & & \\
\hline Mon & 4-Mar-2013 & $07: 35: 39$ & $07: 36: 14$ & 35 & D & & & \\
\hline Mon & 4-Mar-2013 & $07: 36: 14$ & $07: 36: 29$ & 15 & $\mathrm{E}$ & & & \\
\hline Mon & 4-Mar-2013 & $07: 36: 29$ & $07: 37: 33$ & 64 & A & & & \\
\hline Mon & 4-Mar-2013 & $07: 37: 33$ & $07: 37: 46$ & 13 & C & & & \\
\hline Mon & 4-Mar-2013 & $07: 37: 46$ & $07: 38: 21$ & 35 & D & & & \\
\hline Mon & $4-\operatorname{Mar}-2013$ & $07: 38: 21$ & $07: 38: 36$ & 15 & $\mathrm{E}$ & & & \\
\hline Mon & 4-Mar-2013 & $07: 38: 36$ & $07: 39: 44$ & 68 & A & & & \\
\hline Mon & $4-\mathrm{Mar}-2013$ & $07: 39: 44$ & $07: 40: 00$ & 16 & C & & & \\
\hline Mon & 4-Mar-2013 & $07: 40: 00$ & $07: 40: 35$ & 35 & D & & & \\
\hline Mon & $4-\mathrm{Mar}-2013$ & $07: 40: 35$ & $07: 40: 50$ & 15 & $\mathrm{E}$ & & & \\
\hline Mon & 4-Mar-2013 & $07: 40: 50$ & $07: 41: 53$ & 63 & A & & & \\
\hline 1 & & & & & & & 1 & \\
\hline
\end{tabular}

Figure 3-3 SCATS phase log data example

(Source: Portland Bureau of Transportation SCATS system, City of Portland)

SCATS traffic count data offers the 15-minute interval traffic count data for each detector at the intersection. For example, Figure 3-6 shows the vehicle count data for each detector in each 15 
minutes interval at the intersection of $39^{\text {th }}$ Avenue and Powell Boulevard. The detector numbers are the same as those shown in Figure 3-4. There are 10 movement directions at this intersection and each movement direction refers to one or two loop detectors. For example, EBTH (eastbound through) has two detectors, 6 and 22; EBTHRT (eastbound through-right) has one detector, 2. The number of vehicles that passed each detector in each 15-minute interval is recorded. For example, between 00:00 and 00:15, there are 20 vehicles that passed detector 6 and there are 16 vehicles that passed detector 22. The total number of vehicles between 00:00 and 00:15 is 36 for the EBTH movement. This study focuses on the through-movement vehicles; therefore, the 15-minute interval traffic count from EBTH movement detectors (6 and 22) and EBTHRT movement detector (2) are aggregated into an EBTH movement traffic count. Then, the 15-minute interval traffic count is converted to vehicles per hour. For example, between 00:00 and 00:15 a.m., the aggregated EBTH volume for all lanes is $(20+16+6) * 4=168$ vehicles per hour. This traffic count aggregation is also applied to other intersections, although intersection detector configurations are different.

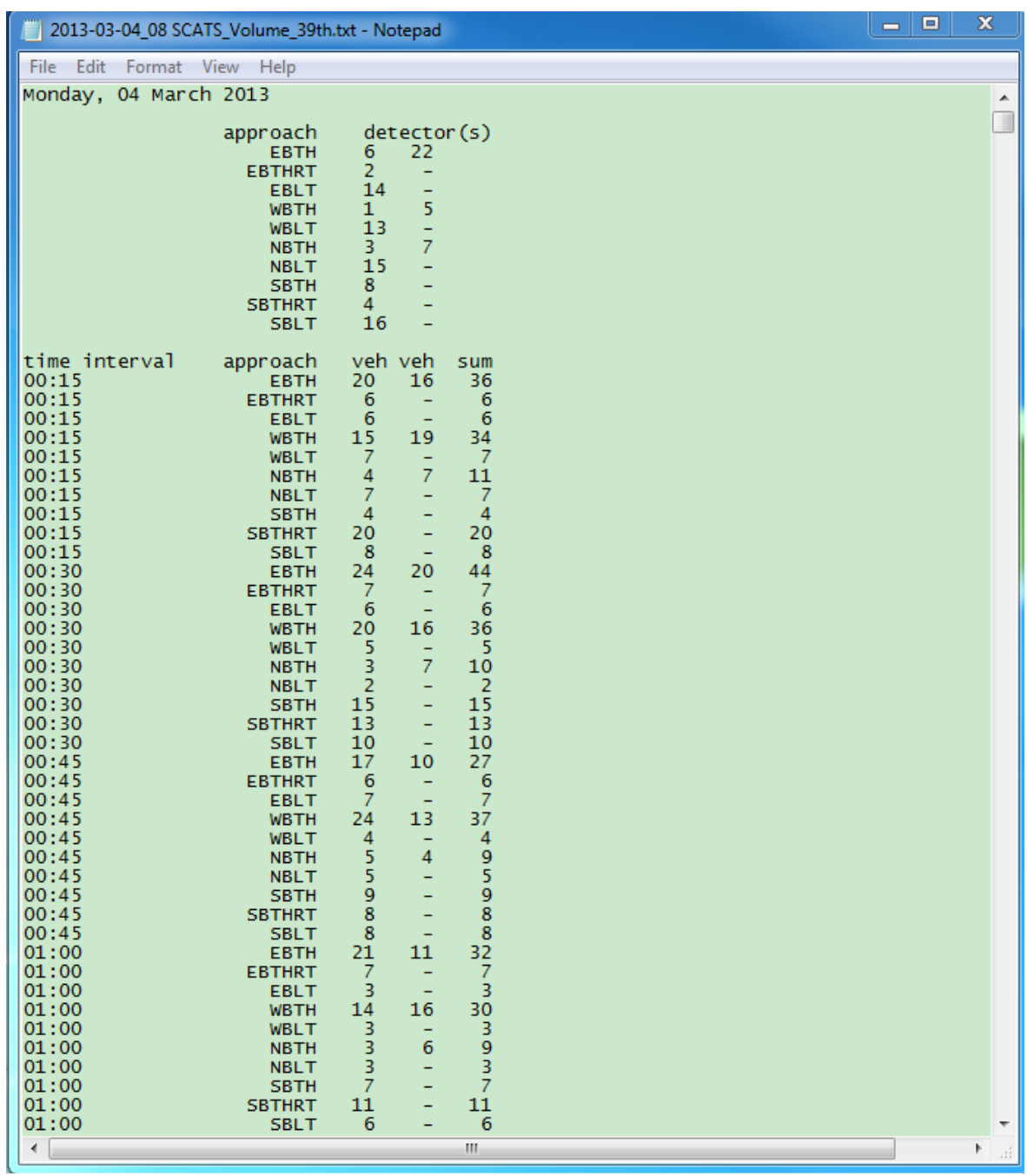

Figure 3-4 SCATS traffic count data example

(Source: Portland Bureau of Transportation SCATS system, City of Portland) 
Two months of data (March and May 2013) from the three databases were used for this study because the TSP system was turned off in April 2013 for a system update. Therefore, the TSP system was working along this corridor in March 2013, but not in May 2013. The numbers of effective weekdays collected from March and May 2013 are 20 and 18 days, respectively. All of the three databases from the two months will be used in the bus travel time modeling analysis to examine whether bus travel time is significantly different before and after the time when TSP was working. Then, the bus AVL/APC data and the SCATS phase log data from March 2013 will be used to evaluate the TSP performance.

\subsection{DATA INTEGRATION}

An integrated database is critical for advanced analysis of travel time regression analysis and TSP performance evaluation. The integrated bus stop-to-stop trip database requires information from three separate databases: bus AVL/APC data, SCATS signal phase log data, and SCATS traffic count databases. A bus stop-to-stop trip is selected as the basic unit to integrate the three databases. Each bus stop-to-stop trip contains three sets of attributes: bus-stop activity attributes, stop-to-stop segment attributes and signal phase attributes, as shown in Table 3-1. Bus stop-tostop trip attributes describe bus trip characteristics, including constants that describe segment geometry, variables that are directly recorded by the three databases, and estimated variables that are computed based on the three databases. Bus-stop activity attributes are recorded variables that describe bus stop-to-stop trip characteristics at the departure and arrival bus stops of a stopto-stop segment. Stop-to-stop segment attributes include segment stationary characteristics (constants that do not vary by bus trip) and variable trip characteristics that are recorded by the bus AVL/APC data and intersection vehicle count data. Signal phase attributes are estimated variables that describe bus stop-to-stop trip characteristics related to signal phases. A new database is created to include these attributes for each bus stop-to-stop trip. This database contains all the necessary information required for the bus travel time regression analysis and TSP performance evaluation.

Table 3-1 Bus stop-to-stop trip attributes

\begin{tabular}{|c|c|c|}
\hline $\begin{array}{l}\text { Bus-stop activity } \\
\text { attributes (recorded) }\end{array}$ & $\begin{array}{l}\text { Stop-to-stop segment } \\
\text { attributes (recorded) }\end{array}$ & $\begin{array}{l}\text { Signal phase attributes } \\
\text { (estimated) }\end{array}$ \\
\hline $\begin{array}{l}\text { Departure/arrival stop: } \\
\text { - Actual arrival time } \\
\text { - Actual departure time } \\
\text { - Scheduled departure time } \\
\text { - } \text { Boarding passengers } \\
\text { - Alighting passengers } \\
\text { - } \quad \text { Number of lift use } \\
\text { - TSP request (estimated) }\end{array}$ & $\begin{array}{l}\text { Constants: } \\
\text { - Stop-to-stop distance } \\
\text { - Upstream distance } \\
\text { - Downstream distance } \\
\text { Variables: } \\
\text { - Departure-to-arrival time } \\
\text { - Arrival-to-arrival time } \\
\text { - Traffic volume }\end{array}$ & $\begin{array}{l}\text { Estimated } \\
\text { - Red } \\
\text { - Probability of arriving in: } \\
\text { o Green } \\
0 \quad \text { Red } \\
0 \quad \text { Green extension } \\
\text { o Early green } \\
\text { - Expected signal delay } \\
\text { - Expected time savings }\end{array}$ \\
\hline
\end{tabular}

\subsubsection{Bus-stop Activity Attributes and Stop-to-stop Segment Attributes}

Most of the bus-stop activity attributes can be directly read from the bus AVL/APC data except for TSP request, which is estimated based on the actual and scheduled departure times. TSP 
request equals one if the actual departure time is more than 30 seconds late than the scheduled departure time; otherwise, it equals zero. The constant stop-to-stop segment attributes are measured on Google Maps. Upstream distance is the distance from the upstream departure stop to the intersection stop bar, and downstream distance is the distance from the intersection stop bar to the downstream arrival stop. Departure-to-arrival time (or arrival-to-arrival time) is the time interval between departure from (or arrival to) the upstream departure stop and arrival at the downstream arrival stop. Traffic volume for each bus stop-to-stop trip is the 15-minute traffic flow for the bus travel direction when the trip is made. In signal phase attributes, the red attribute is a binary variable that indicates whether a bus trip encountered a red signal at the intersection. Because bus AVL/APC data only provide the bus departure time and arrival time at bus stops, the actual bus arrival time at the intersection is not known for certain. Therefore, probabilities of bus arrival time at the intersection during each phase are estimated based on an algorithm that will be explained in the following section. Based on the estimated probabilities of arriving at the intersection in each phase and the phase duration information, the expected signal delay due to a red signal and the expected time savings due to a TSP phase can be estimated. The signal phase attributes will be used for bus travel time modeling and TSP performance analyses. They are estimated based on the integration of the bus AVL/APC data and the SCATS phase log data.

\subsubsection{Signal Phase Attributes}

Before integrating the two data sources, it is important to compare whether the time clock systems are synchronized between the two data sources. Two two-hour videos were collected on February 26 and May 1, 2013, at the intersection of $26^{\text {th }}$ Avenue and Powell Boulevard, and the videos were used as the reference clock system to compare the time clocks between the two data sources. The videos cover all four approaches of the intersection with both the bus stops and the signal heads clearly visible. Therefore, both the bus departure time and arrival time and the signal phase start time and end time recorded from the videos are in the same clock system. By comparing each pair of signal phase start time and end time records from the video and from the SCATS system, an offset between the two systems can be found. Ten bus trips were collected on each day. Results show that the video clock system is perfectly synchronized with the SCATS clock system, which means the offset between the two systems is zero. However, the bus AVL/APC data clock system is not synchronized with the SCATS clock system or the video clock system. In addition, clock systems are not synchronized between buses. In other words, the clock system on each bus has a different offset with the SCATS clock system. By comparing the bus arrival time and departure time from the video and from the bus AVL/APC data, we found that bus clock systems are three to nine seconds later than the SCATS system. Therefore, an average offset of five seconds will be used when comparing the bus AVL/APC data with the signal phase start time and end time data.

Once the clock systems between the bus and the SCATS data are synchronized, algorithms can be developed to integrate the two data sources and calculate signal phase attributes. Define $\boldsymbol{I}$ as the set of bus trips for a stop-to-stop segment, and $i$ as the index for the $i$ th bus trip, so $i \in I$. Define $\boldsymbol{J}$ as the set of signal phase cycles for the intersection in the bus stop-to-stop segment; each cycle is defined as the time interval between two consecutive red phase start times. Because bus-stop activity attributes can be directly read from the bus AVL/APC data and stop-to-stop segment attributes can be easily measured or calculated based on the bus AVL/APC data and 
SCATS traffic count data, these attributes and the SCATS phase log data will be used as input data to estimate the signal phase attributes.

\section{Input data}

$d_{1}, d_{2}$ : upstream distance and downstream distance as defined in Table 3-1;

$d t_{i}, a t_{i}$ : departure time from the departure stop and arrival time at the arrival stop for bus trip $i$

(for near-side segments, $d t_{i}$ is the arrival time at the departure stop);

$\operatorname{load}_{i}$ : number of onboard passengers for bus trip $i$;

$R_{j}^{S}, R_{j}^{e}$ : red phase start time and end time for cycle $j$;

$G E_{j}^{S}, G E_{j}^{e}$ : green extension phase start time and end time for cycle $j$;

$E G_{j}^{S}, E G_{j}^{e}$ : early green phase start time and end time for cycle $j$.

\section{Output signal phase attributes:}

$\operatorname{Red}_{i}$ : binary variable, it is 1 if a bus trip $i$ experienced a red signal delay at the intersection and 0 otherwise;

$\operatorname{Prob} R_{i}$ : probability of arriving at the intersection during a red phase for bus trip $i$;

Prob_G $G_{i}$ : probability of arriving at the intersection during a green phase for bus trip $i$;

Prob_GE $E_{i}$ : probability of arriving at the intersection during a green extension phase for bus trip $i$

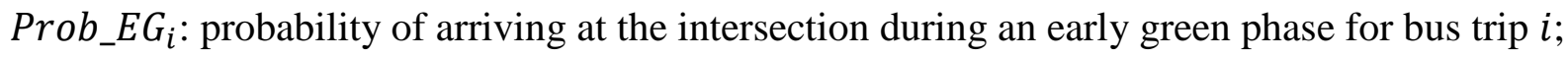

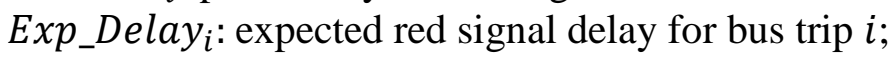

$B T S_{-} G E_{i}, P T S_{-} G E_{i}$ : expected bus (and passenger) time savings due to a green extension phase for bus trip $i$;

$B T S_{-} E G_{i}, P T S_{-} E G_{i}$ : expected bus (and passenger) time savings due to an early green phase for bus trip $i$.

The bus arrival time probability at the intersection is calculated based on the upstream distance and bus travel speed probability distribution, which is estimated based on the observed bus stopto-stop travel speeds. Because some of the bus stop-to-stop travel speed observations may include signal delay, these records will be excluded from the travel speed observations to estimate the non-stop bus travel speed distribution in the upstream distance for far-side segments or in the downstream distance for near-side segments. Assume the total number of bus travel speed observations for a bus stop-to-stop segment at a certain time of day is $N$, and assume the ratio between the median red phase duration and the cycle length of the intersection is $\frac{R}{C}$ ( $0<$ $\left.\frac{R}{C}<1\right)$. First, the $N$ bus travel speed observations are ordered from the lowest to the highest. Then, the first $N \cdot \frac{R}{C}$ bus travel observations are removed. The remaining $N \cdot\left(1-\frac{R}{C}\right)$ speed observations are used to estimate the non-stop bus travel speed probability distribution. The nonstop bus speed probability distribution is estimated based on the frequencies of bus speed observations in each speed bin (1 mph increment). Therefore, the frequency of each speed bin (1 mph increment) is the probability density of the speed. Because the non-stop bus travel speed distribution may vary by time of day, four non-stop bus travel speed probability distributions were estimated in four different times of day: AM peak hours (7-9 a.m.), Mid-day (9 a.m.-4 p.m.), PM peak hours (4-6 p.m.) and Evening (6 p.m.-7 a.m.). The estimated non-stop bus travel speed histograms without signal delay for all stop-to-stop segments in four times of day are 
shown in Appendix A. Because we do not have two separate bus travel speed distributions for the upstream distance and the downstream distance, we assume that the estimated bus travel speed distribution for the stop-to-stop segment applies to both the upstream and the downstream parts.

For a bus stop-to-stop segment at a certain time of day, define $f(v)$ as the probability density function for bus stop-to-stop travel speeds without signal delay, and define $v_{\text {mean }}, v_{\min }$ and $v_{\text {max }}$ as the mean, minimum and maximum of these speeds. Then, the probability of a bus travels between speeds $v_{1}$ and $v_{2}$ is:

$$
P\left[v_{1} \leq v<v_{2}\right]=\int_{v_{1}}^{v_{2}} f(v) \mathrm{d} v
$$

Given the above input data and the probability function $f(v)$, an algorithm is developed to calculate the signal phase attributes output. The concept of the algorithm is explained below.

First, the Red attribute is a binary variable that indicates whether a bus trip encountered a red signal. The value of this variable is determined by comparing bus stop-to-stop travel time intervals with red phase intervals of an intersection.
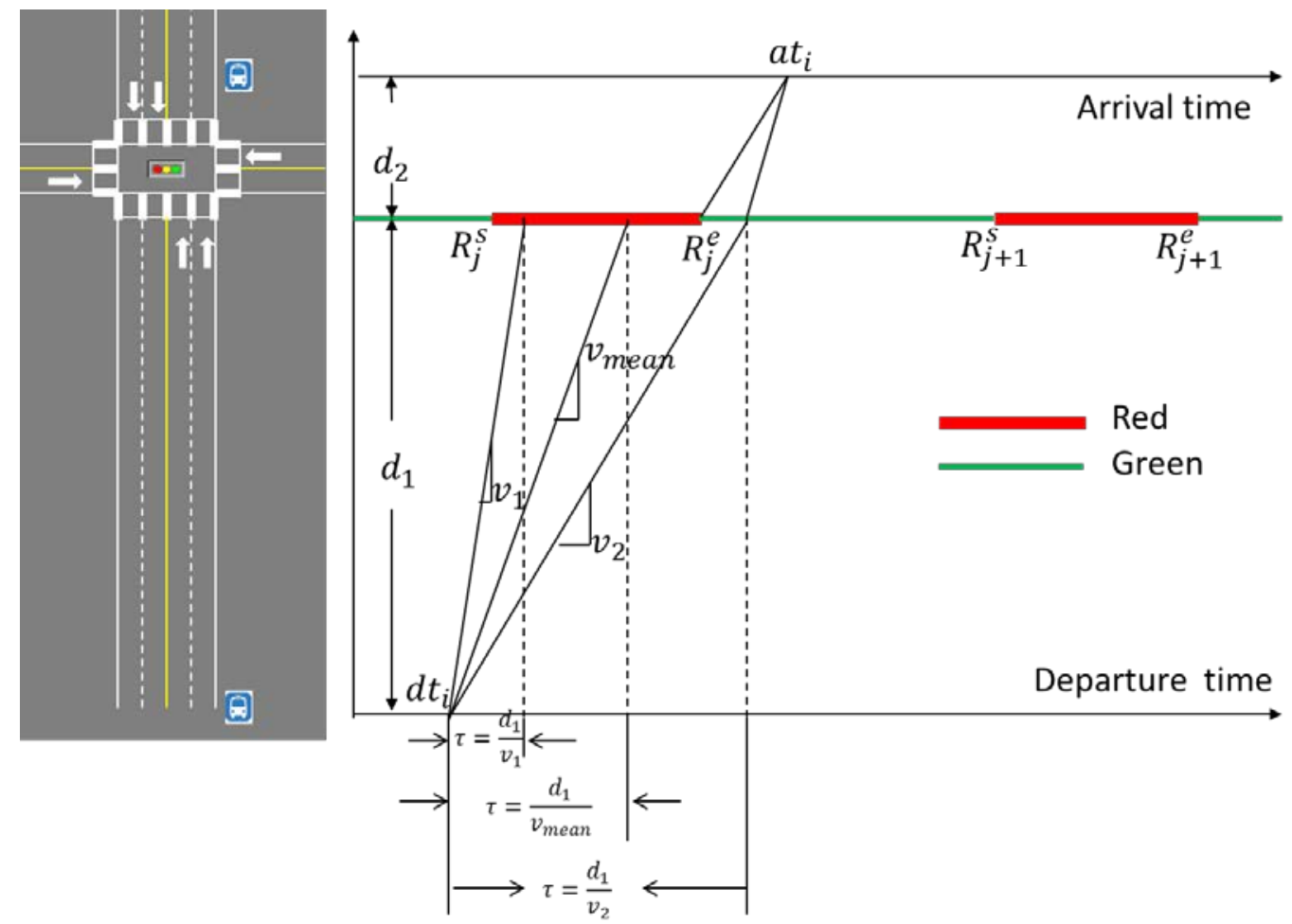

Figure 3-5 Time-space diagram of a bus that encounters a red signal delay

As shown in Figure 3-8, define $\tau$ as the travel time from the upstream bus stop to the intersection, $\tau(v)=\frac{d_{1}}{v}$. The Red variable is equal to 1 for bus trip $i$ if the following conditions are met by any red phase interval $j$ : 


$$
\begin{gathered}
d t_{i}+\tau \leq R_{j}^{e}<a t_{i} \\
R_{j}^{S}<d t_{i}+\tau
\end{gathered}
$$

The above equations mean that a bus $i$ encountered a red signal delay if its arrival time at the intersection $\left(d t_{i}+\tau\right)$ is before the end time $\left(R_{j}^{e}\right)$ of a red phase $j$, and its arrival time at the downstream stop $\left(a t_{i}\right)$ is after the end time $\left(R_{j}^{e}\right)$ of the red phase $j$. Another logical constraint is that the arrival time of bus $i$ at the intersection $\left(d t_{i}+\tau\right)$ should be after the start time $\left(R_{j}^{S}\right)$ of the red phase $j$; otherwise, the bus $i$ would not encounter a red signal. It is possible to state that the logical conditions must be met to determine whether a bus encountered a red signal or not, but the travel time $\tau(v)$ is unknown. According to Figure 3-8, if we use $\tau=\frac{d_{1}}{v_{1}}, \operatorname{Red}_{i}=1$ is correct if the actual travel speed is $v_{1}$; it is wrong if the actual travel speed is $v_{1}$. Similarly, if we use $\tau=$ $\frac{d_{1}}{v_{2}}, \operatorname{Red}_{i}=0$ is correct if the actual travel speed is $v_{2}$, but incorrect if the actual travel speed is $v_{1}$. Therefore, mean travel speed ( $\left.v_{\text {mean }}\right)$ at each segment is used to determine the travel time $\tau=\frac{d_{1}}{v_{\text {mean }}}$.

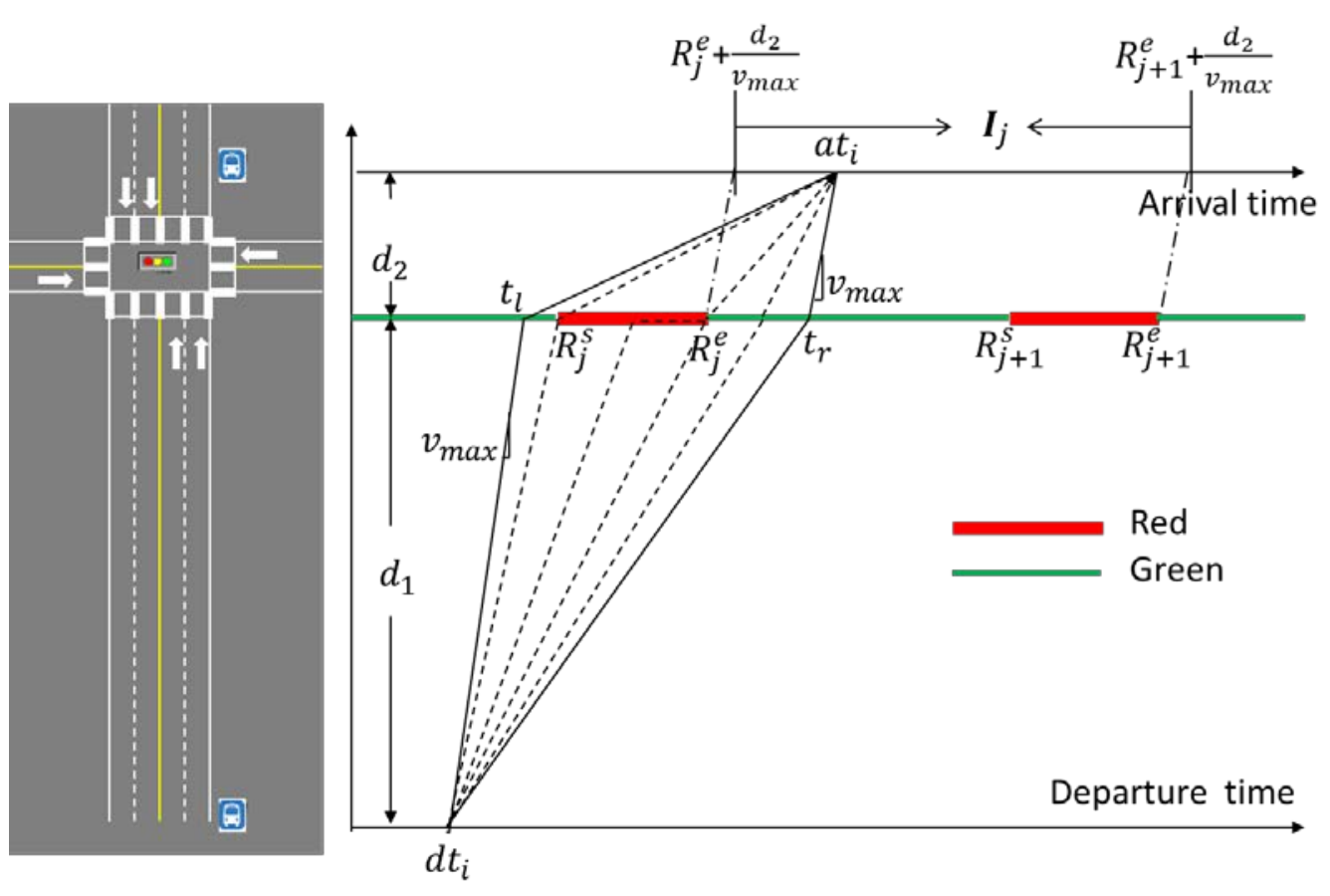

(a) 


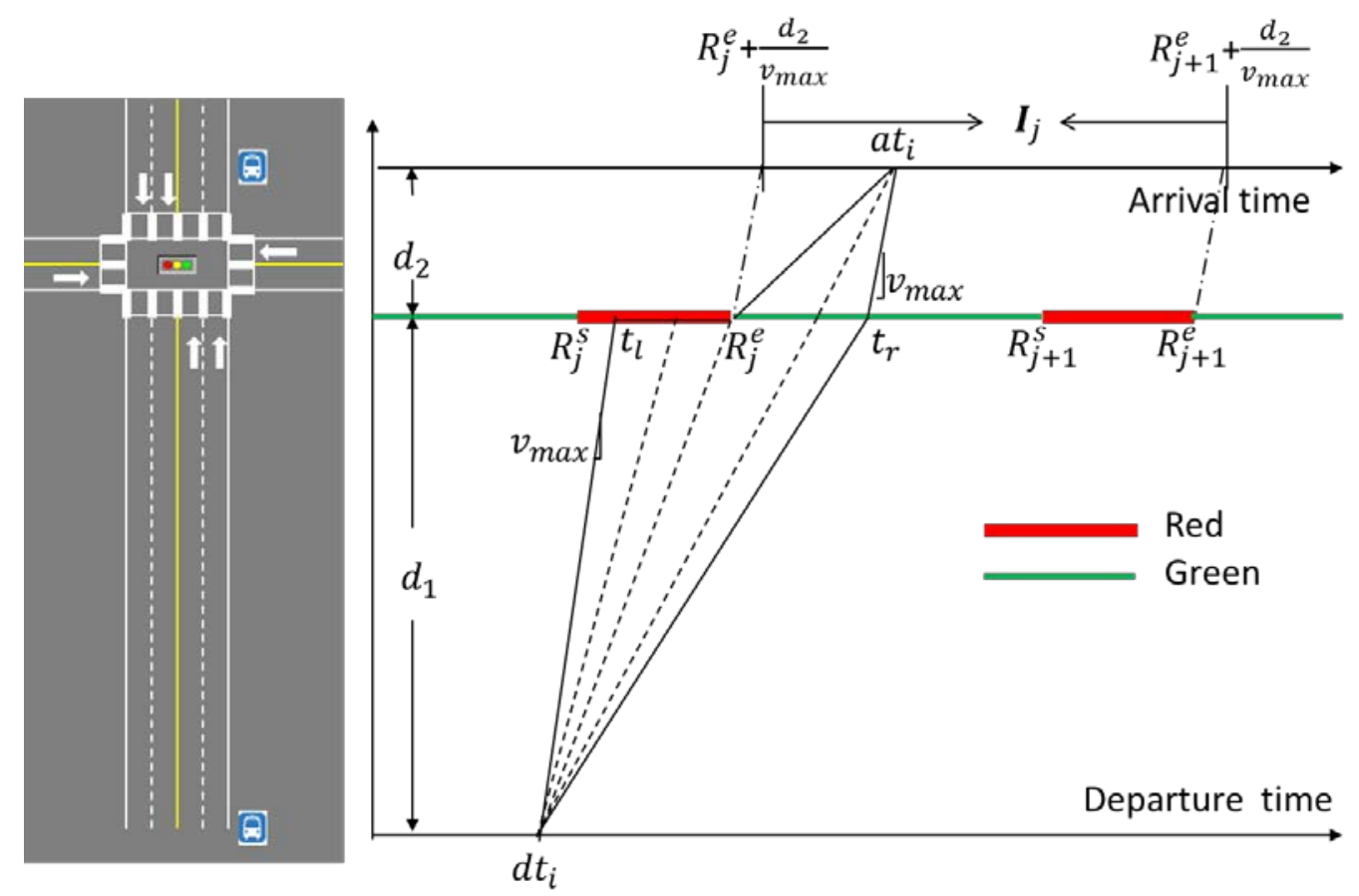

(b)
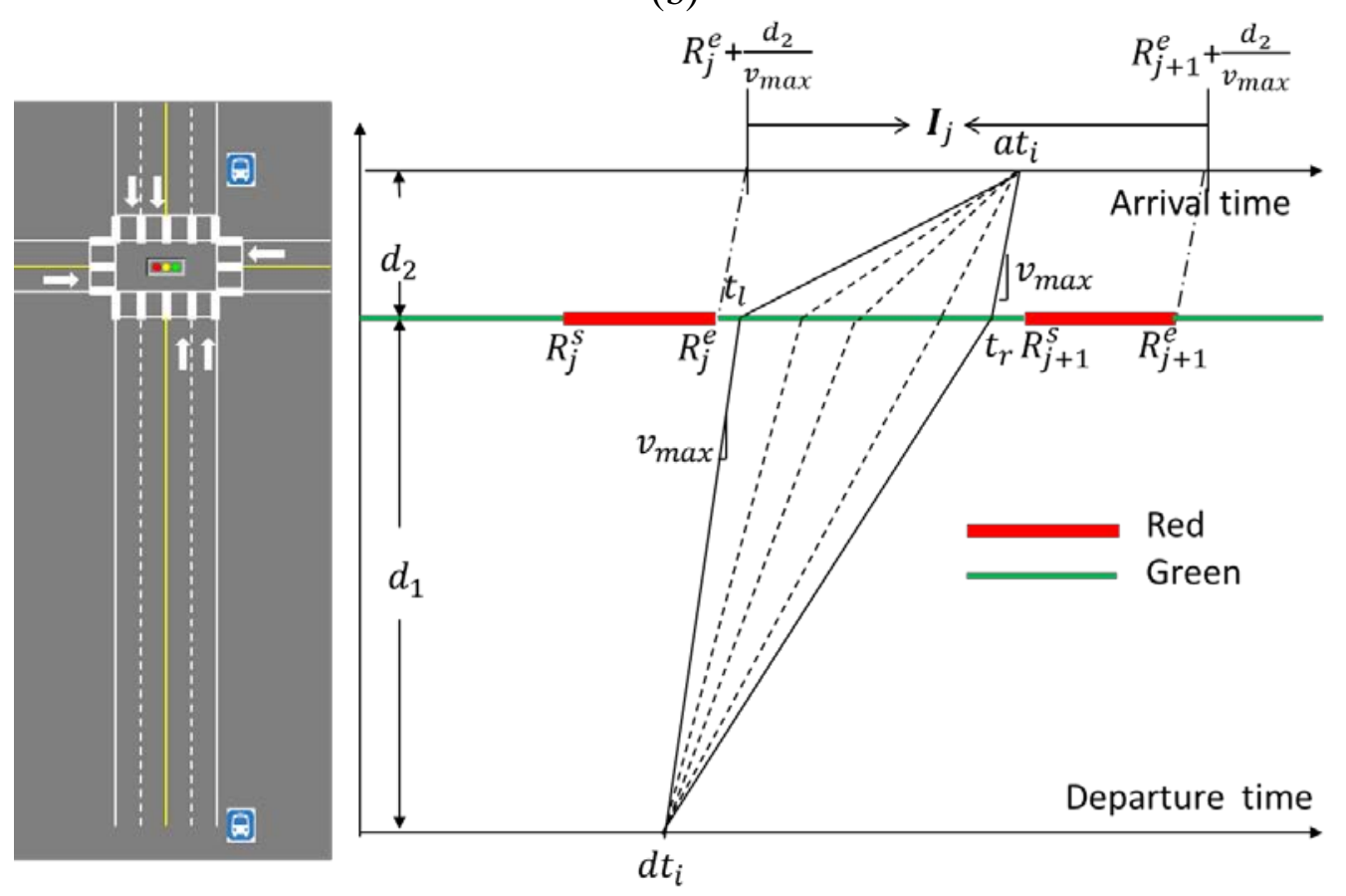

(c) 


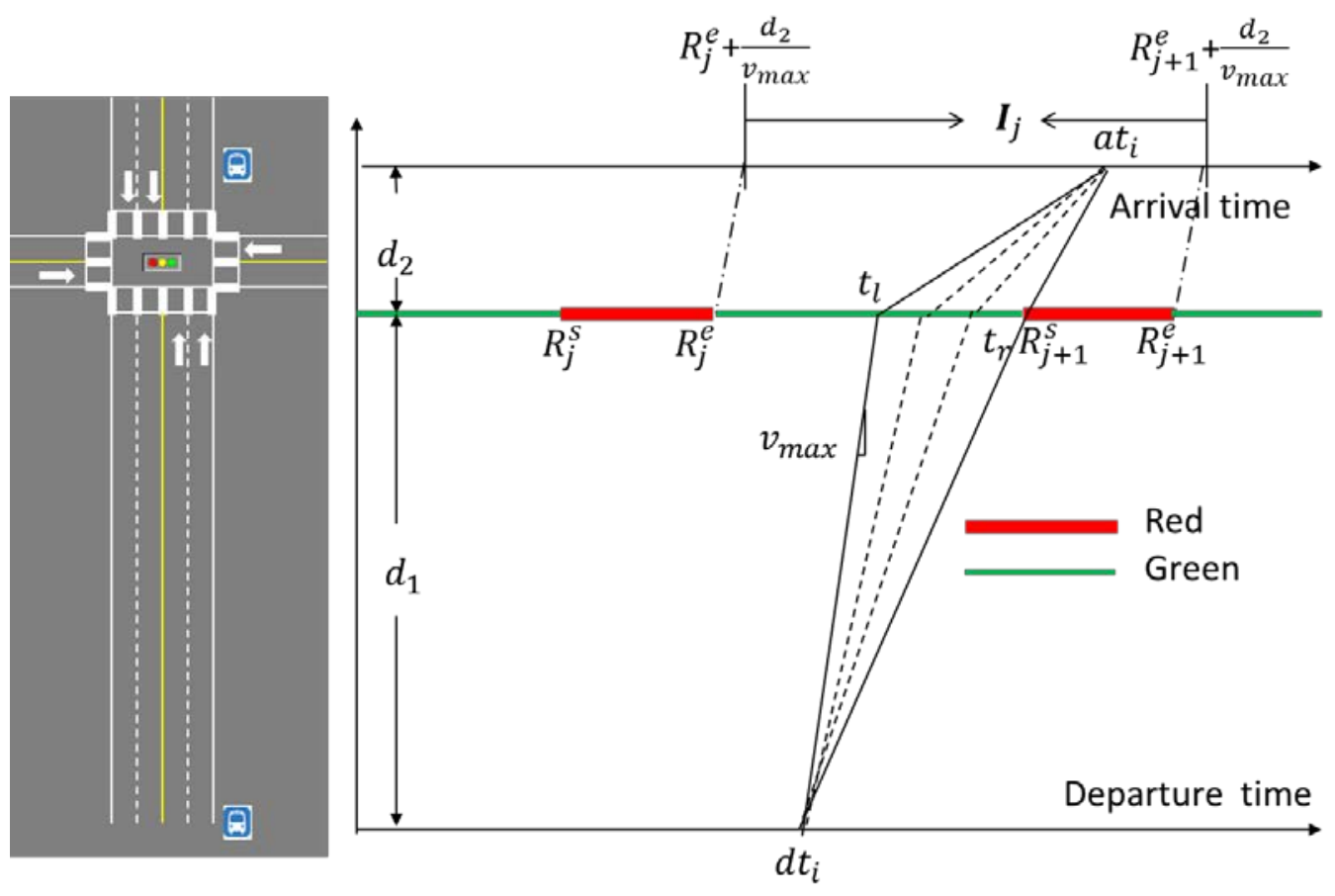

(d)

Figure 3-6 Feasible bus stop-to-stop trip trajectories

Figure 3-9 (a) - (d) show some bus stop-to-stop trajectories in time-space diagrams. For a given cycle $j$, denote $\boldsymbol{I}_{j}$ as the set of bus trips that arrived at the arrival stop during the time interval $\left(R_{j}^{e}+\frac{d_{2}}{v_{\max }}, R_{j+1}^{e}+\frac{d_{2}}{v_{\max }}\right)$, then:

$$
\begin{gathered}
\boldsymbol{I}_{j}=\left\{i \mid i \in \boldsymbol{I}, R_{j}^{e}+\frac{d_{2}}{v_{\max }}<a t_{i} \leq R_{j+1}^{e}+\frac{d_{2}}{v_{\max }}\right\} \\
\boldsymbol{I}_{j} \cap \boldsymbol{I}_{k} \equiv \emptyset, \text { for } \forall j \neq k ; j, k \in \boldsymbol{J}
\end{gathered}
$$

If $\boldsymbol{I}_{j} \neq \emptyset$, based on the red phase start time $\left(R_{j}^{S}\right)$ and end time $\left(R_{j}^{e}\right)$, as well as the departure time $\left(d t_{i}\right)$ and arrival time $\left(a t_{i}\right)$ of the bus trip $i$, four different bus trajectory boundaries may exist as shown in Figure 3-9 (a) - (d). A bus trajectory boundary is defined by $d t_{i}, t_{l}, a t_{i}$ and $t_{r} . t_{l}$ and $t_{r}$ are the earliest and latest possible times that bus trip $i$ could be at the intersection given $d t_{i}$ and $a t_{i}$. They are defined by the following equations:

$$
\begin{gathered}
t_{l}=\max \left\{a t_{i}-\frac{d_{2}}{v_{\min }}, d t_{i}+\frac{d_{1}}{v_{\max }}\right\} \\
t_{r}=\min \left\{a t_{i}-\frac{d_{2}}{v_{\max }}, d t_{i}+\frac{d_{1}}{v_{\min }}, R_{j+1}^{S}\right\}
\end{gathered}
$$

Figure 3-9 (a) - (d) only show some examples when the feasible bus trajectory boundaries are determined by maximum speeds, the minimum speeds are usually not a constraint. There are only a few scenarios when the feasible boundary is determined by both maximum and minimum speeds. Also, Figure 3-9 (a) - (d) only show some examples when the feasible boundary is 
within one cycle, it is also possible that a feasible boundary spans two or more cycles (if a cycle failure occurs). Therefore, we define $\boldsymbol{J}_{i}^{\prime}$ as the set of cycles that maybe within the feasible boundary of bus $i$.

$$
\boldsymbol{J}_{i}^{\prime} \leftarrow\left\{k \mid k \leq j, \quad d t_{i} \leq G_{j}^{e}-\frac{d_{1}}{v_{\max }}\right\}
$$

Once $\boldsymbol{I}_{j}$ and $\boldsymbol{J}_{i}^{\prime}$ are defined, the bus signal phase attributes can be calculated. For each bus $i \in \boldsymbol{I}_{j}$ and each cycle $j \in \boldsymbol{J}_{i}^{\prime}$, the ways of calculating signal phase attributes are explained as below.

Prob_ $R_{i}$ can be estimated by the sum of speed probabilities that could lead bus $i$ arrive at the intersection during the red phases, conditional on the sum of all feasible speed probabilities. Therefore,

$$
\operatorname{Prob}_{-} R_{i}=\sum_{j \in J_{i}^{\prime}} \frac{P\left[\frac{d_{1}}{R_{j}^{e}-d t_{i}} \leq v<\frac{d_{1}}{\max \left\{R_{j}^{S}, t_{l}\right\}-d t_{i}}\right]}{P\left[\frac{d_{1}}{t_{r}-d t_{i}} \leq v<\frac{d_{1}}{t_{l}-d t_{i}}\right]}
$$

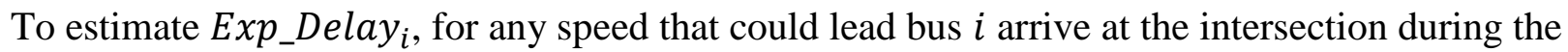
red phase, $v \in\left(\frac{d_{1}}{\max \left\{R_{j}^{S}, t_{l}\right\}-d t_{i}}, \frac{d_{1}}{R_{j}^{e}-d t_{i}}\right)$, the red signal delay is: $R_{j}^{e}-\left(d t_{i}+\frac{d_{1}}{v}\right)$. Given the speed probability density function, $f(v)$, the total expected delay can be estimated by:

$$
\text { Exp_Delay }_{i}=\sum_{j \in J_{i}^{\prime}} \frac{\int_{\frac{d_{1}}{R_{j}^{e}-d t_{i}}}^{\frac{d_{1}}{\max \left\{R_{j}^{S}, t_{l}\right\}-d t_{i}}} f(v) \cdot\left(R_{j}^{e}-d t_{i}-\frac{d_{1}}{v}\right) \mathrm{d} v}{P\left[\frac{d_{1}}{t_{r}-d t_{i}} \leq v<\frac{d_{1}}{t_{l}-d t_{i}}\right]}
$$

Prob_G $G_{i}$ can be estimated similarly as $P r o b \_R_{i}$ :

$$
\operatorname{Prob}_{-} G_{i}=\sum_{j \in J_{i}^{\prime}} \frac{P\left[\frac{d_{1}}{\min \left\{G_{j}^{e}, t_{r}\right\}-d t_{i}} \leq v<\frac{d_{1}}{G_{j}^{S}-d t_{i}}\right]}{P\left[\frac{d_{1}}{t_{r}-d t_{i}} \leq v<\frac{d_{1}}{t_{l}-d t_{i}}\right]}
$$

Therefore, $P r o b \_R_{i}+P r o b \_G_{i} \equiv 1$, if there is no TSP phase.

If there is a TSP phase in a cycle $j$, the probability of bus $i$ arriving at the intersection during the TSP phase and the expected time savings of the bus and the onboard passengers can also be estimated.

1. If there is an EG phase in cycle $j$; 

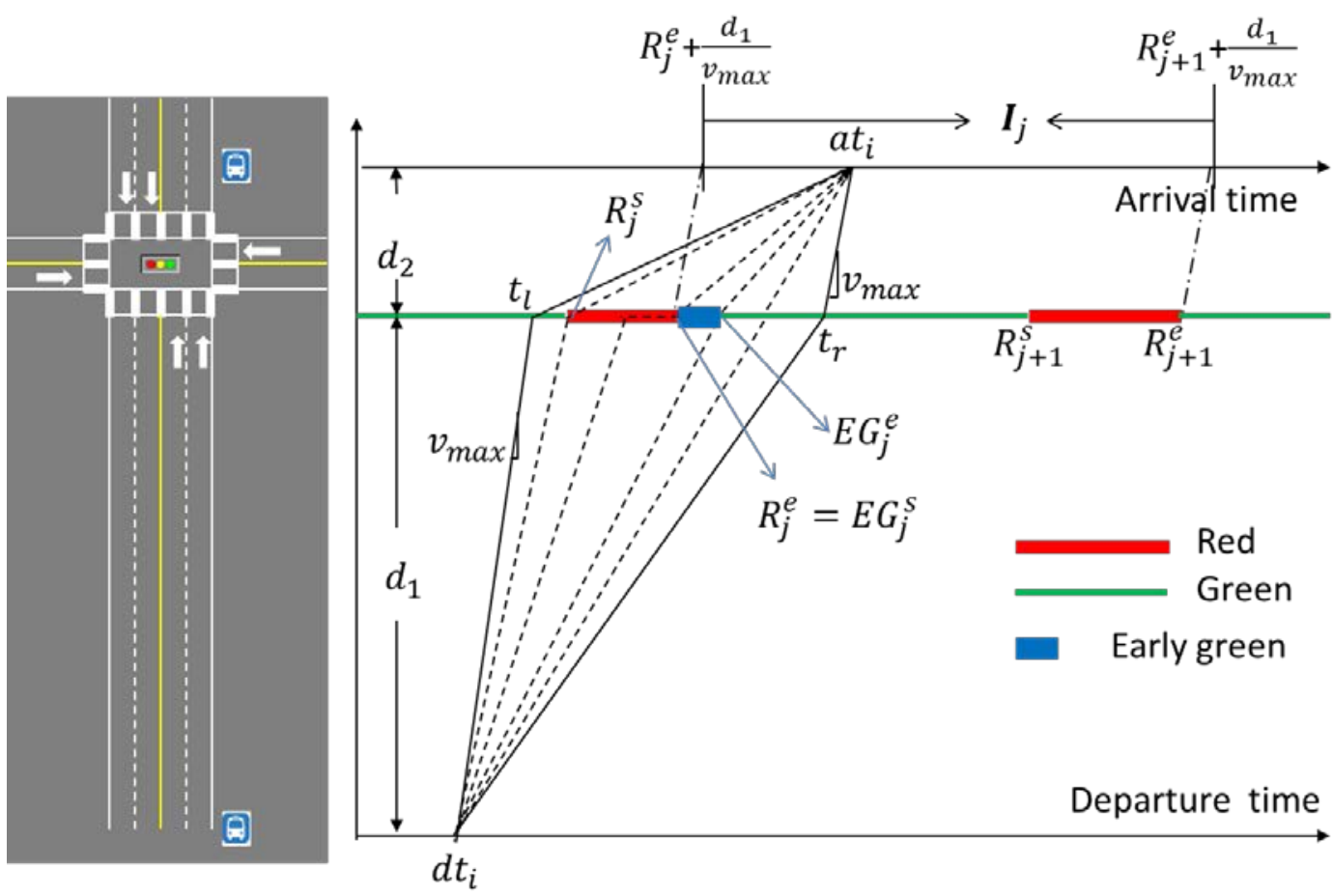

Figure 3-7 Feasible bus stop-to-stop trip trajectories with an early green phase

Figure 3-10 shows an example of the probabilistic bus trajectory during a cycle with an EG phase. Depending on the relationships between $t_{l}, E G_{j}^{s}, t_{r}$ and $E G_{j}^{e}$, the range of speeds that could lead bus $i$ arrive at the intersection during the early green phase is $\left(\max \left\{E G_{j}^{s}, t_{l}\right\}, \min \left\{E G_{j}^{e}, t_{r}\right\}\right)$; therefore, $\operatorname{Prob}_{-} E G_{i}$ can be estimated by:

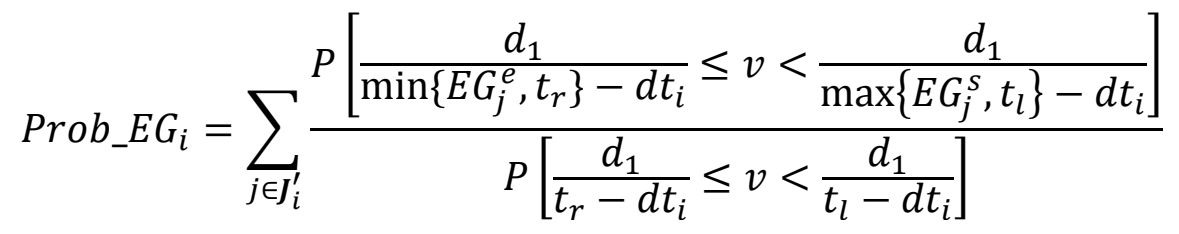

Figure 3-10 shows one scenario where $t_{l}<E G_{j}^{s}$ and $E G_{j}^{e}<t_{r}$, but the above equation works for the other three scenarios: 1) $t_{l}<E G_{j}^{S}$ and $E G_{j}^{e} \geq t_{r}$;2) $t_{l} \geq E G_{j}^{S}$ and $E G_{j}^{e} \geq t_{r}$;3) $t_{l} \geq E G_{j}^{S}$ and $E G_{j}^{e}<t_{r}$.

If $E G_{j}^{S}<t_{l}$, bus $i$ is impossible to arrive at the intersection during the preceding red phase of this early green phase, the time saving for bus $i$ traveling at speed $v \in\left(\frac{d_{1}}{t_{l}-d t_{i}}, \frac{d_{1}}{\min \left\{E G_{j}^{e}, t_{r}\right\}-d t_{i}}\right)$ is $\min \left\{E G_{j}^{e}, t_{r}\right\}-\left(d t_{i}+\frac{d_{1}}{v}\right)$. If $E G_{j}^{s} \geq t_{l}$, bus $i$ is also likely to arrive at the intersection during the preceding red phase of this early green phase. Therefore, time saving for bus $i$ traveling at speed $v \in\left(\frac{d_{1}}{E G_{j}^{s}-d t_{i}}, \frac{d_{1}}{t_{l}-d t_{i}}\right)$ is $E G_{j}^{e}-E G_{j}^{s}$. Therefore, $B T S_{-} E G_{i}$ and $P T S_{-} E G_{i}$ can be estimated by: 


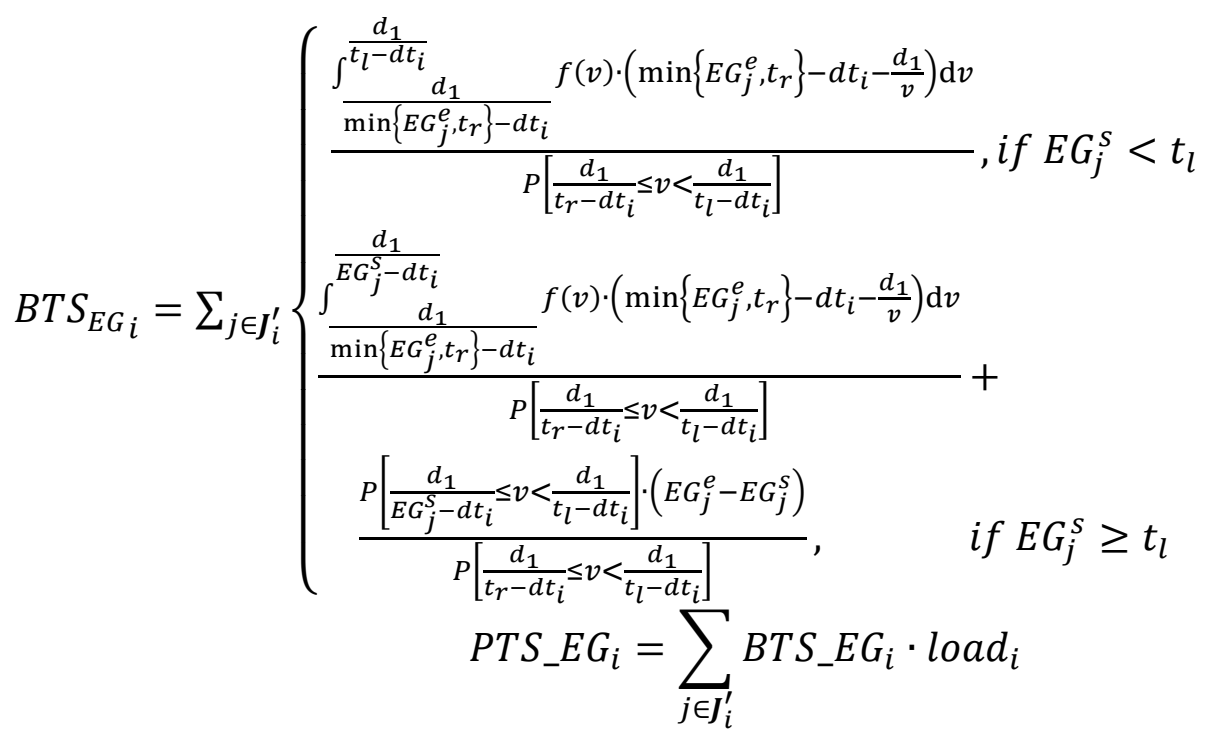

2. If there is a GE phase in cycle $j$.

Figure 3-11 shows an example of the probabilistic bus trajectory during a cycle with a GE phase. Because bus $i$ could benefit from a green extension phase only when it arrives at the intersection during the green extension phase, depending on the relationships between $t_{l}, G E_{j}^{s}, t_{r}$ and $G E_{j}^{e}$, bus $i$ will benefit from GE phase if it travels with speed $v \in\left(\frac{d_{1}}{\min \left\{G E_{j}^{e}, t_{r}\right\}-d t_{i}}, \frac{d_{1}}{\max \left\{G E_{j}^{s}, t_{l}\right\}-d t_{i}}\right)$, therefore:

$$
P r o b_{-} G E_{i}=\sum_{j \in J_{i}^{\prime}} \begin{cases}P\left[\frac{d_{1}}{\min \left\{G E_{j}^{e}, t_{r}\right\}-d t_{i}} \leq v<\frac{d_{1}}{\max \left\{G E_{j}^{S}, t_{l}\right\}-d t_{i}}\right] \\ P\left[\frac{d_{1}}{t_{r}-d t_{i}} \leq v<\frac{d_{1}}{t_{l}-d t_{i}}\right] & \text { if } t_{r} \geq G E_{j}^{S} \\ 0 & \text { if } t_{r}<G E_{j}^{S}\end{cases}
$$




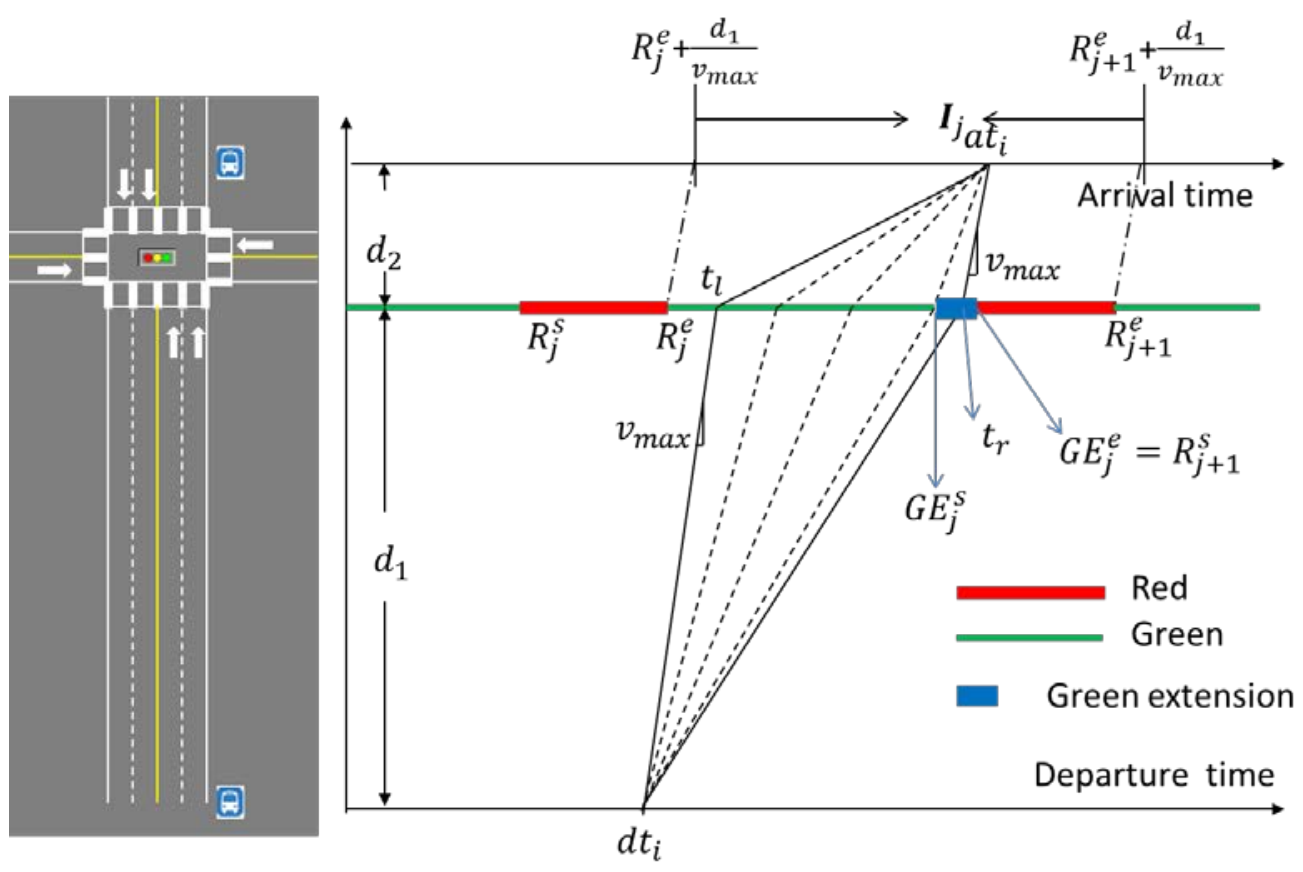

Figure 3-8 Feasible bus stop-to-stop trip trajectories with a green extension phase

Similarly, Figure 3-11 shows one scenario where $t_{l}<G E_{j}^{S}$ and $G E_{j}^{e}>t_{r}$, but the above equation works for the other three scenarios: 1) $t_{l}<G E_{j}^{S}$ and $G E_{j}^{e} \leq t_{r}$;2) $t_{l} \geq G E_{j}^{s}$ and $G E_{j}^{e} \leq t_{r}$; 3) $t_{l} \geq G E_{j}^{S}$ and $G E_{j}^{e}>t_{r}$.

If bus $i$ travels with speed $v \in\left(\frac{d_{1}}{\min \left\{G E_{j}^{e}, t_{r}\right\}-d t_{i}}, \frac{d_{1}}{\max \left\{G E_{j}^{s}, t_{l}\right\}-d t_{i}}\right)$, the time saving is $R_{j+1}^{e}-\left(d t_{i}+\right.$ $\left.\frac{d_{1}}{v}\right)$; therefore, $B T S_{-} G E_{i}$ and $P T S_{-} G E_{i}$ can be estimated by:

$$
\begin{aligned}
& B T S_{-} G E_{i}=\sum_{j \in J_{i}^{\prime}} \begin{cases}\frac{\int_{\frac{d_{1}}{\max \left\{G E_{j}^{s}, t_{l}\right\}-d t_{i}}}^{\frac{d_{1}}{\min \left\{G E_{j}^{e}, t_{r}\right\}-d t_{i}}}}{P\left[\frac{d_{1}}{t_{r}-d t_{i}} \leq v<\frac{d_{1}}{t_{l}-d t_{i}}\right]} & \text {, if } t_{r} \geq G E_{j}^{S} \\
0 & \text {,if } t_{r}<G E_{j}^{S}\end{cases} \\
& P T S_{-} G E_{i}=\sum_{j \in J_{i}^{\prime}} B T S_{-} G E_{i} \cdot \operatorname{load}_{i}
\end{aligned}
$$




\subsection{TRANSIT SIGNAL PRIORITY PERFORMANCE EVALUATION}

To understand how well the transit signal priority (TSP) system helps buses reduce delay through signalized intersections, this chapter evaluates the relationships between TSP requests and TSP phases, the effectiveness of TSP phases (percent of effective TSP phases), and the expected benefits (time savings) and delay due to TSP phases. This chapter also investigates how these results vary by TSP phase type (green extension or early green); by bus-stop location type (nearside or far-side bus stop); and by user type (bus, passengers, automobiles on the major street and the side street). TSP performance evaluation is based on the integration of two archived data sources: TriMet bus AVL/APC data and SCATS signal phase log data. Results from the evaluation analyses are useful for cities and transit agencies to identify potential problems, challenges and improvement opportunities.

\subsection{TRANSIT SIGNAL PRIORITY IN PORTLAND}

The current TSP system in Portland is an active conditional TSP system. It consists of two systems: the TSP request system and the TSP phase grant system. If a bus meets certain conditions, an emitter on the bus will be activated. This emitter will send a TSP request to a downstream signalized intersection. Once the downstream traffic signal receives the TSP request, the signal controller in the traffic signal will decide whether to grant a TSP phase and which TSP phase is to be granted. The decision frameworks of the two systems are shown in Figure 4-1 (a) and (b). Figure 4-2 shows the priority request detection zone length for each intersection from each direction.

Figure 4-3 shows the average number of bus trips per day that requested TSP and that did not request TSP from both directions at intersections between $26^{\text {th }}$ and $72^{\text {nd }}$ avenues along Powell Boulevard. It shows that almost half of the bus trips requested TSP at each intersection. Figure 4-4 shows the average numbers of green extension phases and early green phases per day and the percentages of cycles that have a TSP phase. It shows that few TSP phases were granted at the intersections of $26^{\text {th }}$ and $33^{\text {rd }}$ avenues on Powell, which indicates a potential TSP setting problem at these two intersections. The average duration of green extension phases is seven seconds, and the average duration of early green phases is 11 seconds. Figure 4-3 and Figure 4-4 show that the average number of TSP requests is much higher than the number of TSP phases at each intersection. Therefore, not all of the TSP requests resulted in the granting of a TSP phase. 


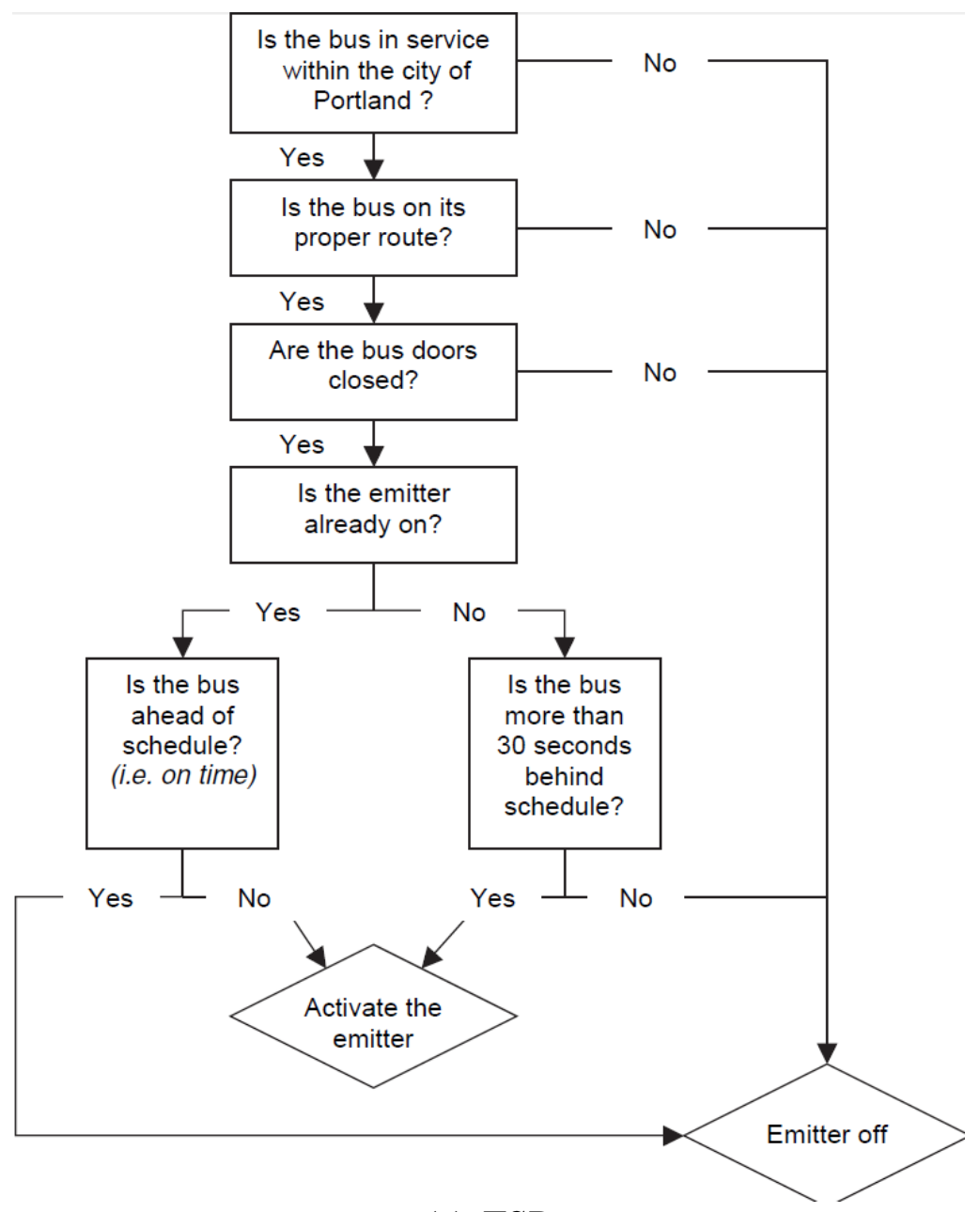

(a) TSP request

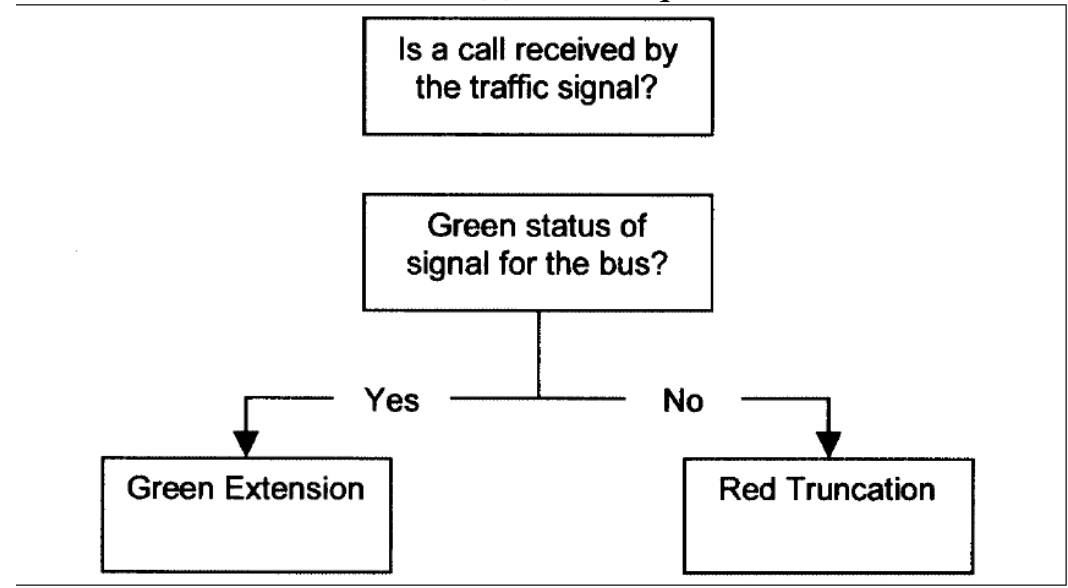

(b) TSP phase grant

Figure 4-1 TSP system decision framework (Byrne et al., 2005) 


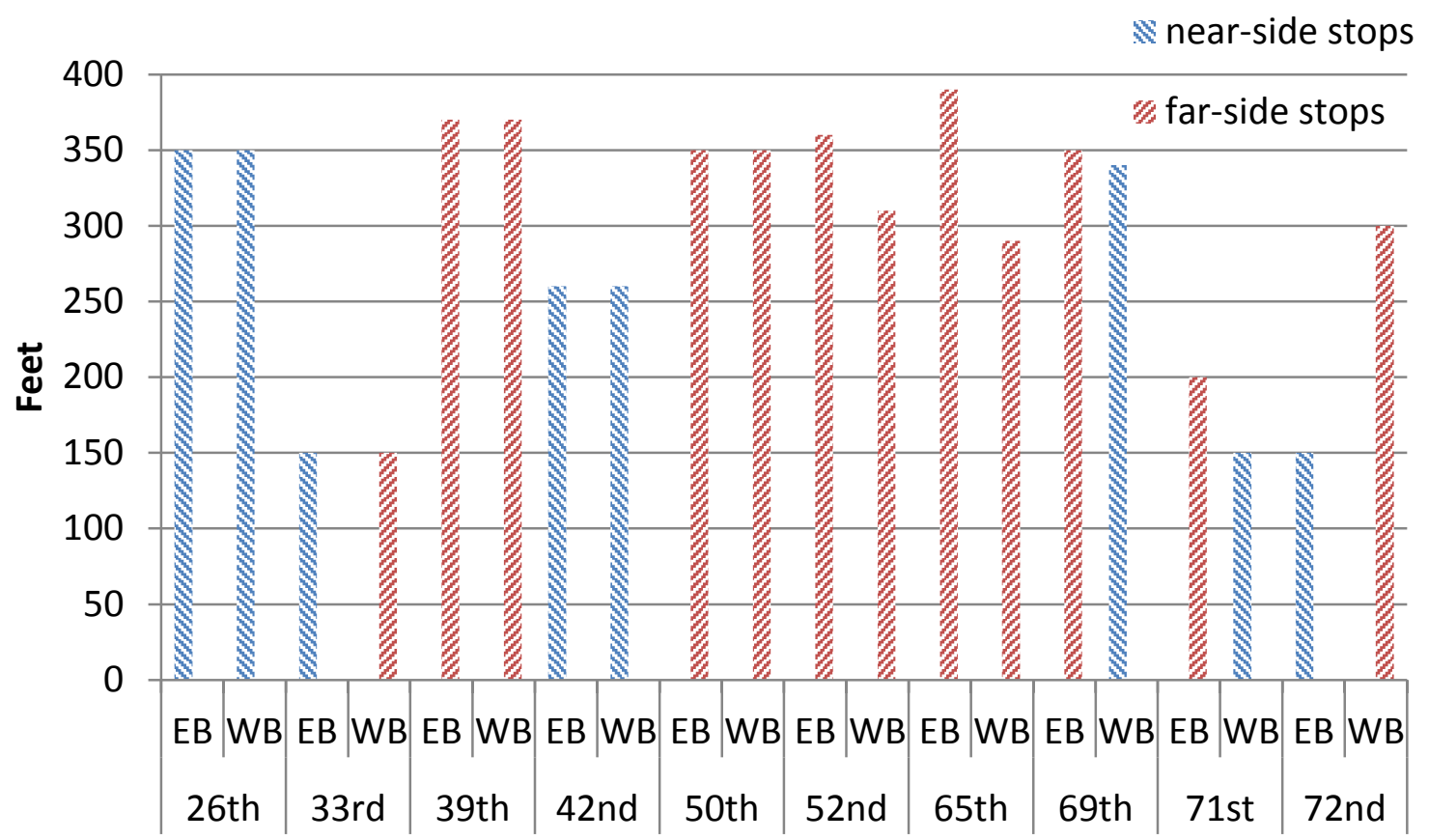

Figure 4-2 TSP detection distance

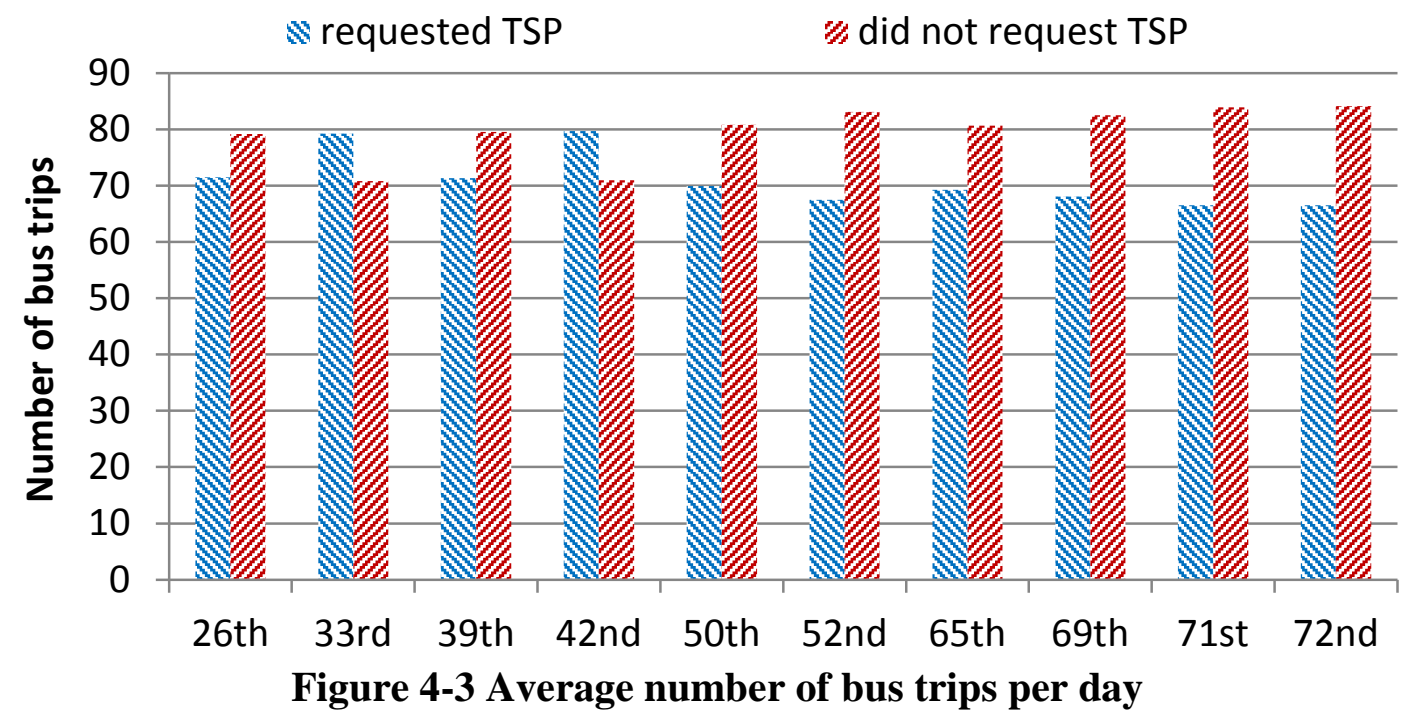




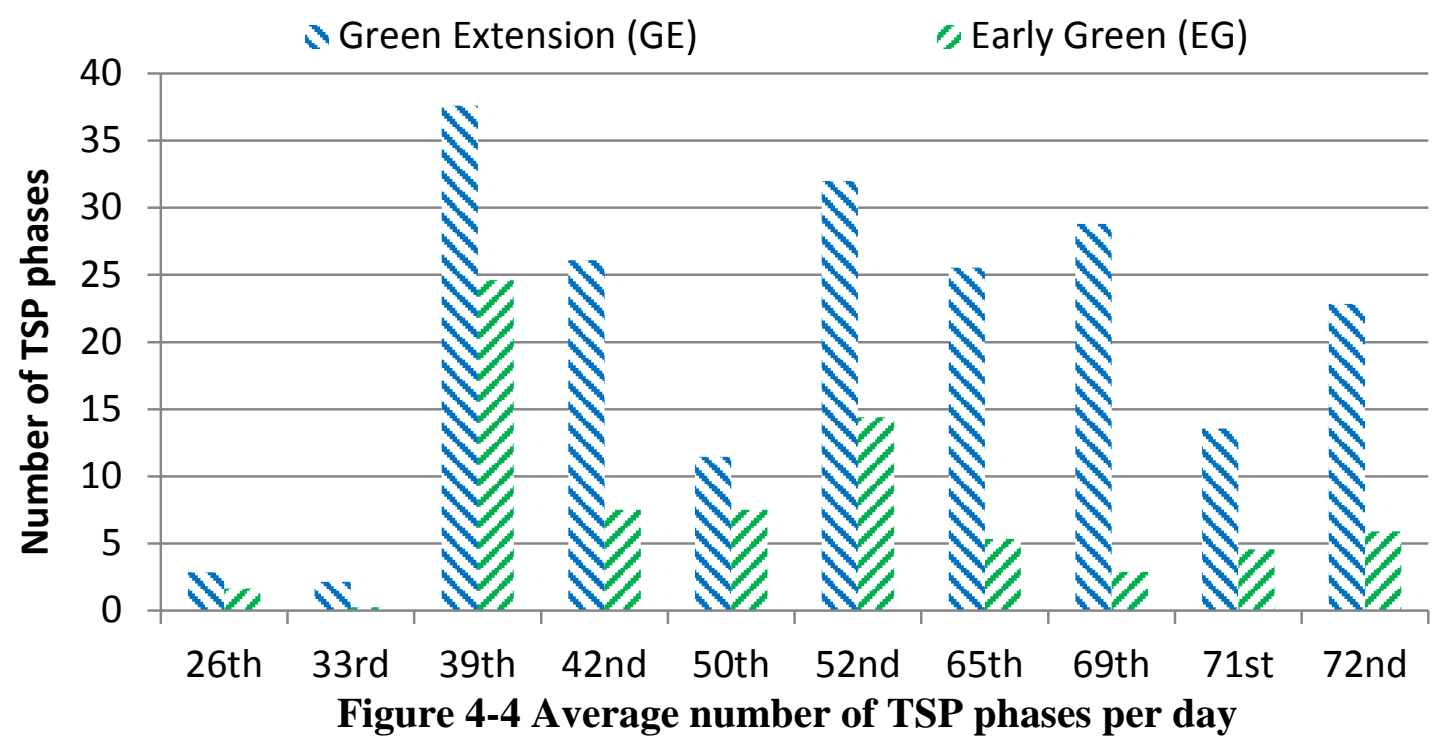

\subsection{RELATIONSHIPS BETWEEN TSP PHASES AND TSP REQUESTS}

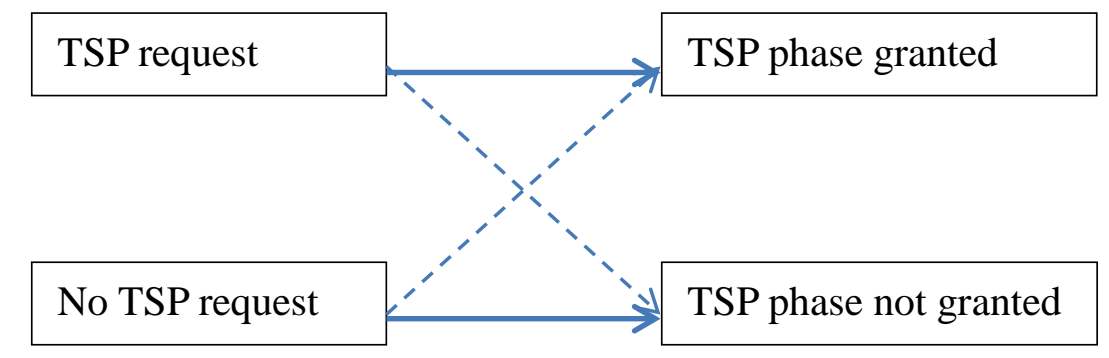

Figure 4-5 Relationships between TSP requests and TSP phases

Figure 4-5 shows the potential relationships between TSP requests and TSP phases. A TSP request may or may not result in the granting of a TSP phase. Also, a TSP phase may or may not result from a TSP request. Therefore, this section tries to answer the following two questions:

1) How many TSP requests resulted in the granting of a TSP phase?

2) How many TSP phases were a result of a TSP request?

\subsubsection{Assumptions and Definitions}

To answer these two questions, some assumptions and definitions need to be clarified. First, because there are no records of bus emitter activation or deactivation, once a bus meets the TSP request conditions shown in Figure 4-1 (a) it is assumed that the bus sends a TSP request to the downstream traffic signal. Second, it is important to define whether a TSP request triggered a TSP phase and whether a TSP phase was a result of a TSP request. For example, it is unreasonable to define that a bus TSP request resulted in a TSP phase granted if the TSP phase was granted 10 minutes after the TSP request. In this study, we define that a TSP request resulted in a TSP phase or a TSP phase was a result of a TSP request if the arrival time of the bus that requested TSP at an intersection and the start and end times of the TSP phase are close enough in time. In this study, we define that if the arrival time of a bus at the intersection and the TSP 
phase start time and end times are within the same cycle, then the bus that requests TSP is defined to have resulted in the granting of the TSP phase, and the TSP phase is defined to be a result of the TSP request from this bus.

\section{Green extension (GE)}

In order to define a cycle that includes the closest TSP requests to a GE phase, the cycle for GE analysis is defined as the time interval between the beginning times of two consecutive green phases. In other words, if the arrival time of a bus that requests TSP at an intersection is in a GE phase, in the preceding green phase of the GE phase, or the following red phase of the GE phase, this TSP request is defined to have resulted in the granting of the GE phase, or the GE phase is defined to be a result of the TSP request from this bus. Note that this cycle is for TSP performance analysis; it is different from the cycle definition in Chapter 3, which is used for data integration. Figure 4-6 shows the relationships between TSP requests and GE phases in six cycles. Because the bus arrival time at an intersection is probabilistic, a TSP request is defined as resulting in a GE phase, or a GE phase is defined as resulting from a TSP request, if the bus that requests TSP has a positive probability of arriving at an intersection during the GE phase, or the preceding green or the following red phase (e.g., cycle (2) in Figure 4-6). Cycles (1) and (5) show examples of TSP requests that do not result in the granting of a GE phase. Cycle (3) shows an example of no TSP request (either no bus or a bus does not request TSP) and no granting of a GE phase. Cycles (4) and (6) show examples of granted GE phases without any TSP request in a cycle.
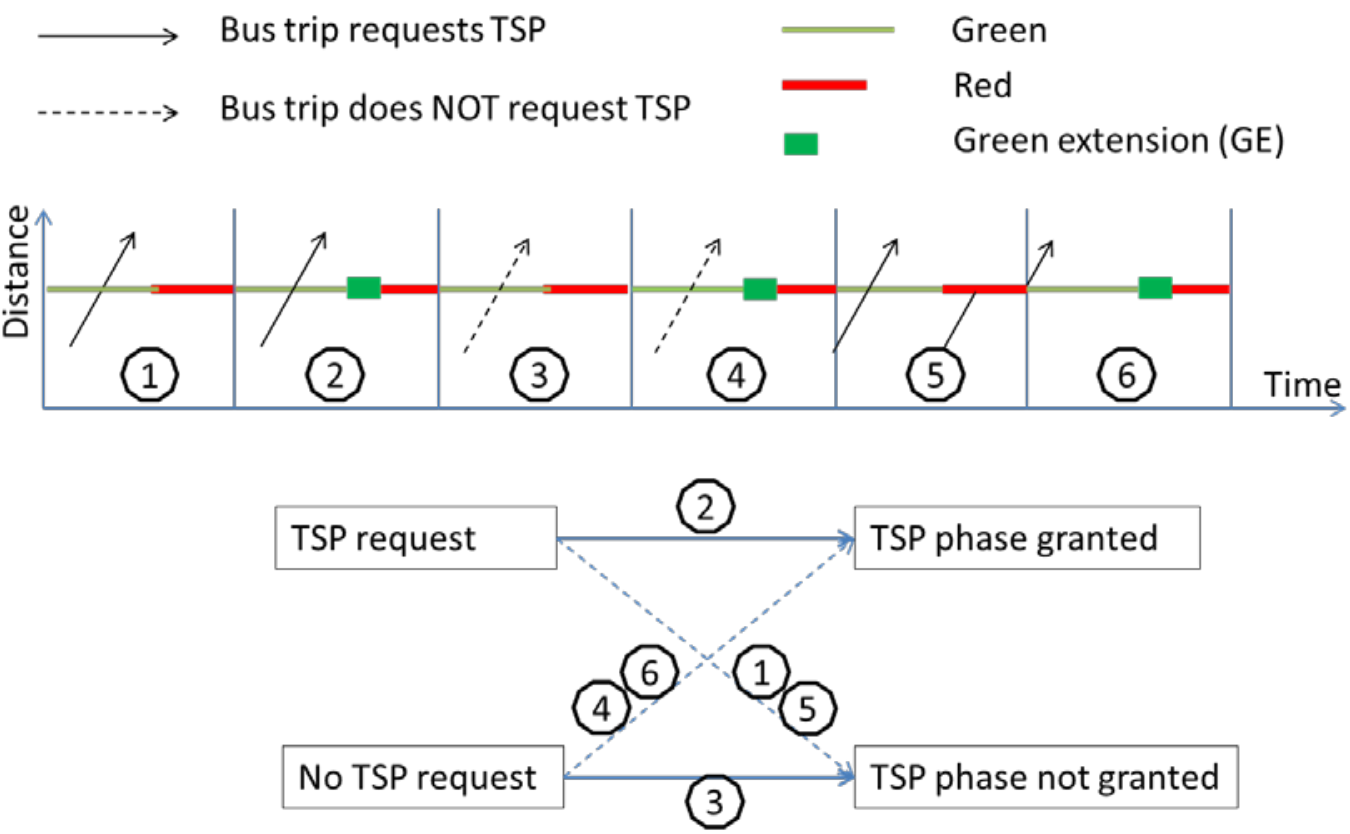

Figure 4-6 Relationships between TSP requests and green extension phases 


\section{Early green (EG)}

Similarly, in order to define a cycle that includes the closest TSP requests to an EG phase, the cycle for EG analysis is defined as the time interval between the middle of two consecutive green phases. In other words, if the arrival time of a bus that requests TSP at an intersection is in an EG phase, in the preceding red phase of the EG phase, in the second half of the preceding green phase of the EG phase, or in the first half of the following green phase of the EG phase, this TSP request is defined to have resulted in the granting of the EG phase, or the EG phase is defined to be a result of the TSP request from this bus. Figure 4-7 shows the relationships between TSP requests and EG phases in six cycles. A TSP request is defined as resulting in an EG phase, or an EG phase is defined as resulting from a TSP request, if a bus that requests TSP has a positive probability of arriving at an intersection during the EG phase, the preceding red phase, the second half of the preceding green phase, or the first half of the following green phase (e.g., cycle (2) in Figure 4-7).
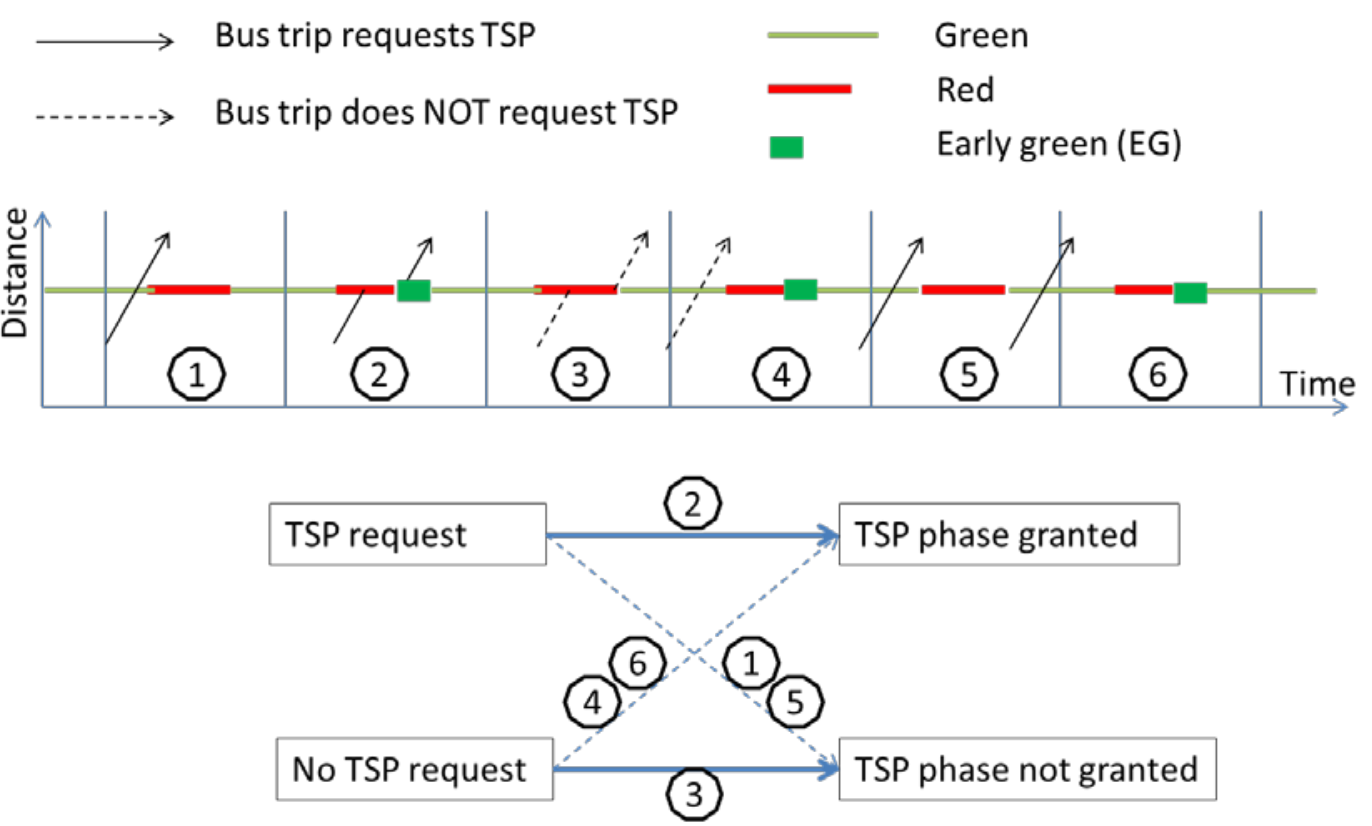

Figure 4-7 Relationships between TSP requests and early green phases

\subsubsection{Results}

1. How many TSP requests resulted in TSP phases granted?

A TSP request could result in four potential outcomes: A GE phase was granted; an EG phase was granted; both GE and EG phases were granted; or no TSP phase was granted within a cycle. Results are shown in Figure 4-8. Because bus arrival time at an intersection is probabilistic, the four potential outcomes are described as below:

1) "GE only" means a bus that requested TSP had a positive probability of arriving at an intersection during a cycle with a GE phase, but had zero probability of arriving at the intersection during a cycle with an EG phase. 
2) “EG only" means a bus that requested TSP had a positive probability of arriving at an intersection during a cycle with an EG phase, but had zero probability of arriving at the intersection during a cycle with a GE phase.

3) "Both GE and EG" means a bus that requested TSP had a positive probability of arriving at an intersection during a cycle with a GE phase, and had a positive probability of arriving at the intersection during a cycle with an EG phase.

4) "Neither GE nor EG" means a bus that requested TSP had zero probability of arriving at an intersection during a cycle with a GE phase or during a cycle with an EG phase.

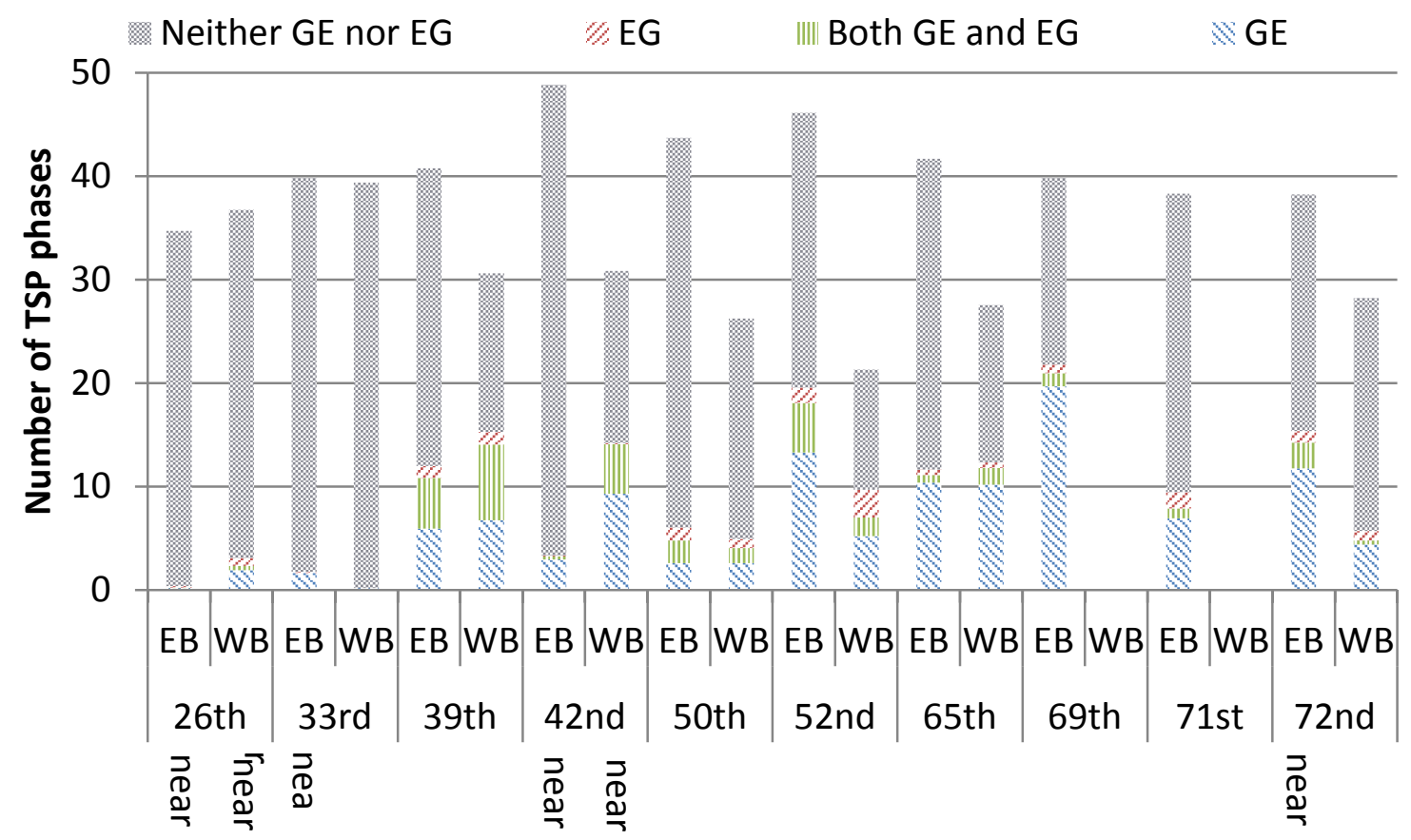

Figure 4-8 Average number of TSP requests per day

Figure 4-8 shows the breakdown of the average number of TSP requests per day at each intersection in each direction. Note that there are no results for the intersections at $69^{\text {th }}$ and $71^{\text {st }}$ avenues on Powell Boulevard in the WB direction because there are two signalized intersections in this stop-to-stop segment and bus arrival time at intersections are not available. Results vary significantly across intersections and by direction. For example, very few TSP requests resulted in the granting of a TSP phase at $42^{\text {nd }}$ Avenue in the EB direction, or at $26^{\text {th }}, 33^{\text {rd }}$ or $50^{\text {th }}$ avenues in either direction. This indicates potential problems at these intersections. Results show that more than half of the TSP requests did not result in the granting of any TSP phases in most of the intersections in both directions. This may be because a bus emitter was not activated when conditions were met, a TSP request was not received by the traffic signal, or the signal controller did not decide to grant a TSP phase. Another interesting finding is that TSP requests resulted in more GE phases than EG phases. This may be because there is more green time in the EB and WB directions and buses have a higher probability of arriving at the intersection during a green phase. Also, there is no clear difference in the results between near-side segments and far-side segments in the plots. 
2. How many granted TSP phases were a result of a TSP request?

A granted TSP phase could be a result of one or more TSP requests from EB only, from WB only or from both directions. It could also occur with no TSP requests from either direction in the same cycle. The granted TSP phases are broken down into the following four categories:

1) “EB only" means at least one EB bus that requested TSP had a positive probability of arriving at the intersection during the cycle with this TSP phase, and no WB bus had a positive probability of arriving at the intersection during the same cycle.

2) "WB only" means at least one WB bus that requested TSP had a positive probability of arriving at the intersection during the cycle with this TSP phase, and no EB bus had a positive probability of arriving at the intersection during the same cycle.

3) "Both EB and WB" means at least one EB bus and one WB bus that requested TSP had a positive probability of arriving at the intersection during the cycle with this TSP phase.

4) “Neither EB nor WB" means no EB or WB bus that requested TSP had a positive probability of arriving at the intersection during the cycle with this TSP phase.

Figure 4-9 shows the breakdown of the average number of granted GE and EG phases for each intersection. There are more GE phases than EG phases; $90 \%$ of the GE and EG phases resulted from TSP requests within a cycle. However, about $30 \%$ of GE and EG phases at $39^{\text {th }}$ Avenue and $30 \%$ of GE phases at $42^{\text {nd }}$ Avenue did not result from a TSP request in the same cycle. This may indicate problems with TSP request detection or deactivation at these intersections. For example, a TSP call in the signal controller was not canceled after a bus passed the intersection.

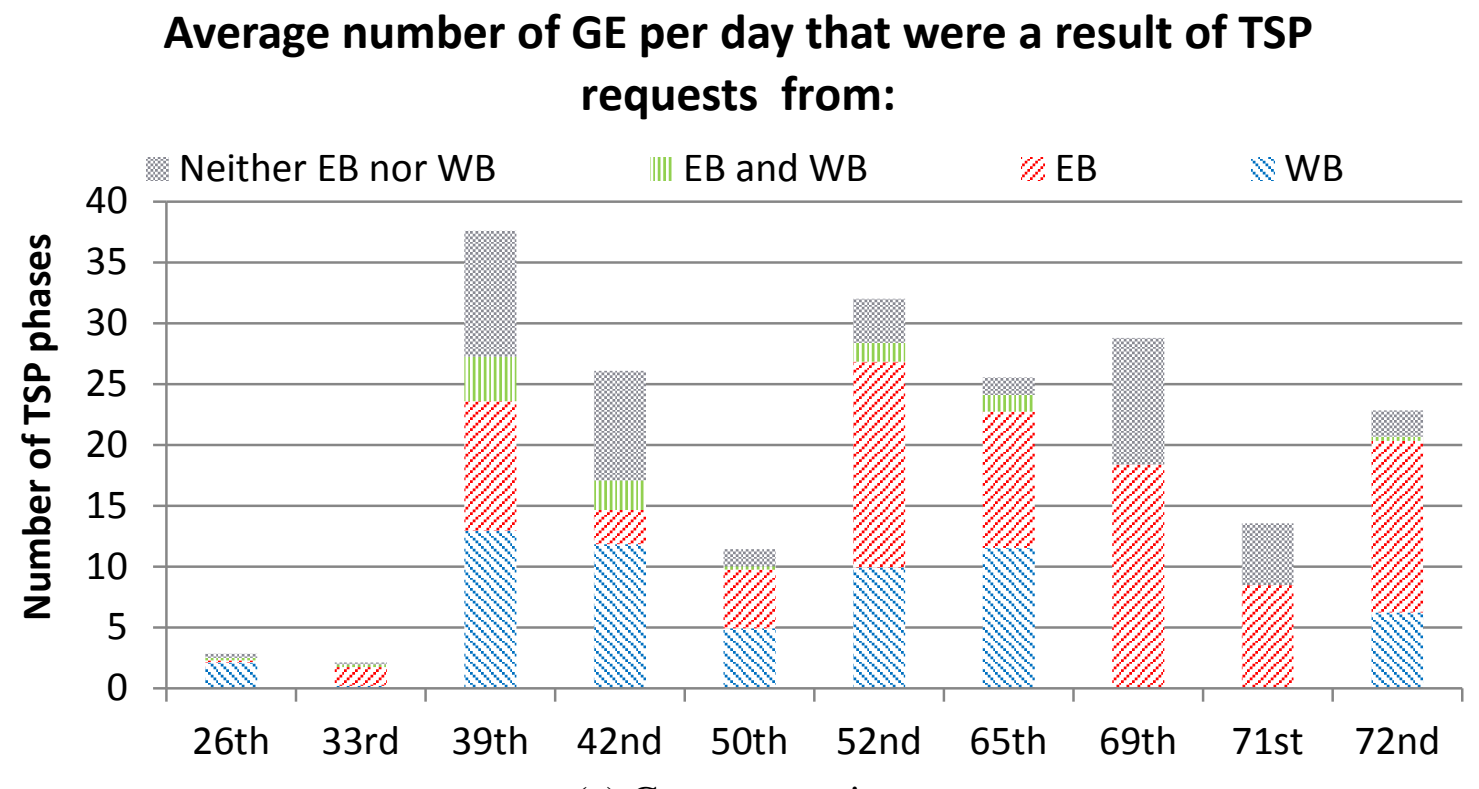

(a) Green extension 


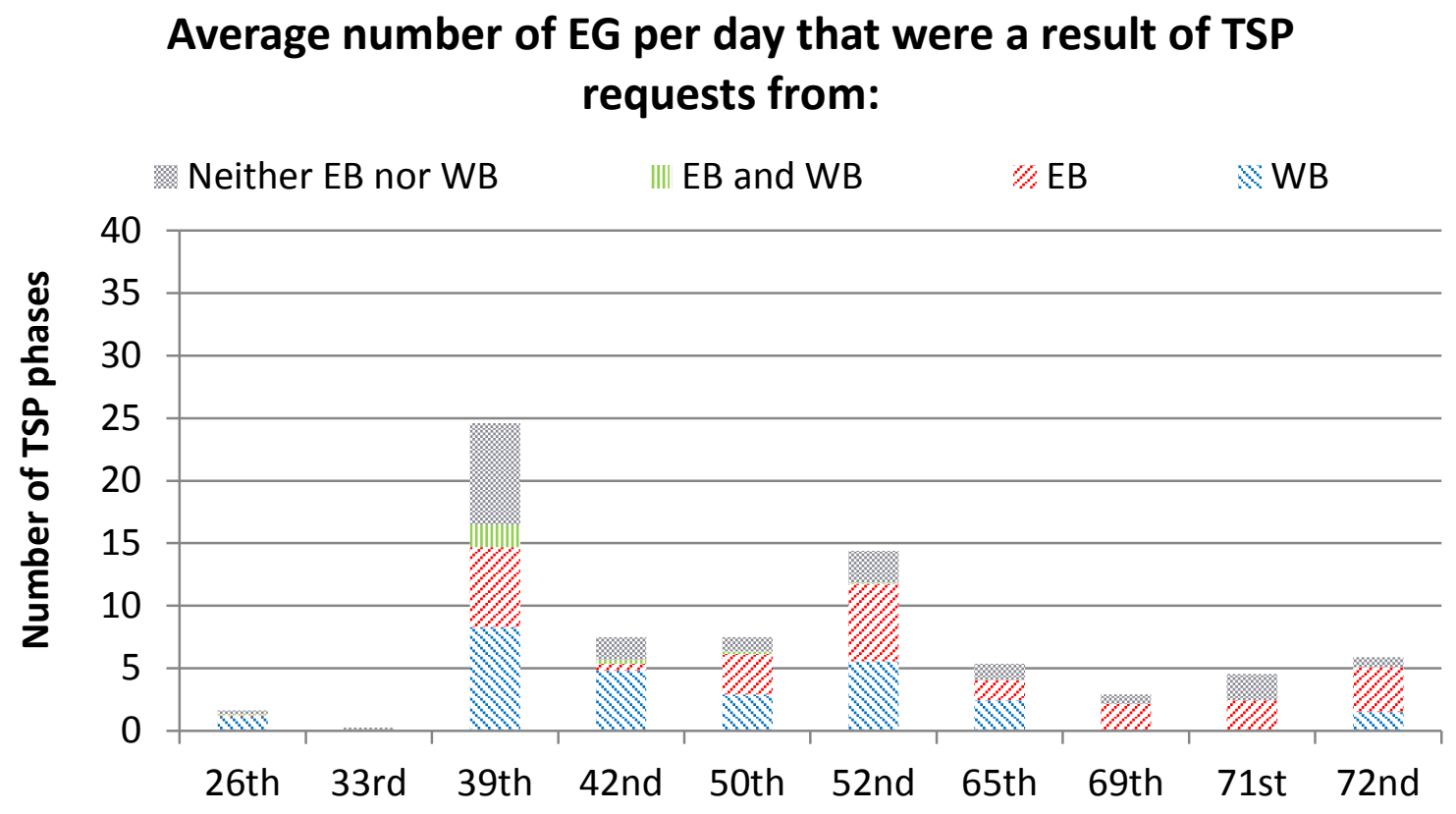

(b) Early green

Figure 4-9 Average number of GE and EG phases per day

\subsection{TSP EFFECTIVENESS}

The previous section investigated the relationships between TSP requests and TSP phases. However, even if a bus TSP request resulted in the granting of a TSP phase in the same cycle, the bus may or may not benefit from this TSP phase; this TSP phase may be granted early, on time or late. It is important to know the effectiveness of those TSP phases that resulted from TSP requests, and how many of them were granted early, on time and late. This will be helpful for identifying more potential problems or improvement opportunities. TSP effectiveness can be defined separately for TSP requests and TSP phases. TSP phase effectiveness can be defined as the percent of TSP phases that benefited at least a TSP request; and TSP request effectiveness can be defined as the percent of TSP requests that benefit from at least a TSP phase. A bus TSP request is defined to benefit from a TSP phase if the TSP phase is granted on time.

Similar to Figure 4-5, Figure 4-10 shows the relationships between TSP requests and four outcomes of TSP phases. This section tries to answer the following two questions:

1) For each bus TSP request, what are the probabilities that a TSP phase was granted early, on time or late; or that no TSP phase was granted in a cycle?

2) For each TSP phase, what are the probabilities that this TSP phase was granted early, on time or late as a result of one or more TSP requests; or that no TSP request existed within a cycle? 


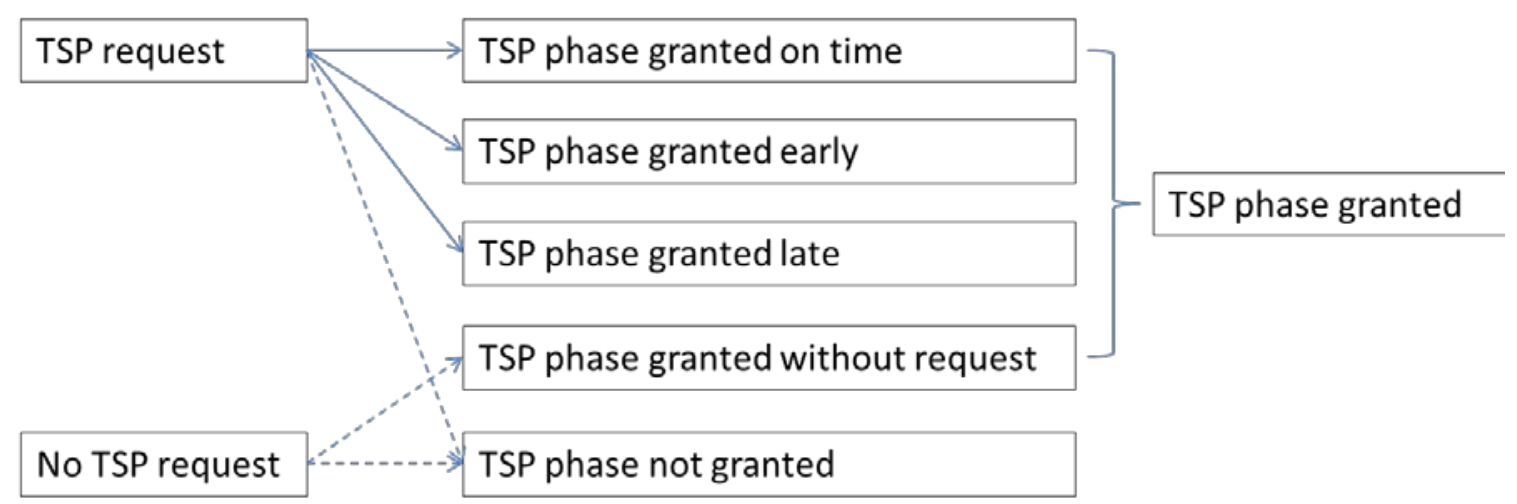

Figure 4-10 Detailed relationships between TSP requests and TSP phases

Figure 4-11 and Figure 4-12 explain when a TSP phase is granted early, late, on time or without any TSP request in the same cycle. For example, the GE (or EG) phase in cycle (2) in Figure 4-11 (or Figure 4-12) is late for bus "a"; it is on-time for bus "b”; and it is early for bus "c." All other cycles have been explained in Figure 4-6 and Figure 4-7.

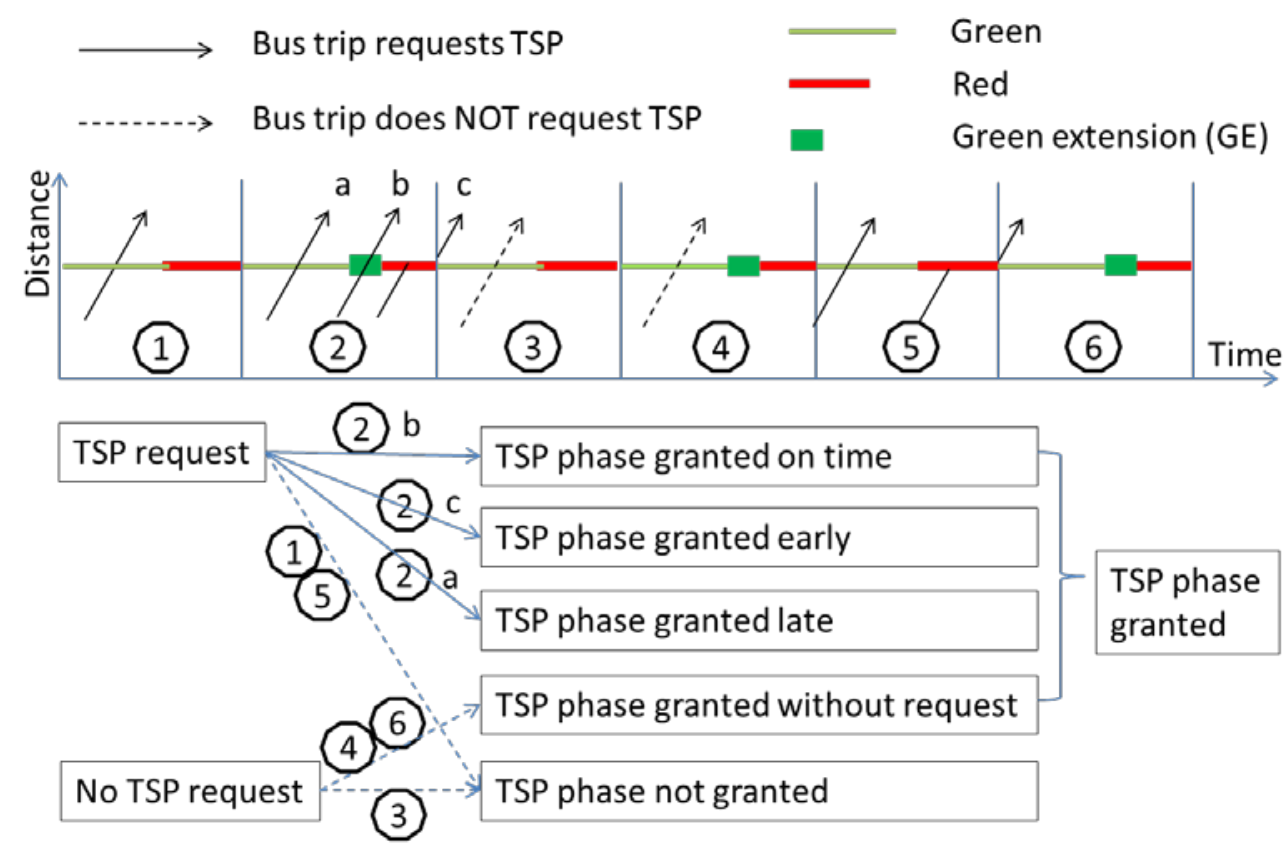

Figure 4-11 Detailed relationships between TSP requests and green extension phases 


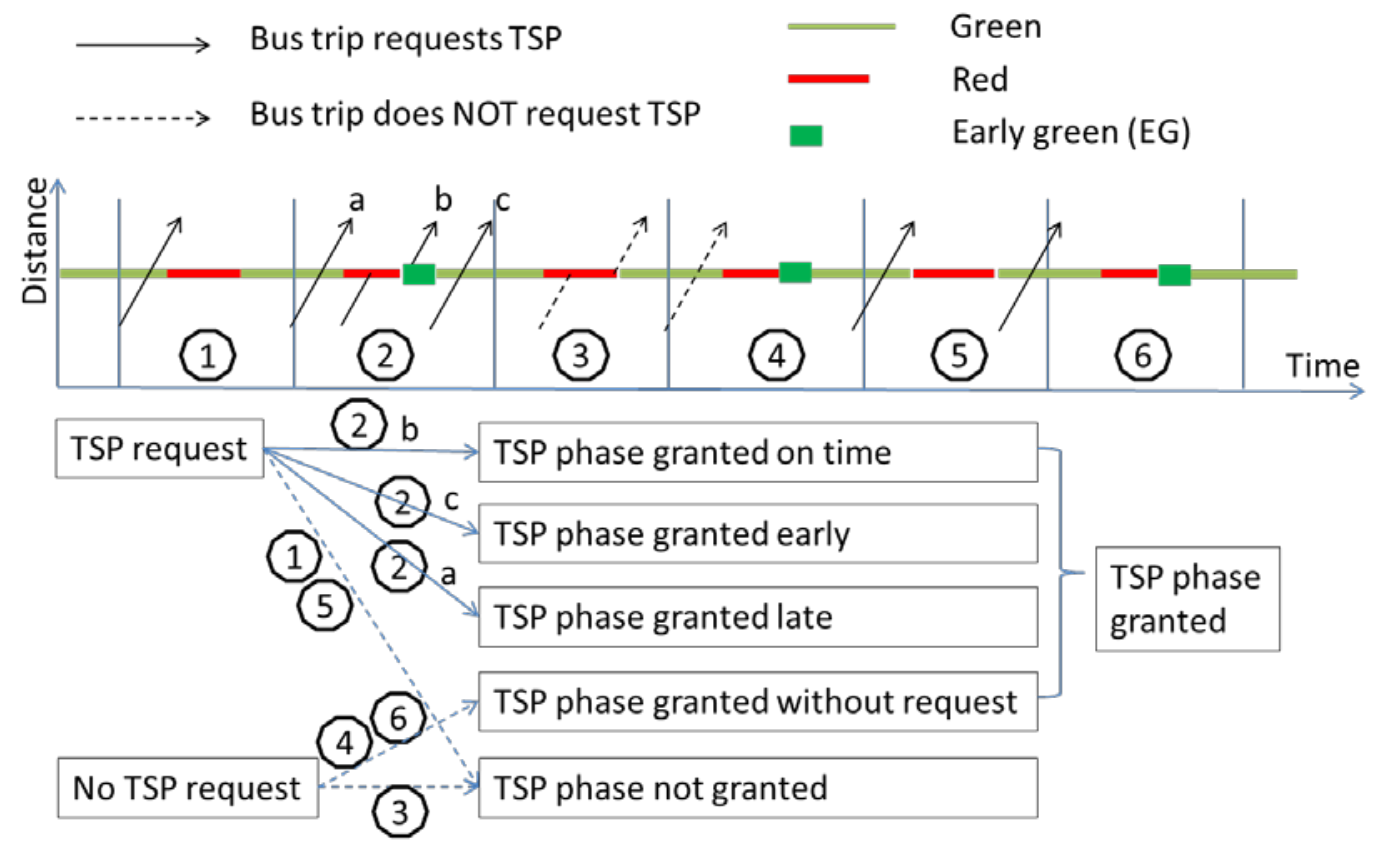

Figure 4-12 Detailed relationships between TSP requests and early green phases

\subsubsection{TSP Request Effectiveness}

Because a bus that requests TSP can benefit from a GE phase only when the bus arrives at an intersection during the GE phase, the expected probability of a bus benefiting from the GE phase can be estimated by the ratio between the GE phase duration and the cycle length, assuming the bus arrival pattern at the intersection is uniform. Similarly, a bus that requests TSP can benefit from an EG phase if the bus arrives at an intersection during the regular red phase. The expected probability of a bus benefiting from an EG phase can be estimated by the ratio between the regular red phase duration and the cycle length, assuming bus arrival time at the intersection is uniform and traffic conditions are unsaturated. In saturated traffic conditions, buses that arrive at the tail of a queue after the end of the EG phase may also benefit from the EG phase. Figure 4-13 shows the expected probabilities that a bus can benefit from a GE phase and from an EG phase, based on the observed median GE phase duration, regular red phase duration and cycle length. On average, a bus that requests TSP has 6\% probability of benefiting from a GE phase and it has $5-50 \%$ probability of benefiting from an EG phase. 


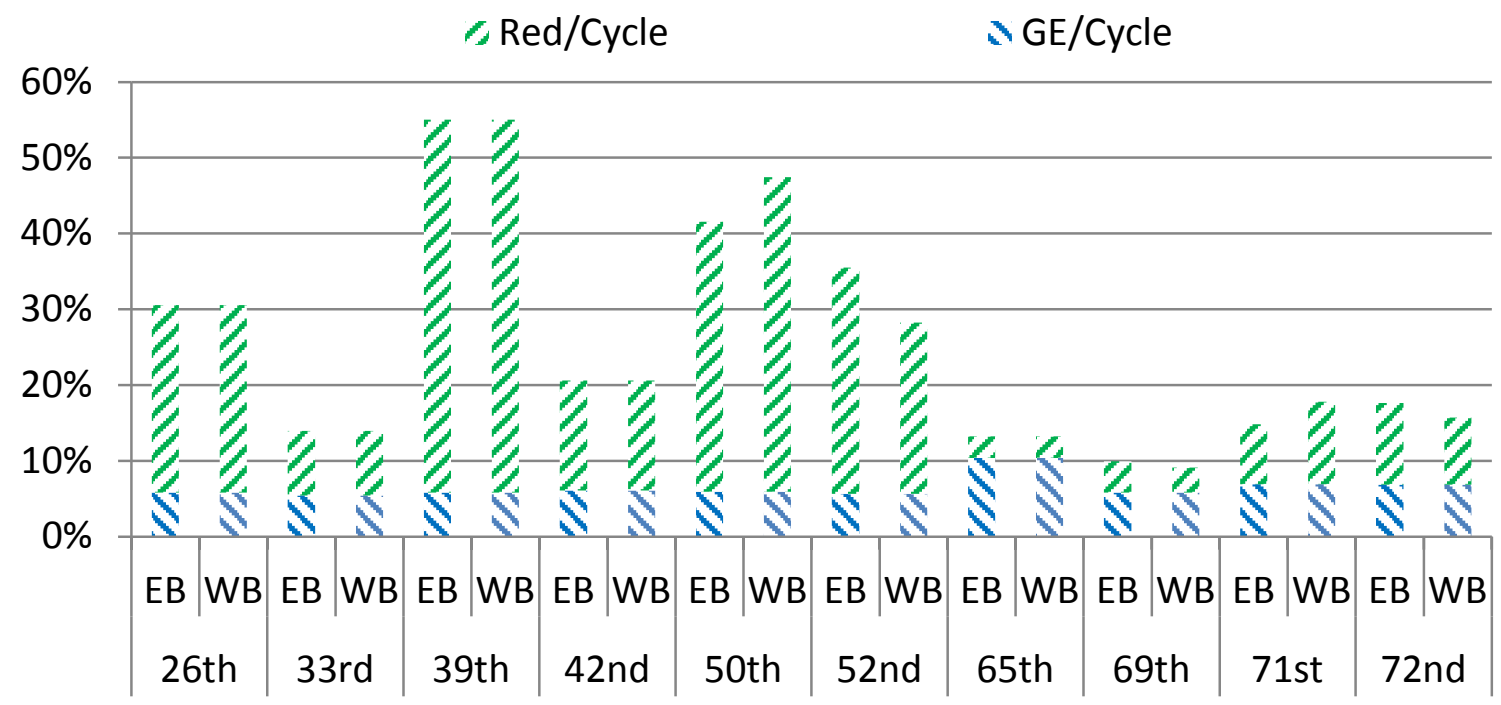

Figure 4-13 Probability that a bus TSP request can benefit from a TSP phase

Figure 4-14 shows the actual probabilities that a TSP request resulted in the granting of an early, on-time, and late GE phase, and that no GE phase was granted in the same cycle. Note that the probability that a TSP request does not result in a GE phase includes the probability that the TSP request results in an EG phase. Results indicate a low performance of GE phases because too many unnecessary (late) GE phases were granted, and the actual probability of a TSP request benefiting from a GE phase is much lower (1.5\%) than the expected probability (6\%). This may indicate a problem with the TSP control logic. For example, a GE phase will be granted irrespective of whether a TSP request is received in the beginning of a regular green phase or at the end of a regular green phase. It may also indicate a problem with the TSP request deactivation. For example, a TSP call in the signal controller may not have been canceled even if a bus has already passed the intersection.

d: no GE $\quad$ W c early GE III b: on time GE $\quad$ a: late GE

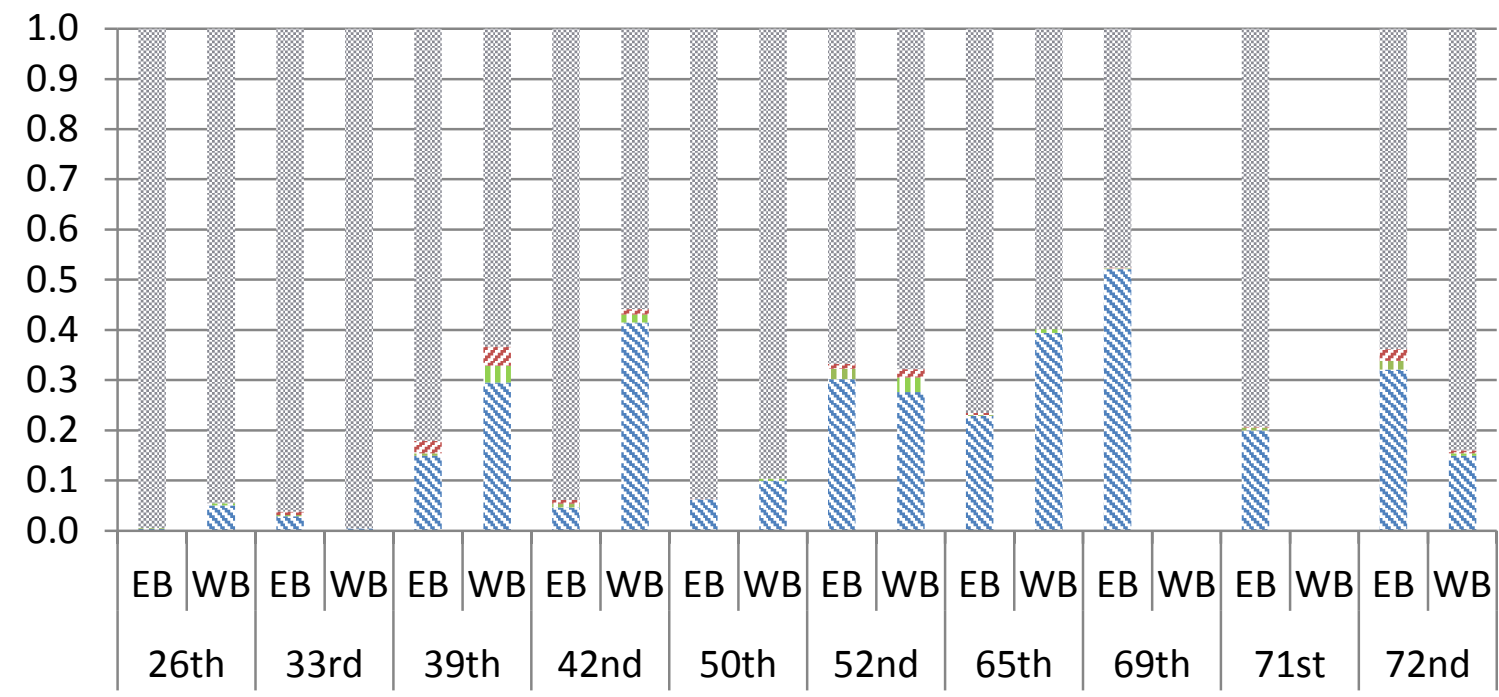

Figure 4-14 Probabilities of TSP request outcomes for GE 
Figure 4-15 shows the actual probabilities that a TSP request resulted in the granting of an early, on-time, and late EG phase, and that no EG phase was granted. Note that the probability that a TSP request does not result in an EG phase includes the probability that the TSP request results in a GE phase. Results show that, on average, a bus TSP request has a 5-15\% probability of benefiting from an EG phase and 0-15\% probability of resulting in an EG phase to be granted early. EG phases that were granted early might also be beneficial to buses because queuing delay can be reduced due to EG phases. Another interesting finding is that EG phases are more effective at minor intersections than at major intersections. For example, at $42^{\text {nd }}$ Avenue WB direction, $69^{\text {th }}$ and $71^{\text {st }}$ avenues EB direction, and $65^{\text {th }}$ and $72^{\text {nd }}$ avenues both directions, the actual probabilities that a TSP request benefited from an EG phase are close to the expected probabilities as shown in Figure $4-13$. However, at $26^{\text {th }}, 39^{\text {th }}, 50^{\text {th }}$ and $52^{\text {nd }}$ avenues both directions, the measured probabilities that a TSP request benefited from an EG phases are much less than the expected probabilities.

In general, a TSP request has very high probability of resulting in an unnecessary (late) GE phase, but very low probability of benefiting from a GE phase. In contrast, a TSP phase has a high probability of benefiting from an EG phase and a low probability of resulting in an unnecessary EG phase.

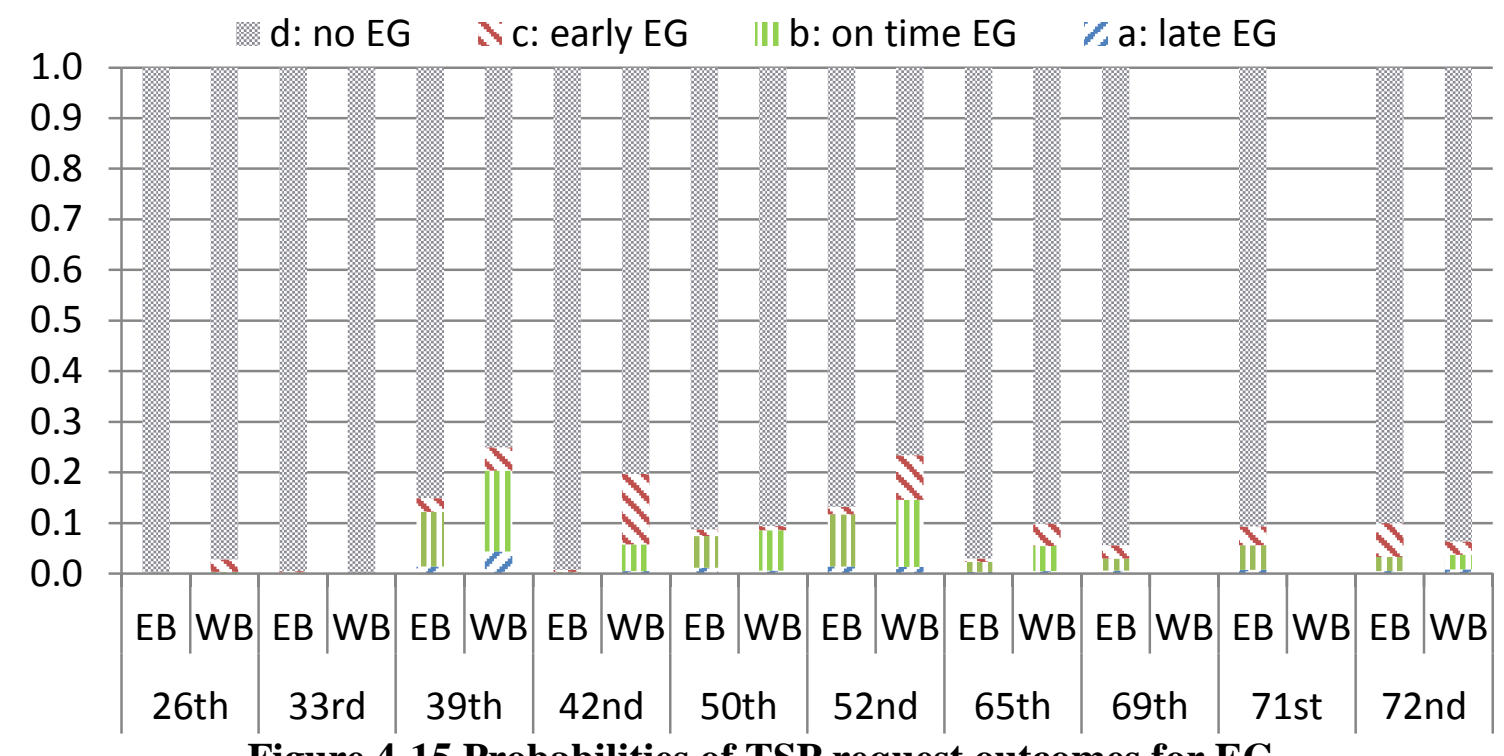

Figure 4-15 Probabilities of TSP request outcomes for EG

\subsubsection{TSP Phase Effectiveness}

The above section presents evaluation results of the TSP request effectiveness and provides some information about the probabilities of early, on-time and late TSP phases. However, it is also worthwhile evaluating the TSP effectiveness from the perspective of TSP phases as opposed to TSP requests. The probabilities that a TSP phase was granted early, on time, late or in a different cycle are calculated to measure the TSP phase effectiveness.

GE phase effectiveness and EG phase effectiveness are shown in Figure 4-16 and Figure 4-17. The rest of each bar is the percent of TSP phases without any TSP request within the same cycle. 
Results vary significantly across intersections and by direction. Figure 4-16 shows that, on average, a GE phase has $64 \%$ probability of being late, $28 \%$ probability of being in a different cycle, $5 \%$ probability of being on time and 3\% probability of being early. This means that $95 \%$ of the GE phases are not effective and most of them are late. Results clearly indicate a problem with the GE phases. This might be a TSP control logic problem or a TSP request detection/deactivation problem. Figure 4-17 shows that, on average, an EG phase has 40\% probability of being on time, $30 \%$ probability of being early, $28 \%$ probability of being in a different cycle and $2 \%$ probability of being late. Therefore, EG phases are much more effective than GE phases.
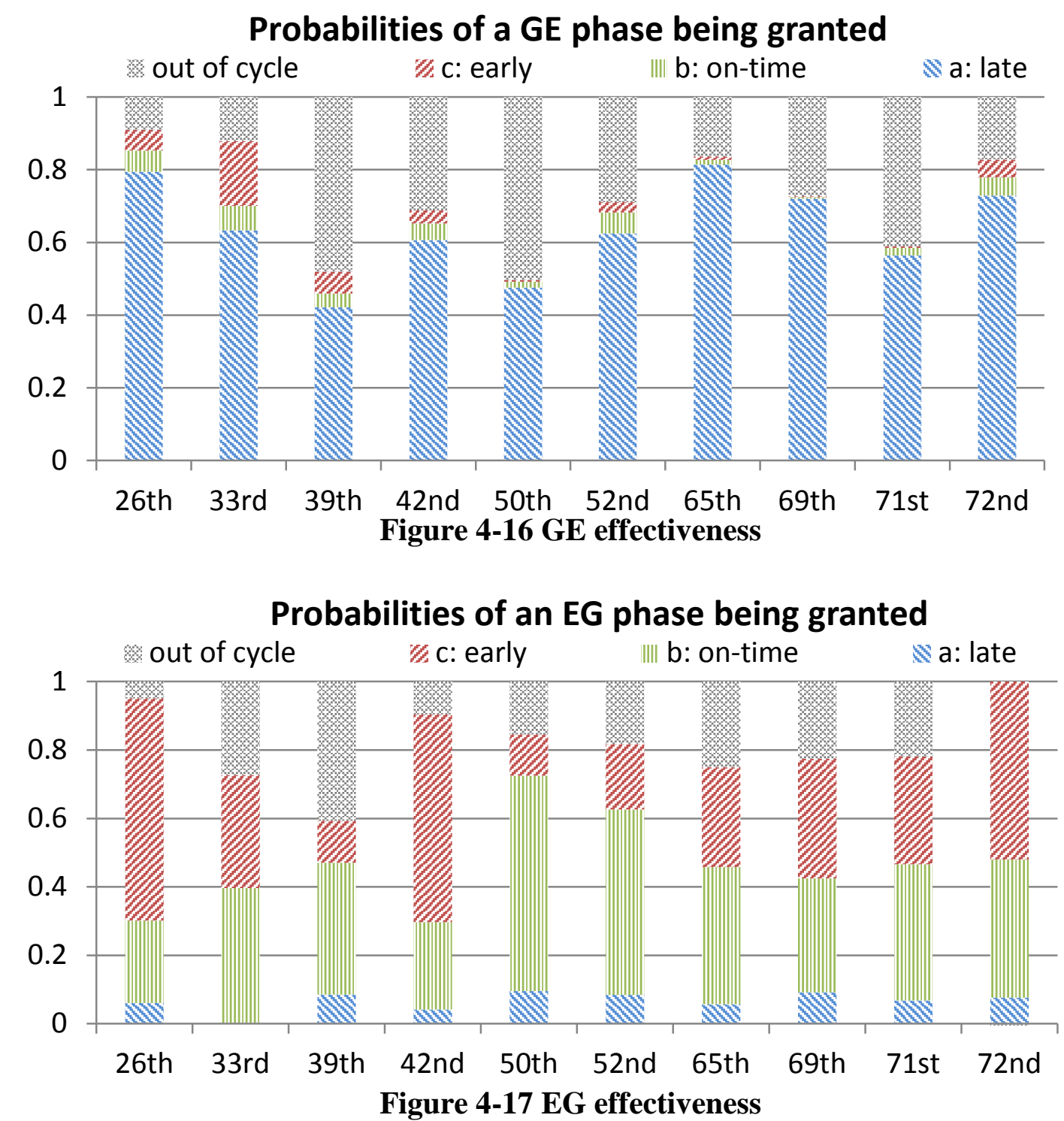

\subsection{TSP BENEFITS}

The above section shows that a TSP request is less likely to benefit from a GE phase than from an EG phase even though there are more GE phases. However, if a bus benefits from a GE 
phase, the time savings will be the time interval between the arrival time of this bus at the intersection and the end time of the following red phase. If a bus benefits from an EG phase, the maximum time savings will be the EG phase duration. Because red phase duration is longer than EG phase duration in most of the intersections, the time savings for a bus that benefits from a GE phase is usually higher than when it benefits from an EG phase. Therefore, it is important to measure the benefit (time savings) for each TSP request. On the other hand, because TSP phases can cause additional delay to side-street traffic, it is also important to measure the benefit (time savings) of each TSP phase, and to compare whether the benefits for the bus and its onboard passengers outperform the cost (delays) to side-street vehicles. Time savings for the bus and the passengers are estimated based on the algorithm presented in Chapter 3. The estimation of time savings for other vehicles on the major street and delays to vehicles on the minor street will be shown in the following sections.

\subsubsection{Estimated Benefit per TSP Request}

Figure 4-18 shows that the estimated time savings per TSP request from a GE phase is 0.3 seconds, and the estimated time savings per TSP request from an EG phase is 0.5 seconds. These estimated time savings are very low for both GE and EG phases because the probabilities of a TSP request benefiting from a TSP phase are very small at most of the intersections. Figure 4-19 shows that the estimated passenger time savings for a TSP request from a GE phase and from an EG phase are 7.5 and 10 seconds, respectively. Results indicate that a TSP request has slightly higher time savings from an EG phase than from a GE phase.

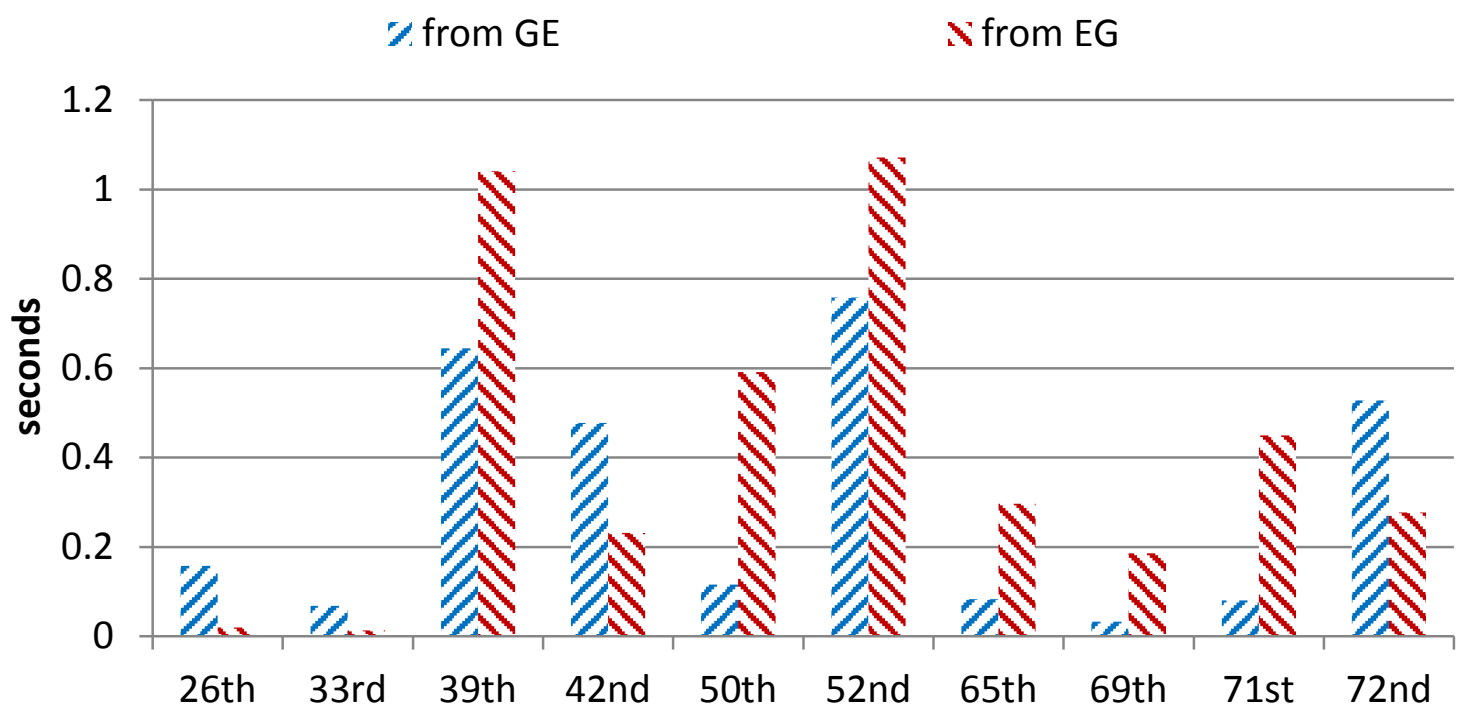

Figure 4-18 Estimated bus time savings per TSP request 


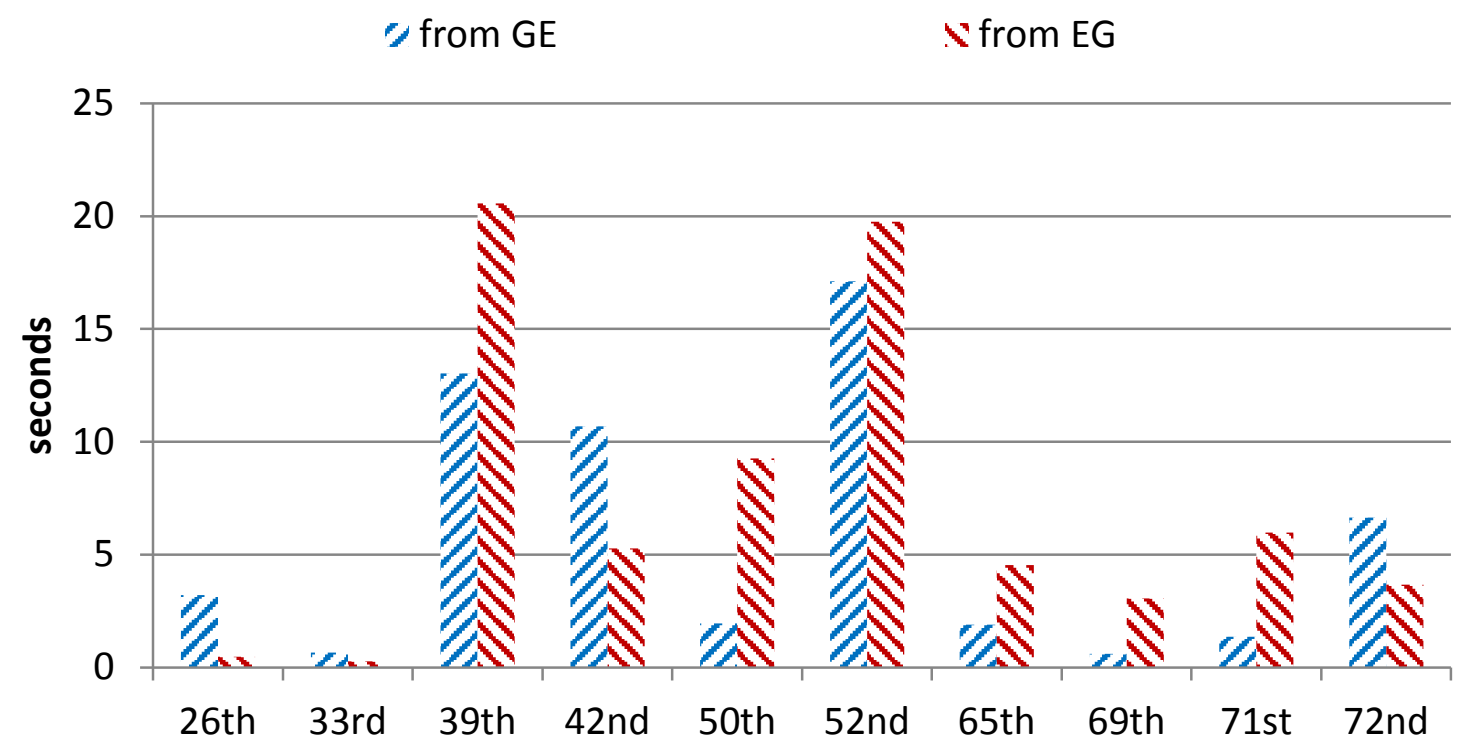

Figure 4-19 Estimated total passenger time savings per TSP request

\subsubsection{Estimated Benefit per TSP Phase}

Although the expected benefit from a GE phase is higher than from an EG phase, Figure 4-20 (a) and (b) show that the estimated bus time savings per GE phase and per EG phase are one and four seconds, respectively. Similarly, Figure 4-21 (a) and (b) show that the estimated passenger time savings for each granted GE phase and EG phase are 20 and 90 seconds, respectively. This may be because too many non-beneficial GE phases were granted than EG phases.

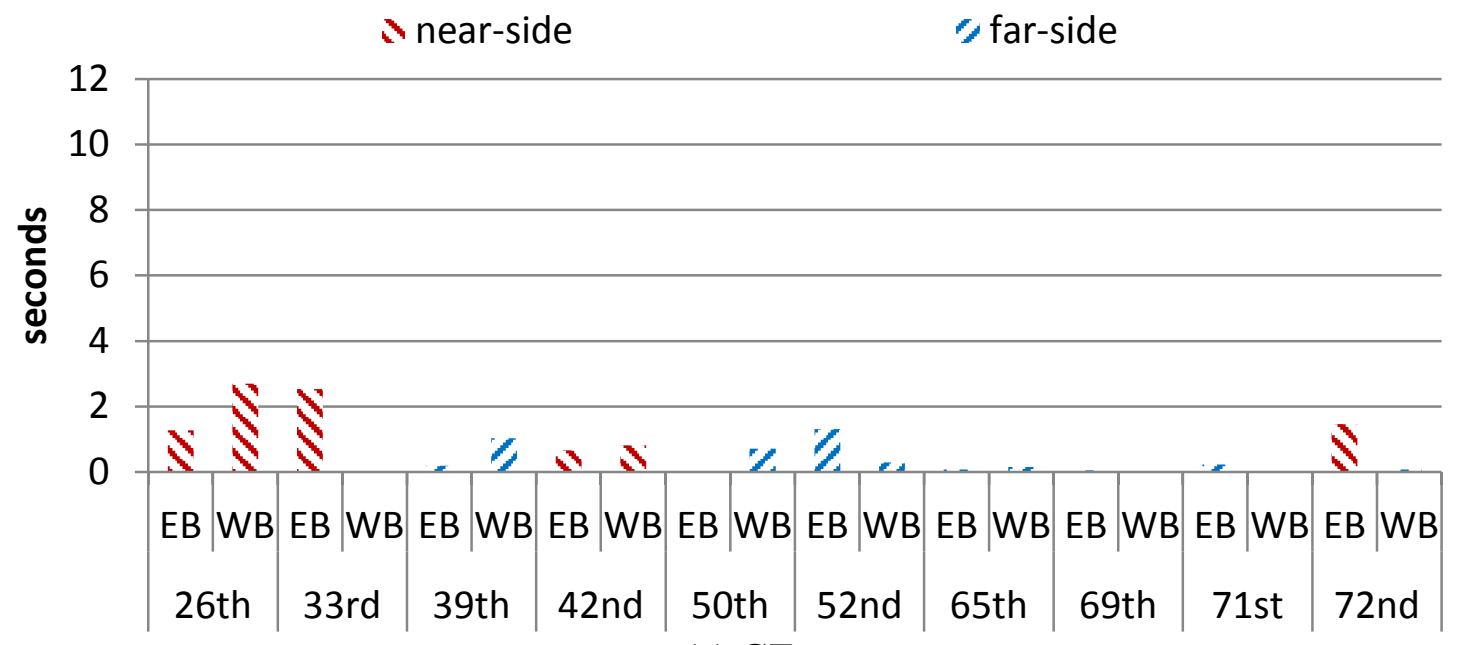

(a) GE 


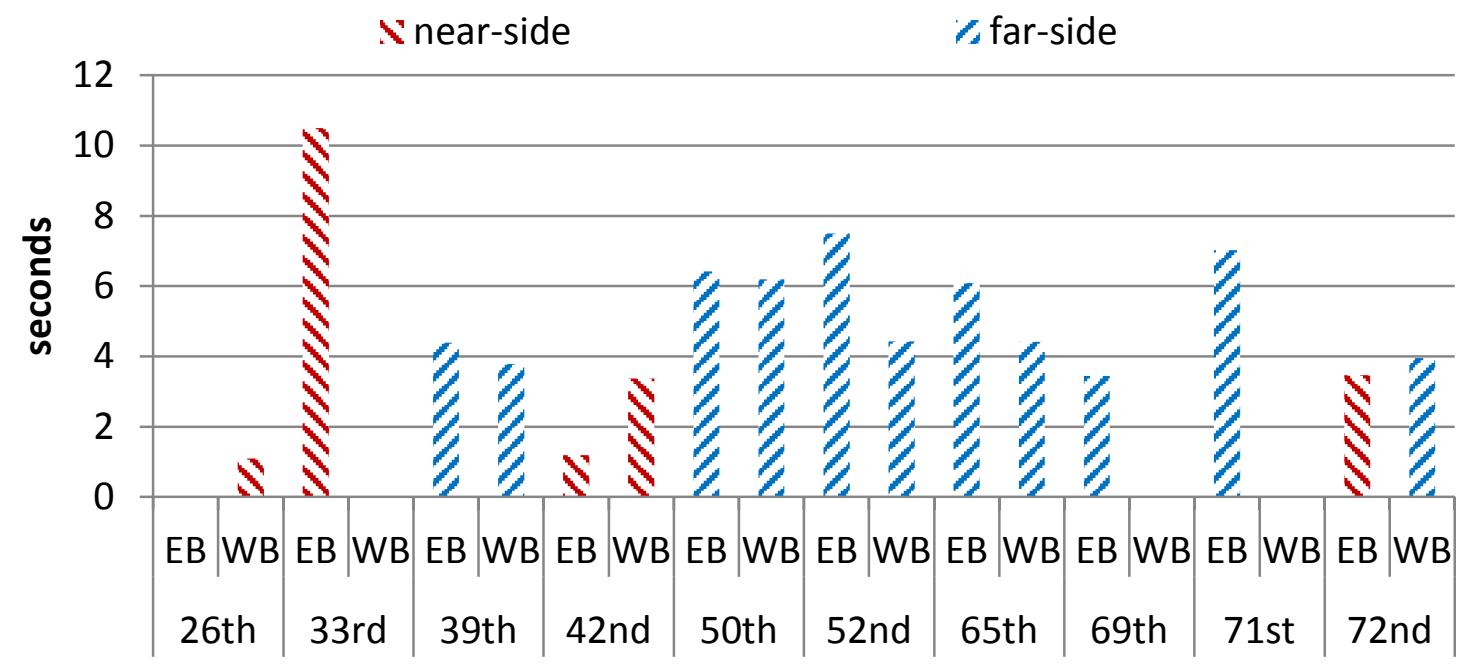

(b) EG

Figure 4-20 Estimated bus time savings per TSP phase

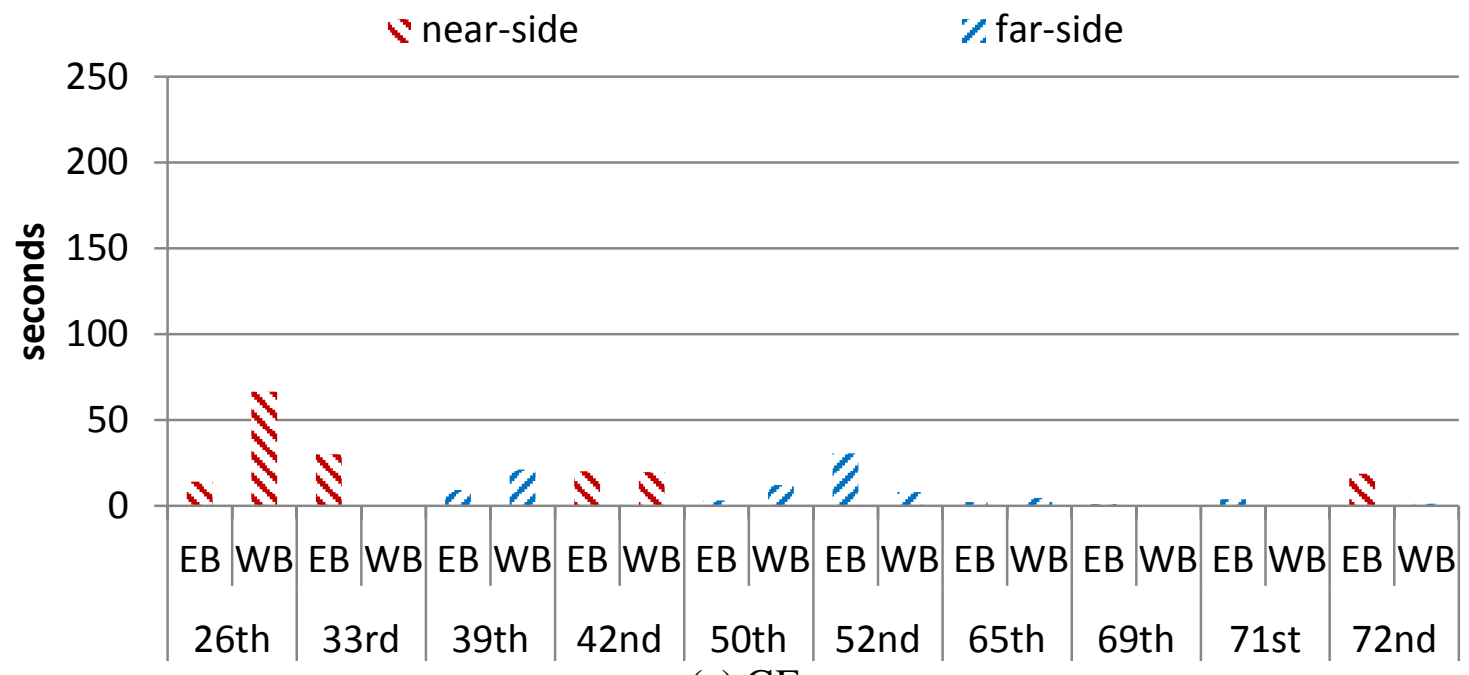

(a) GE 


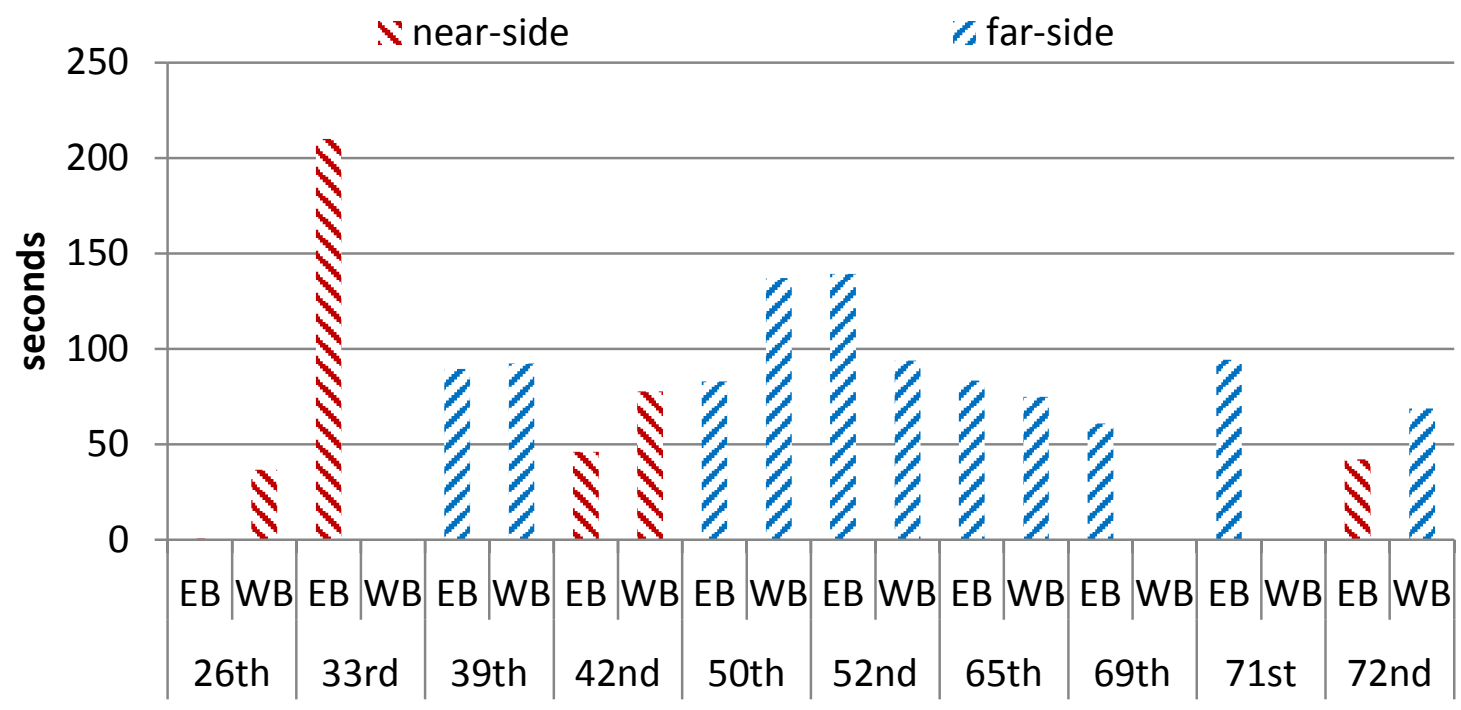

(b) EG

Figure 4-21 Estimated total passenger time savings per TSP phase

According to Smith et al. (2005), TSP works better at far-side stops because bus arrival time prediction is more reliable at far-side stops. However, our results did not show clear differences in the estimated bus time savings and passenger time savings per TSP phase between near-side stops and far-side stops. This finding does not indicate that near-side and far-side stop configurations have no impact on TSP performance because there are only six near-side stop segments and four of them may have TSP setting problems.

\subsubsection{Time Savings and Delay between Buses and Other Vehicles}

It is also necessary to compare time savings for the buses and vehicles on Powell Boulevard due to a TSP phase with delays for vehicles on the side streets due to the TSP phase. Assuming vehicle and bus arrival rates at intersections are uniform (vehicle platooning arrival pattern was not considered in this case), traffic conditions are unsaturated in all four approaches, and regular green phase and red phase durations will not change if a GE phase or an EG phase is granted, the total time savings (TTS) for vehicles on the major street and the total delay (TD) for vehicles on the side streets can be estimated by the following equations:

$$
\begin{aligned}
& T T S=\frac{q_{1} \cdot q_{2}}{2\left(q_{2}-q_{1}\right)}\left(2 \cdot \mathrm{Red} \cdot T S P-T S P^{2}\right) \\
& T D=\frac{q_{1} \cdot q_{2}}{2\left(q_{2}-q_{1}\right)}\left(2 \cdot \mathrm{Red} \cdot T S P+T S P^{2}\right)
\end{aligned}
$$

The derivations of these equations are illustrated in Figure 4-22. $q_{2}$ is the discharge flow, it is assumed to be 1,800 vehicles per hour per lane. $q_{1}$ is the vehicle arrival flow from an approach of an intersection. Red is the regular red phase duration for an approach of an intersection. TSP is the median TSP phase duration (either GE or EG) for an intersection. 

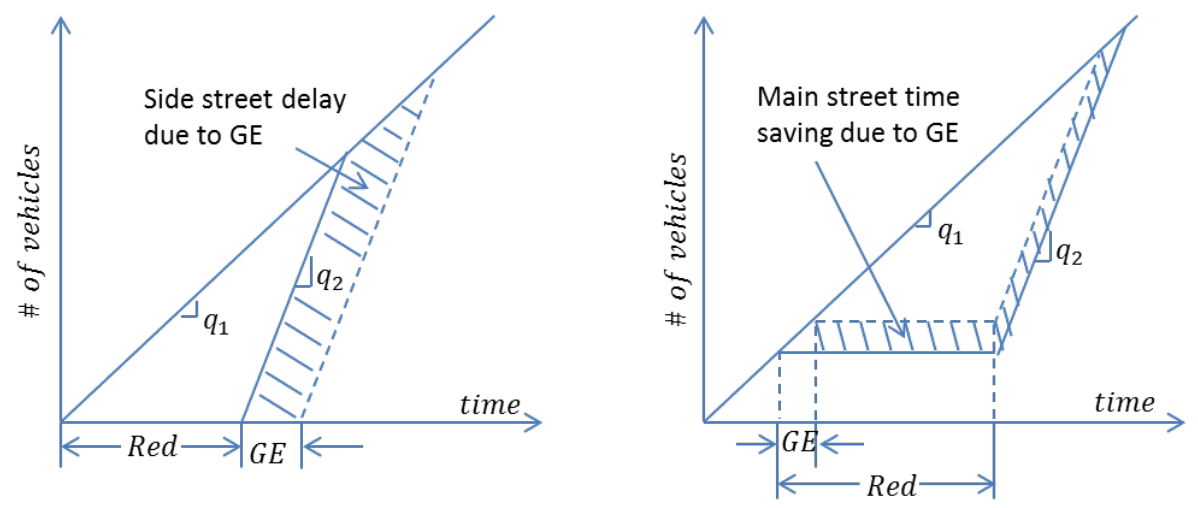

$$
T D=\frac{q_{1} \cdot q_{2}}{2\left(q_{2}-q_{1}\right)}\left(2 \cdot \operatorname{Red} \cdot G E+G E^{2}\right)
$$

$$
T T S=\frac{q_{1} \cdot q_{2}}{2\left(q_{2}-q_{1}\right)}\left(2 \cdot \operatorname{Red} \cdot G E-G E^{2}\right)
$$
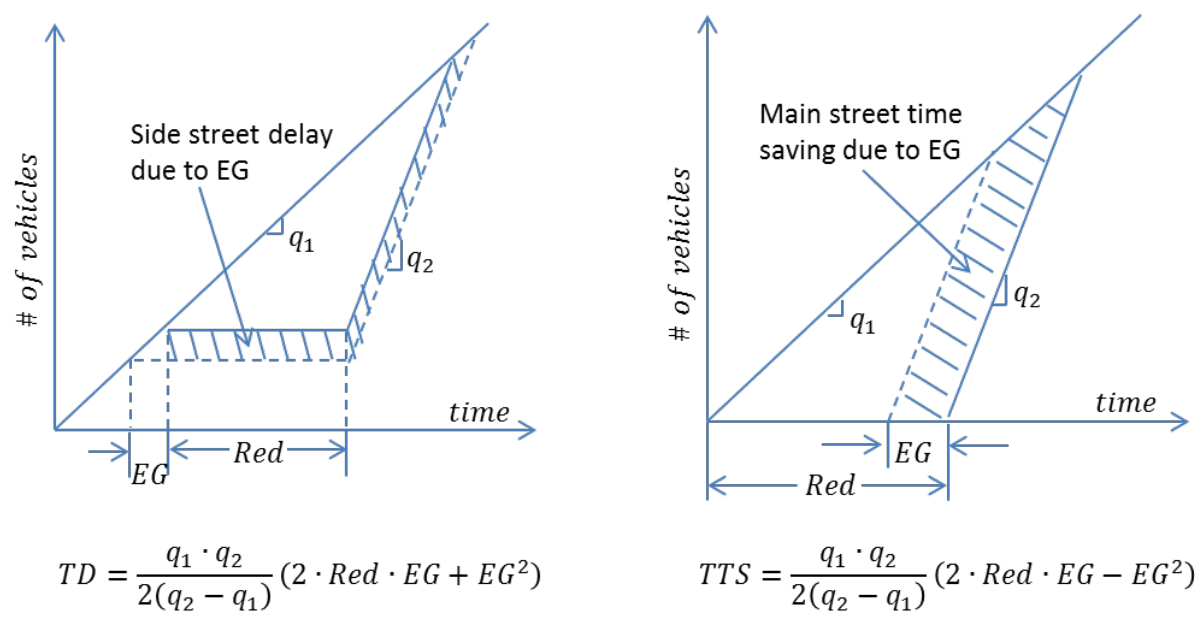

Figure 4-22 Illustration of major street time savings and side-street delay 


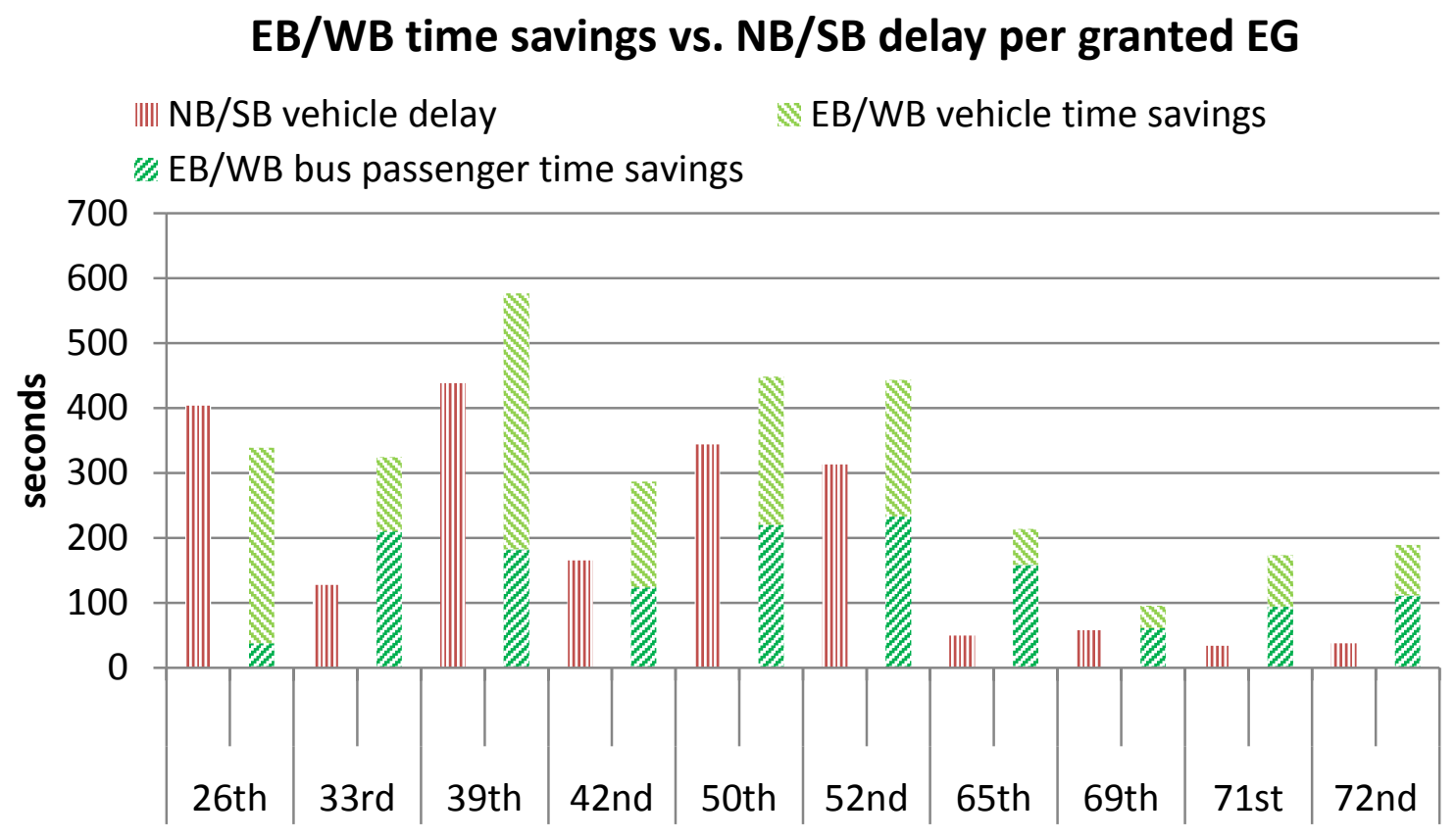

(a) EG

EB/WB time savings vs. NB/SB delay per granted GE

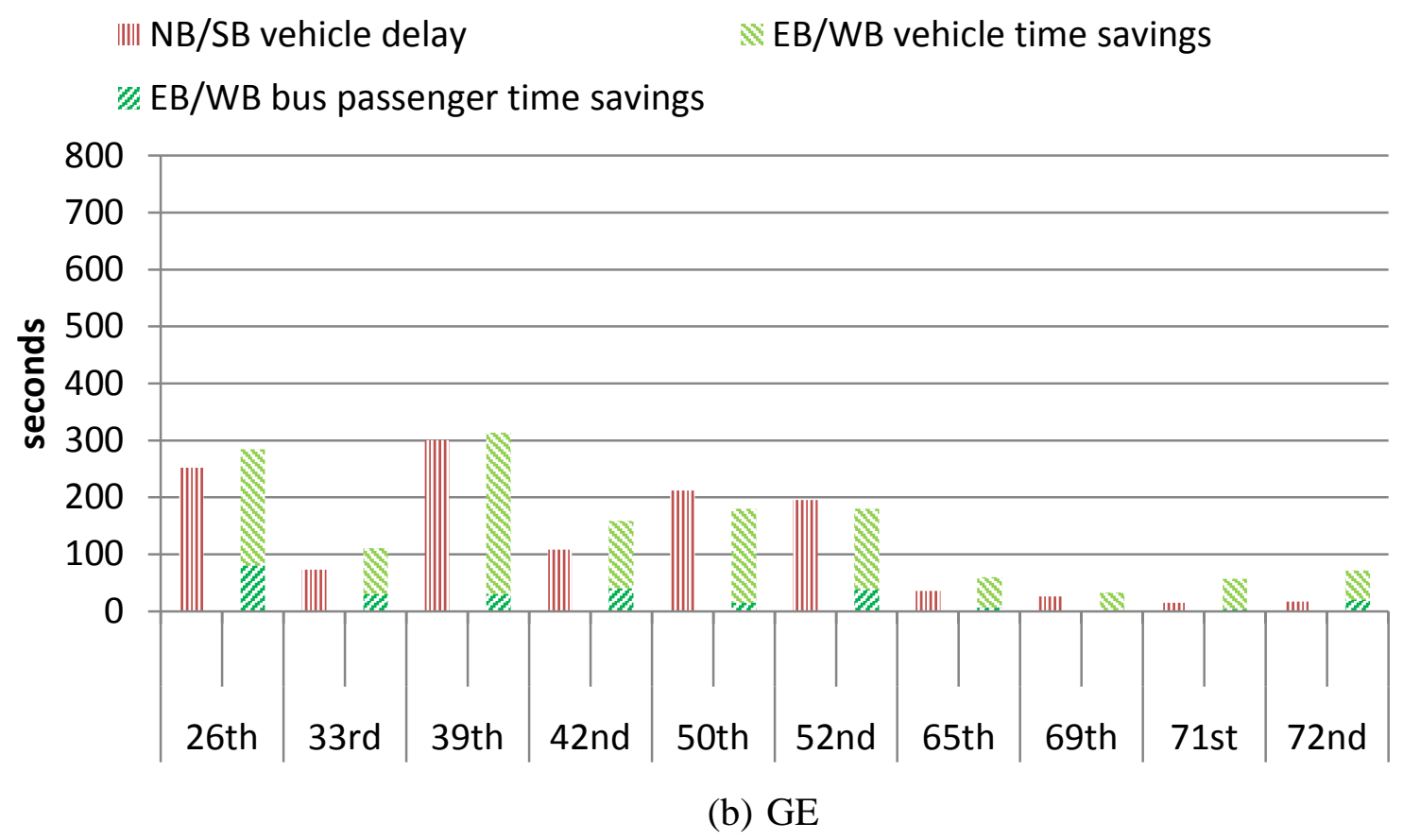

Figure 4-23 Total passenger time savings and delay per TSP phase

Assuming all other vehicles are single occupancy vehicles, the total estimated vehicle delays for the NB and SB approaches, the total vehicle time savings for the EB and WB approaches, and the passenger time savings are shown in Figure 4-23. Results show that an EG phase creates more side-street delay than a GE phase because the EG phase duration is longer than the GE 
phase duration. For each EG phase, the bus passenger time savings is slightly less than the total vehicle delay on the side street for intersections west of $52^{\text {nd }}$ Avenue, but the sum of the bus passenger time savings and the total vehicle time savings on the major street is much higher than the side-street vehicle delay at all intersections. For each GE phase, the sum of the bus passenger time savings and the vehicle time savings on the major street is almost equal to the vehicle delay on the side street.

Because the average duration of a GE phase is smaller than the average duration of an EG phase, it is worth comparing the efficiencies between them (total time savings and delays per second GE phase and EG phase). According to equations shown in Figure 4-22, the total vehicle delays on the minor street increase concavely $\left(G E^{\prime}>0, G E^{\prime \prime}>0, E G^{\prime}>0\right.$ and $\left.E G^{\prime \prime}>0\right)$, which means the total vehicle delay incremental rate increases when TSP phase duration increases. However, the total time savings for vehicles on the major street increase convexly $\left(G E^{\prime}>\right.$ $0, G E^{\prime \prime}<0, E G^{\prime}>0$ and $\left.E G^{\prime \prime}<0\right)$ when $(0<G E$ or $E G<2 R e d)$, which means the total vehicle time savings incremental rate decreases when TSP phase duration increases. Bus passenger time savings will also increase if GE or EG duration increases; however, the incremental rate is unknown because bus passenger time savings are estimated by comparing each pair of bus departure time and arrival time with TSP phase start and end times. Therefore, assuming total bus passenger time savings and other vehicles' time savings on the major street and total delays for vehicles on the minor street all increase linearly with GE and EG durations, the average total time savings and total delays per second GE phase and per second EG phase can be estimated by dividing the total time savings and delays by TSP durations (seven seconds for GE and 11 seconds for EG). The results are shown in Figure 4-24.

Results show that the total time savings and delays for non-bus vehicles per second GE phase and per second EG phase are very similar (less than two seconds difference), which means the nonlinear effect of TSP phase duration on non-bus vehicles time savings and delays is very small. However, the total bus passenger time savings per second EG phase is much higher than the total bus passenger time savings per second GE phase. Therefore, after controlling for TSP phase duration, EG phases are more efficient than GE phases. 


\section{EB/WB time saving vs. NB/SB delay per second EG phase}

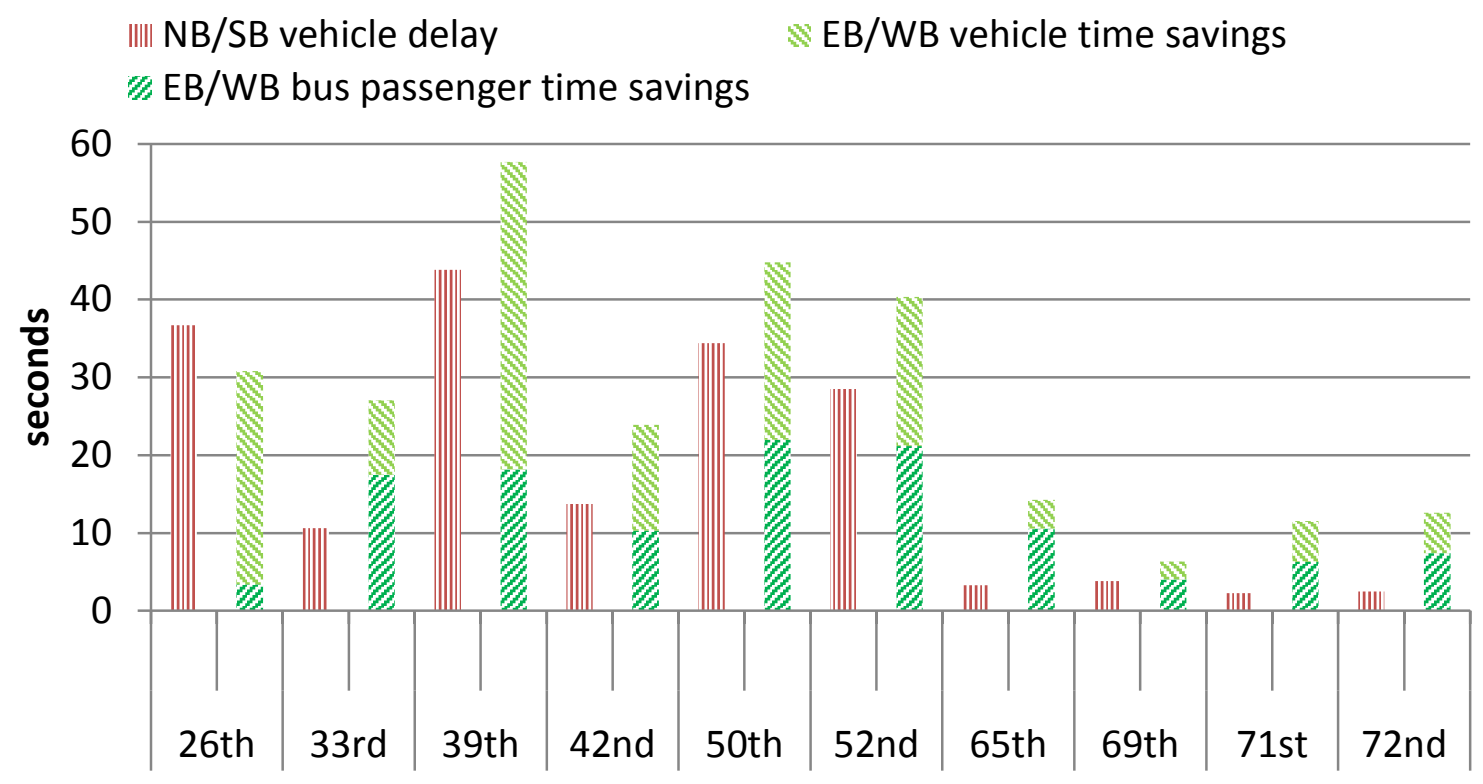

(a) Green extension

\section{EB/WB time savings vs. NB/SB delay per second GE phase}

|III NB/SB vehicle delay

$\mathrm{NE} / \mathrm{WB}$ vehicle time savings

ZEB/WB bus passenger time savings

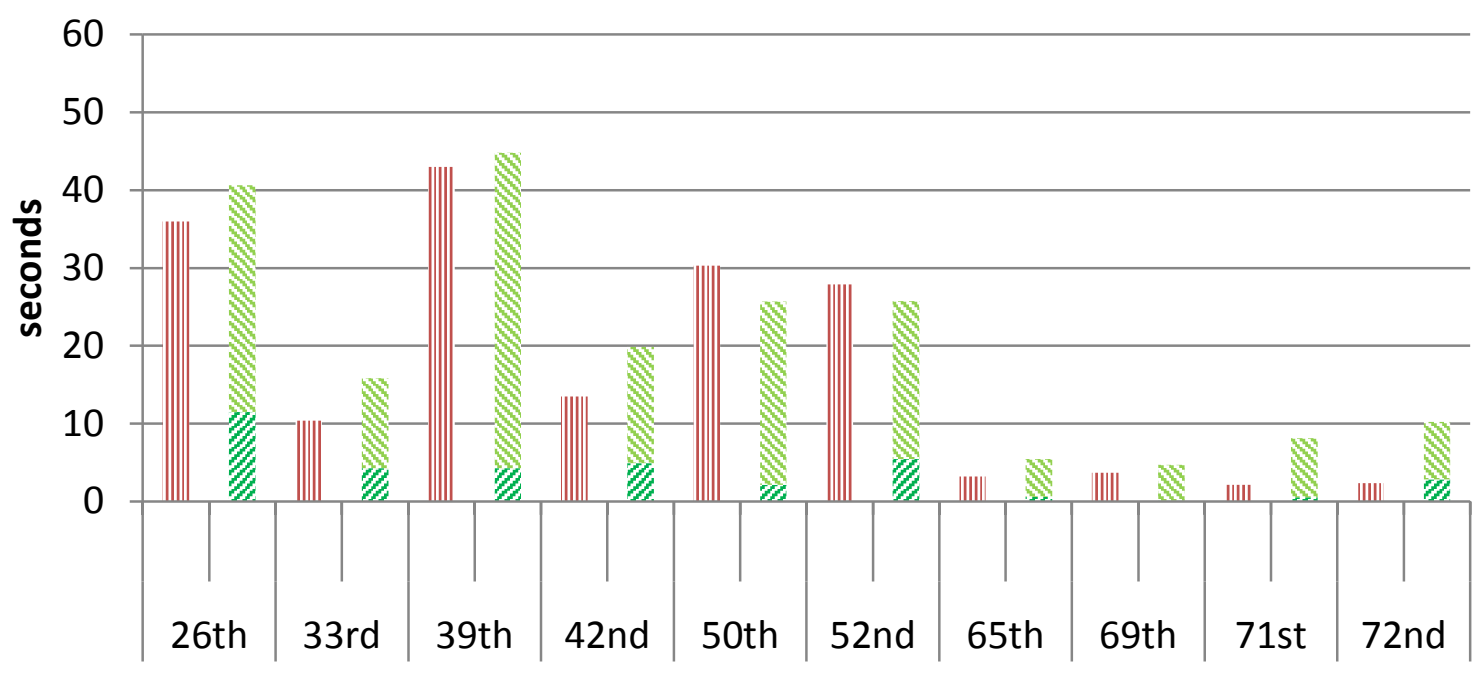

(b) Early green

Figure 4-24 Total passenger time savings and vehicle delays per second TSP phase 


\subsection{CONCLUSIONS AND DISCUSSIONS}

This study has integrated three databases: bus AVL/APC data, SCATS signal phase log data and traffic count data. A bus stop-to-stop trip database was utilized to evaluate the TSP system performance.

\subsection{TSP PERFORMANCE EVALUATION}

Several performance measures were proposed in this study to evaluate how well the TSP system helps reduce bus delay through signalized intersections. These performance measures include: the percentage of TSP requests that lead to the granting of a TSP phase within the same cycle; the percentage of granted TSP phases that were triggered by a TSP request in the same cycle; the probability of a TSP request benefiting from a TSP phase; the percentage of granted TSP phases that were beneficial to at least one TSP request (TSP phase effectiveness); bus and passenger time savings for a granted TSP phase; and other vehicles' time savings and delay due to TSP phases. Because this is the first study that has utilized and integrated the bus AVL/APC data and SCATS signal phase log data, and evaluated the TSP system performance at the stop-to-stop segment level, most of the results are new to the literature. Some of the key findings are summarized below.

The average number of TSP requests per day at each intersection from both directions is 70 . The average numbers of green extension (GE) and early green (EG) phases per day are 21 and 11, respectively. However, these numbers vary significantly across intersections. For example, there are 63 TSP phases (both GE and EG) per day at the intersection of $39^{\text {th }}$ Avenue, but only five TSP phases per day at the intersections of $26^{\text {th }}$ and $33^{\text {rd }}$ avenues. The mean durations of GE and EG phases are seven and 11 seconds, respectively.

An average of $45 \%$ of TSP requests resulted in the granting of a TSP phase within the same cycle (29\% GE and 16\% EG). For each TSP request, the probabilities that a GE phase is granted early, on time and late are 2.5\%, 1.5\% and 25\%, respectively. The probabilities that an EG phase is granted early, on time and late are $5 \%, 10 \%$ and $1 \%$, respectively. Although a TSP request is more likely to result in the granting of a GE phase (29\%) than an EG phase (16\%) within a cycle, a TSP request is less likely to benefit from a GE phase (1.5\% on time) than from an EG phase (10\% on time). Assuming that the bus arrival rate at each intersection follows a uniform distribution, the theoretical probabilities that a bus TSP request can benefit from a GE phase and from an EG phase are 6\% and 30\%, respectively. Therefore, the difference between the actual and the theoretical probabilities of a TSP request benefiting from TSP phases indicates that it is necessary to improve the TSP system performance by increasing the probability that a TSP request benefits from TSP phases, and reducing the probability that a TSP request results in a TSP phase granted early or late.

The estimated bus time savings per TSP request from a GE phase and from an EG phase are 0.3 and 0.5 seconds, respectively. Based on regression analysis on the same corridor, Albright and Figliozzi (2012a) found that the average time savings for a bus that requests TSP is 0.41 seconds, 
which is very close to the $0.3-0.5$ seconds time savings. The estimated total passenger time savings per TSP request from a GE phase and from an EG phases are 7.5 and 10 seconds, respectively.

For GE phases, only 5\% of them were granted on time to a TSP request; $3 \%$ and $64 \%$ of the GE phases were granted early and late to a TSP request in the same cycle; and $28 \%$ of the GE phases were granted without a TSP request in the same cycle. On the other hand, the percentages of EG phases that were granted early, on time and late to a TSP request in the same cycle are $40 \%, 40 \%$ and $8 \%$, respectively, and $12 \%$ of the EG phases were granted without a TSP request in the same cycle. These results indicate that early green effectiveness is much higher than green extension effectiveness, and too many green extension phases were granted late (64\%).

The estimated bus time savings of a GE phase and an EG phase are one and four seconds, respectively. The estimated passenger time savings of a GE phase and an EG phase are 20 and 90 seconds, respectively. Although Smith et al. (2005) suggested that a TSP system works better for far-side bus stops than near-side bus stops because it is difficult to predict bus arrival time at near-side bus stops, our results did not show clear differences in bus and passenger time savings per TSP phase between near-side stops and far-side stops. However, this does not mean that busstop configuration has no impact on TSP performance because most of the evaluated near-side stop segments may have TSP setting problems.

The estimated bus passenger time savings per EG phase is less than the delay to side-street vehicles at intersections with large side-street traffic volumes; but the estimated passenger time savings per GE phase is less than the delay to side-street vehicles at all intersections. In addition, the total time savings of bus passengers and vehicles on the major street is higher (or equal to) than the delay to side-street vehicles for an EG phase (or a GE phase) at all intersections.

\subsection{RECOMMENDATIONS}

The TSP phase effectiveness results show that too many green extension phases were granted either late (64\%) but still in the same cycle or in a different cycle (28\%). These results indicate potential problems with the TSP control logic or signal controllers' reliability issues. For example, a GE phase might be granted regardless of the time when a TSP request is detected. Late granted GE phases are not helpful for buses on the major street and they create additional delay to the side-street traffic. If the percent of late GE phases can be reduced significantly, the expected bus time savings and passenger time savings per granted GE phase will increase significantly.

Based on the results from this research, a few recommendations to improve TSP system effectiveness include:

1. Examine bus emitter activation/deactivation reliability and traffic signal controller reliability. The TSP Opticom log data (available in the City of Portland) can be utilized to evaluate the reliability of traffic signal controllers. By integrating the TSP Opticom log data with the bus AVL/APC data, bus emitter activation and deactivation reliability can also be estimated. In addition, it is necessary to better understand SCATS TSP control logic. 
2. Do not grant green extensions at intersections where the TSP performance is below average or does not provide a significant benefit to late buses.

3. Try to reduce unnecessary (late) granted green extension phases by comparing the predicted bus arrival time at the intersection when a priority request is received with the remaining time of a green phase. For example, no green extension phase should be granted if a bus TSP request is detected 10 seconds before the end of a regular green phase. However, the optimization of the threshold values can be challenging because TSP request detection zone length and signal timing characteristics have to be considered. 


\subsection{REFERENCES}

Abdy, Z.R., Hellinga, B.R., 2011. Analytical Method for Estimating the Impact of Transit Signal Priority on Vehicle Delay. Journal of Transportation Engineering 137, 589-600.

Abkowitz, M.D., 1978. Transit Service Reliability ( No. UMTA-MA-06-0049-78-1). Cambridge, MA.

Abkowitz, M.D., Eiger, A., Engelstein, I., 1986. Optimal Control of Headway Variation on Transit Routes. Journal of Advanced Transportation 20, 73-88.

Abkowitz, M.D., Engelstein, I., 1983. Factors affecting running time on transit routes. Transportation Research Part A: General 17, 107-113.

Abkowitz, M.D., Engelstein, I., 1984. Methods for Maintaining Transit Service Regularity. Transportation Research Record 961, 1-8.

Abkowitz, M.D., Lepofsky, M., 1990. Implementing Headway-based Reliability Control on Transit Routes. Journal of Transportation Engineering 116, 49-63.

Abkowitz, M.D., Tozzi, J., 1987. Research contributions to managing transit service reliability. Journal of Advanced Transportation 21, 47-65.

Albright, E., Figliozzi, M., 2012a. Factors Influencing Effectiveness of Transit Signal Priority and Late-Bus Recovery at Signalized-Intersection Level. Transportation Research Record 186-197.

Albright, E., Figliozzi, M., 2012b. Schedule recovery for late buses: What are the individual and joint contributions of Transit Signal Priority and bus operator behavior?, in: Working Paper.

Albright, E., Figliozzi, M., 2012c. Analysis of the impacts of transit signal priority on bus bunching and performance, in: Proceedings of the 12th Conference on Advanced Systems for Public Transport. Santiago, Chile.

Balke, K., Dudek, C., Urbanik II, T., 2000. Development and Evaluation of Intelligent Bus Priority Concept. Transportation Research Record 1727, 12-19.

Bertini, R.L., El-Geneidy, A.M., 2004. Modeling transit trip time using archived bus dispatch system data. Journal of Transportation Engineering 130, 56-67.

Byrne, N., Koonce, P., Bertini, R., Pangilinan, C., Lasky, M., 2005. Using Hardware-in-the-Loop Simulation to Evaluate Signal Control Strategies for Transit Signal Priority. Transportation Research Record 1925, 227-234.

Ceder, A., 2007. Public Transit Planning And Operation: Theory, Modelling And Practice. Elsevier.

Chada, S., Newland, R., 2002. Effectiveness of bus signal priority: final report ( No. NCTR-41604).

Christofa, E., Skabardonis, A., 2011. Traffic Signal Optimization with Application of Transit Signal Priority to an Isolated Intersection. Transportation Research Record 2259, 192201.

Conrad, M., Dion, F., Yagar, S., 1998. Real-Time Traffic Signal Optimization with Transit Priority: Recent Advances in the Signal Priority Procedure for Optimization in Real-Time Model. Transportation Research Record 1634, 100-109.

Crout, D., 2007. Accuracy and Precision of the Transit Tracker System. Transportation Research Record 1992, 93-100. 
Diab, E.I., El-Geneidy, A.M., 2012. Understanding the impacts of a combination of service improvement strategies on bus running time and passenger's perception. Transportation Research Part A: Policy and Practice 46, 614-625.

Diab, E.I., El-Geneidy, A.M., 2013. Variation in bus transit service: understanding the impacts of various improvement strategies on transit service reliability. Public Transp 4, 209-231.

Dion, F., Hellinga, B., 2002. A Rule-based Real-time Traffic Responsive Signal Control System with Transit Priority: Application to An Isolated Intersection. Transportation Research Part B: Methodological 36, 325-343.

Dion, F., Rakha, H., Zhang, Y., 2004. Evaluation of Potential Transit Signal Priority Benefits along a Fixed-Time Signalized Arterial. Journal of Transportation Engineering 130, 294303.

Dueker, K.J., Kimpel, T.J., Strathman, J.G., Callas, S., 2004. Determinants of Bus Dwell Time. Journal of Public Transportation 7, 21-40.

Eberlein, X.J., Wilson, N.H.M., Barnhart, C., 1998. The Real-Time Deadheading Problem in Transit Operations Control. Transportation Research Part B: Methodological 32, 77-100.

Eberlein, X.J., Wilson, N.H.M., Bernstein, D., 2001. The Holding Problem with Real-Time Information Available. Transportation Science 35, 1-18.

EI-Geneidy, A., 2005. The Use of Advanced Information Technology in Urban Public Transportation Systems: An Evaluation of Bus Stop Consolidation (Ph.D. Dissertation). Portland State University, Portland, Oregon.

El-Geneidy, A., Strathman, J., Kimpel, T., Crout, D., 2006. Effects of Bus Stop Consolidation on Passenger Activity and Transit Operations. Transportation Research Record 1971, 32-41.

El-Geneidy, A.M., Horning, J., Krizek, K.J., 2011. Analyzing Transit Service Reliability Using Detailed Data From Automatic Vehicular Locator Systems. Journal of Advanced Transportation 45, 66-79.

El-Geneidy, A.M., Hourdos, J., Horning, J., 2009. Bus Transit Service Planning and Operations in a Competitive Environment. Journal of Public Transportation 12, 39-59.

El-Geneidy, A.M., Surprenant-Legault, J., 2010. Limited-stop bus service: an evaluation of an implementation strategy. Public Transport 2, 291-306.

Figliozzi, M., Feng, W., 2012. A study of headway maintenance for bus routes: causes and effects of "bus bunching" in extensive and congested service areas ( No. OTREC-RR-1209). Portland State University, Portland, Oregon.

Fu, L., Liu, Q., Calamai, P., 2003. Real-Time Optimization Model for Dynamic Scheduling of Transit Operations. Transportation Research Record 1857, 48-55.

Furth, P., Muller, T.H., 2000. Conditional Bus Priority at Signalized Intersections: Better Service with Less Traffic Disruption. Transportation Research Record 1731, 23-30.

Furth, P., Rahbee, A., 2000. Optimal Bus Stop Spacing Through Dynamic Programming and Geographic Modeling. Transportation Research Record 1731, 15-22.

Furth, P.G., Hemily, B., Muller, T.H.J., Strathman, J.G., 2006. Using Archived AVL-APC Data to Improve Transit Performance and Management ( No. TCRP Report 113).

HCM, 2010. Highway Capacity Manual: Chapter 4 - Traffic Flow and Capacity Concepts, in: Highway Capacity Manual. Transportation Research Board, Washington, DC.

He, Q., Head, K.L., Ding, J., 2011. Heuristic Algorithm for Priority Traffic Signal Control. Transportation Research Record 2259, 1-7. 
Hensher, D.A., Stopher, P., Bullock, P., 2003. Service quality—developing a service quality index in the provision of commercial bus contracts. Transportation Research Part A: Policy and Practice 37, 499-517.

Hunter-Zaworski, K.M., Kloos, W.C., Danaher, A.R., 1995. Bus Priority at Traffic Signals in Portland: The Powell Boulevard Pilot Project. Transportation Research Record 1503, 29 33.

Kim, S., 2013. The R Package "ppcor."

Kimpel, T., Strathman, J., Bertini, R., Callas, S., 2005. Analysis of Transit Signal Priority Using Archived TriMet Bus Dispatch System Data. Transportation Research Record 1925, 156166.

Kimpel, T.J., 2001. Time Point-Level Analysis of Transit Service Reliability and Passenger Demand (Ph.D. Dissertation). Portland State University, Portland, Oregon.

Kimpel, T.J., Strathman, J.G., Callas, S., 2008. Improving Scheduling Through Performance Monitoring, in: Computer-Aided Systems in Public Transport. Springer Berlin Heidelberg, Berlin, Heidelberg, pp. 253-280.

Kittelson \& Associates, Inc., 2013. Transit Capacity and Quality of Service Manual. 3rd Edition. TCRP Report 165.

Koonce, P.J.V., Kloos, B., Callas, S., 2002. Bus priority at Traffic Signals in Portland—Version 2.0: The Streamline Project. Presented at the ITE 2002 Annual Meeting and Exhibit.

Levinson, H., Zimmerman, S., Clinger, J., Rutherford, S., Smith, R., Cracknell, J., Soberman, R., 2003. Bus Rapid Transit, Volume 1: Case Studies in Bus Rapid Transit ( No. TCRP Report 90).

Levinson, H.S., 1991. Supervision Strategies for Improved Reliability of Bus Routes (NCTRP Synthesis of Transit Practice).

Li, H., Bertini, R., 2009. Assessing a Model for Optimal Bus Stop Spacing with High-Resolution Archived Stop-Level Data. Transportation Research Record 2111, 24-32.

Lin, W.-H., 2002. Quantifying Delay Reduction to Buses with Signal Priority Treatment in Mixed-Mode Operation. Transportation Research Record 1811, 100-106.

Ma, W., Liu, Y., Han, B., 2013. A rule-based model for integrated operation of bus priority signal timings and traveling speed: BUS PRIORITY SIGNAL TIMINGS. Journal of Advanced Transportation 47, 369-383.

Ma, W., Yang, X., Liu, Y., 2010. Development and Evaluation of a Coordinated and Conditional Bus Priority Approach. Transportation Research Record 2145, 49-58.

Mazloumi, E., Currie, G., Rose, G., 2010. Using GPS Data to Gain Insight into Public Transport Travel Time Variability. Journal of Transportation Engineering 136, 623-631.

Mazloumi, E., Moridpour, S., Currie, G., Rose, G., 2012. Exploring the Value of Traffic Flow Data in Bus Travel Time Prediction. Journal of Transportation Engineering 138, 436446.

McKnight, C., Levinson, H., Ozbay, K., Kamga, C., Paaswell, R., 2004. Impact of Traffic Congestion on Bus Travel Time in Northern New Jersey. Transportation Research Record 1884, 27-35.

Milkovits, M., 2008. Modeling the Factors Affecting Bus Stop Dwell Time: Use of Automatic Passenger Counting, Automatic Fare Counting, and Automatic Vehicle Location Data. Transportation Research Record 2072, 125-130. 
Mirchandani, P.B., Lucas, D.E., 2004. Integrated Transit Priority and Rail/Emergency Preemption in Real-Time Traffic Adaptive Signal Control. Journal of Intelligent Transportation Systems 8, 101-115.

Murray, A.T., Wu, X., 2003. Accessibility tradeoffs in public transit planning. Journal of Geographical Systems 5, 93-107.

Rutherford, G.S., Watkins, K.E., 2011. Measurement and Evaluation of Transit Travel Time Reliability ( No. TNW2010-10). University of Washington, Seattle, WA.

Saka, A., 2001. Model for Determining Optimum Bus-Stop Spacingin Urban Areas. Journal of Transportation Engineering 127, 195-199.

Schweiger, C., 2003. Real-Time Bus Arrival Information Systems ( No. TCRP Synthesis Report 48).

Skabardonis, A., 2000. Control Strategies for Transit Priority. Transportation Research Record: Journal of the Transportation Research Board 1727, 20-26. doi:10.3141/1727-03

Slavin, C., Feng, W., Figliozzi, M., Koonce, P., 2013. A Statistical Study of the Impacts of SCATS Adaptive Traffic Signal Control on Traffic and Transit Performance. Transportation Research Record 2356, 117-126.

Smith, H.R., Hemily, P.B., Ivanovic, M., 2005. Transit Signal Priority (TSP): A Planning and Implementation Handbook. ITS America.

Strathman, J., Dueker, K., Kimpel, T., Gerhart, R., Turner, K., Taylor, P., Callas, S., Griffin, D., Hopper, J., 1999. Automated Bus Dispatching, Operations Control, and Service Reliability: Baseline Analysis. Transportation Research Record 1666, 28-36.

Strathman, J.G., Dueker, K.J., Kimpel, T., Gerhart, R.L., Turner, K., Taylor, P., Callas, S., Griffin, D., 2000. Service Reliability Impacts of Computer-Aided Dispatching and Automatic Vehicle Location Technology: A TriMet Case Study. Transportation Quarterly 54, 85-102.

Strathman, J.G., Hopper, J.R., 1993. Empirical analysis of bus transit on-time performance. Transportation Research Part A: Policy and Practice 27, 93-100.

Strathman, J.G., Kimpel, T.J., Callas, S., 2003. Headway Deviation Effects on Bus Passenger Loads: Analysis of Tri-Met's Archived AVL-APC Data ( No. TNW2003-01).

Strathman, J.G., Kimpel, T.J., Dueker, K.J., Gerhart, R.L., Callas, S., 2002. Evaluation of Transit Operations: Data Applications of Tri-Met's Automated Bus Dispatching System. Transportation 29, 321-345.

Sun, A., Hickman, M., 2005. The Real-Time Stop-Skipping Problem. Journal of Intelligent Transportation Systems 9, 91-109.

Sun, A., Hickman, M., 2008. The Holding Problem at Multiple Holding Stations, in: ComputerAided Systems in Public Transport, Lecture Notes in Economics and Mathematical Systems. Springer Berlin Heidelberg, pp. 339-359.

Tétreault, P.R., El-Geneidy, A.M., 2010. Estimating bus run times for new limited-stop service using archived AVL and APC data. Transportation Research Part A: Policy and Practice 44, 390-402.

Texas Transportation Institute, 1996. Guidelines for the Location and Design of Bus Stops provides information on locating and designing bus stops in various operating environments ( No. TCRP 19).

Tirachini, A., 2013. Estimation of travel time and the benefits of upgrading the fare payment technology in urban bus services. Transportation Research Part C: Emerging Technologies 30, 239-256. 
TriMet, 2013. Data Resources Derived from BDS Card Data.

Turnquist, M.A., 1981. Strategies for Improving Reliability of Bus Transit Service.

Transportation Research Record 818, 7-13.

Turnquist, M.A., Blume, S.W., 1980. Evaluating Potential Effectiveness of Headway Control Strategies for Transit Systems. Transportation Research Record 746, 25-29.

Vuchic, V., 2005. Urban Transit: Operations, Planning and Economics. John Wiley \& Sons. Yagar, S., Han, B., 1994. A Procedure for Real-Time Signal Control That Considers Transit Interference and Priority. Transportation Research Part B: Methodological 28, 315-331. 


\subsection{APPENDIX A: BUS TRAVEL SPEED EMPIRICAL DISTRIBUTIONS}

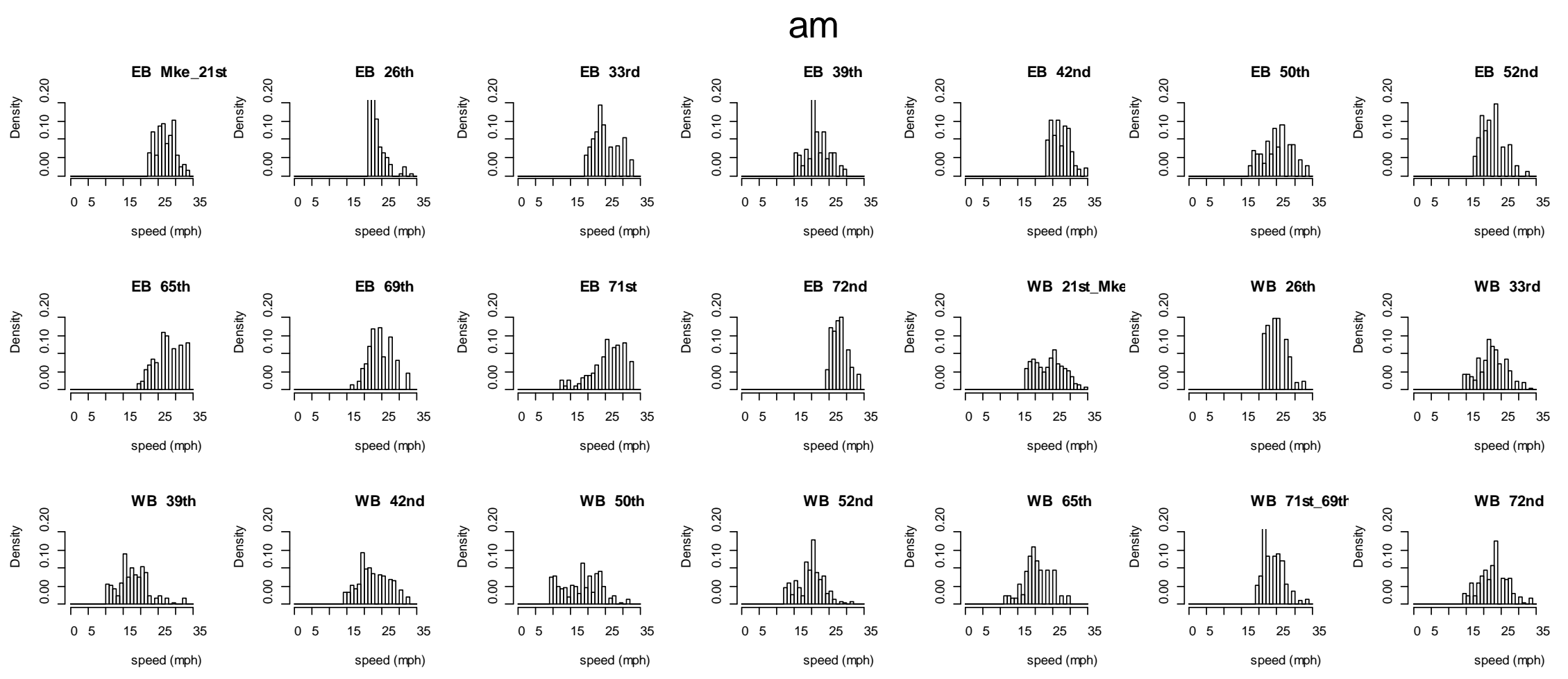




\section{mid}
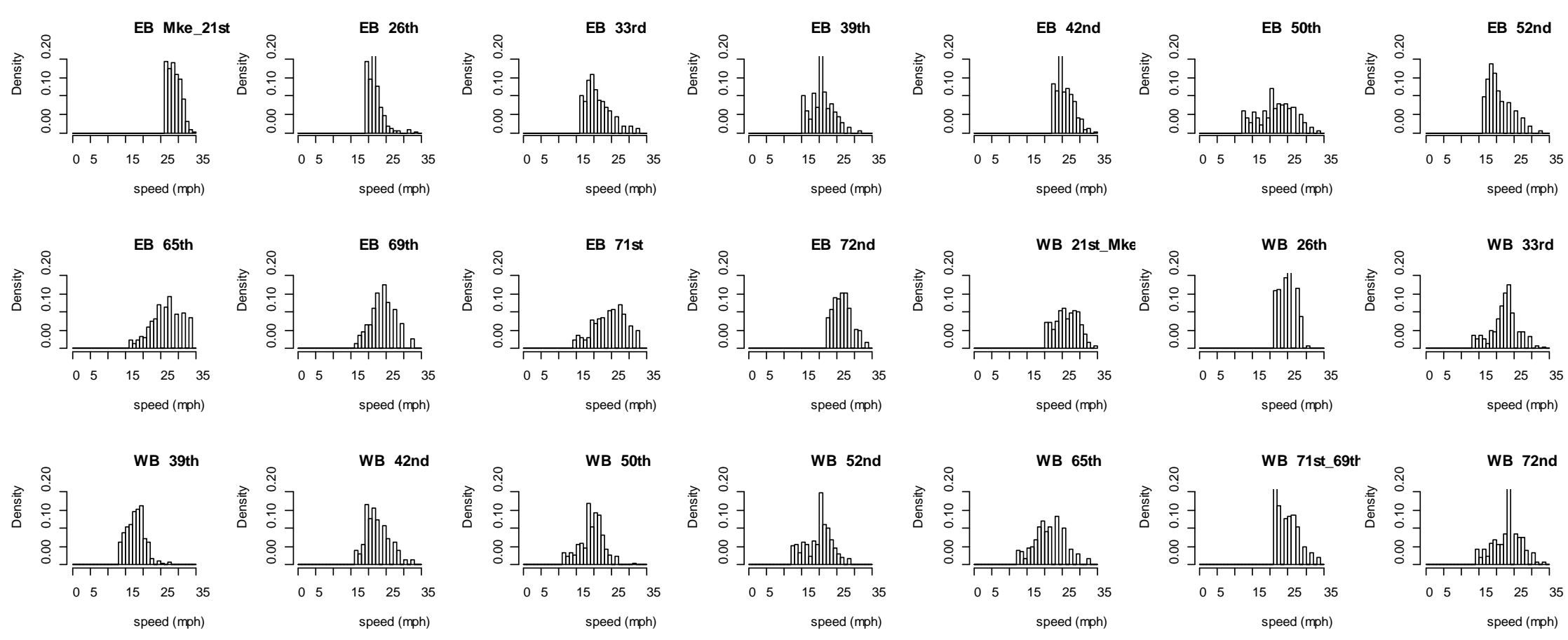


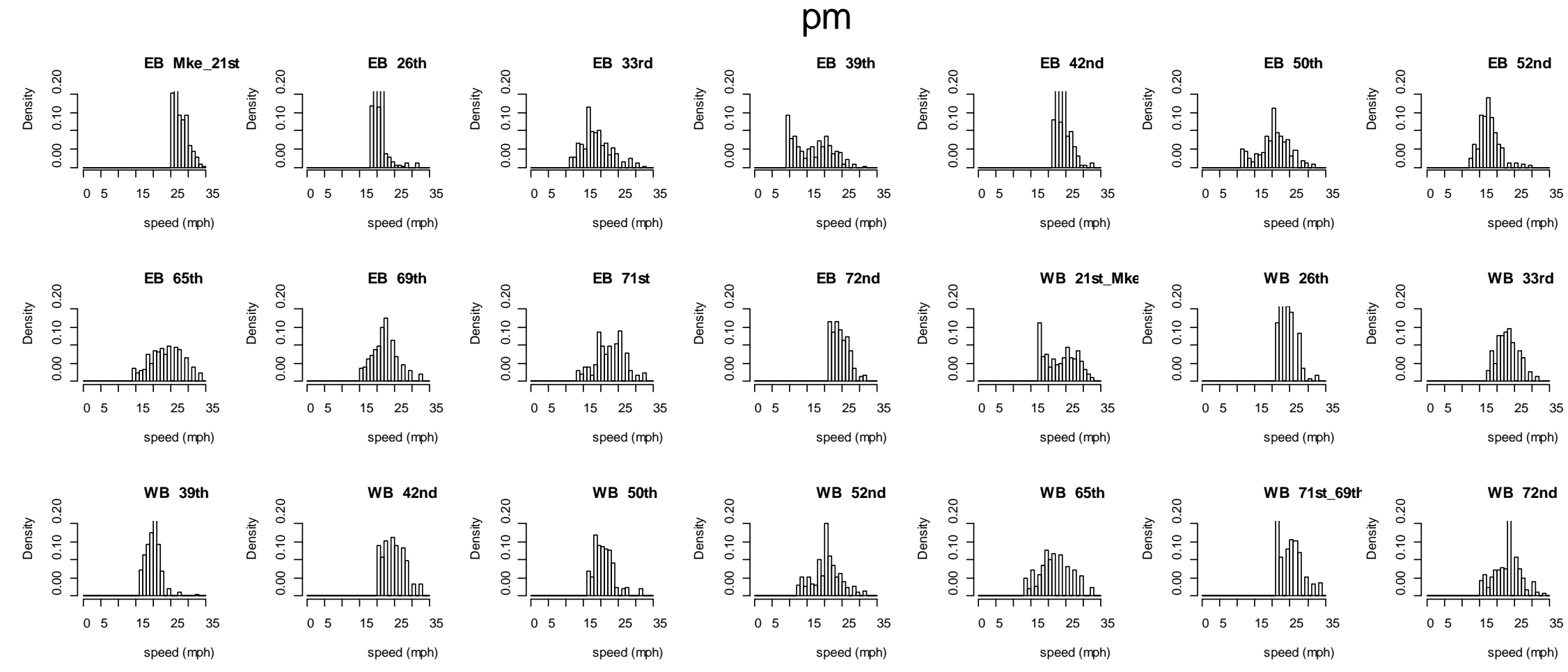



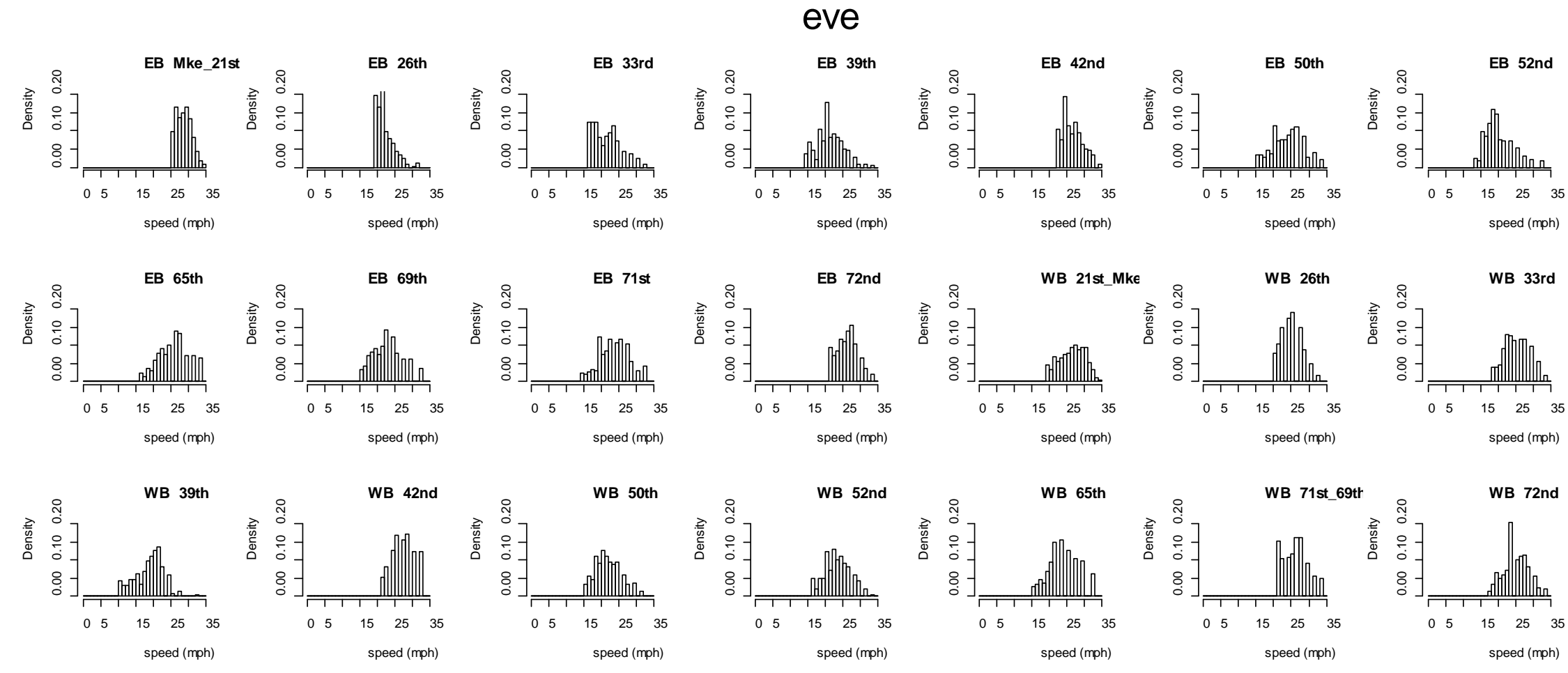